Check for updates

Cite this: Mater. Adv., 2021, 2,7308

Received 12th August 2021,

Accepted 25th September 2021

DOI: $10.1039 / \mathrm{d} 1 \mathrm{ma} 00719 j$

rsc.li/materials-advances

\title{
First transition series metal-organic frameworks: synthesis, properties and applications
}

\author{
Sandeep Kaushal, (D) * Gurmeet Kaur, Jasmeen Kaur and Prit Pal Singh (D) * \\ Metal organic frameworks (MOFs) have captured immense attention in the last decade, owing to their \\ better adsorption properties as compared to those of organic as well as inorganic materials, like \\ enormous surface area, highly porous nature, tunable pore size, and high stability. Herein, the regular \\ advancements in MOFs of metals of the first transition series, their morphology, properties, synthesis \\ methods, and numerous applications like gas storage, separation, ion-exchange and catalysis have been \\ discussed. The doping of MOFs and their composites has been classified and discussed, in addition to \\ fabrication of MOFs with various types of organic linkers. MOFs have been discussed for their sustainable \\ and convenient use in future. Various characterization techniques confirmed the rigid, porous and fine \\ structure of MOFs.
}

\section{Introduction}

Metal organic frameworks (MOFs) are an evolving class of porous materials fabricated from metal clusters or ions and organic linkers in three-dimensional space. ${ }^{1-3}$ MOFs are attractive materials for both researchers and engineers, owing to their tunable structures and functionality as well as their ever-increasing applications. ${ }^{4,5}$ M. Yaghi is known as the father of MOFs as he fabricated advanced MOFs, zeolitic imidazolate frameworks (ZIFs) and covalent organic frameworks (COFs). Various techniques such as in situ synthesis, encapsulation, impregnation, gas phase infiltration, co-precipitation etc. are employed for the fabrication of MOFs. ${ }^{3-5}$ In recent years, synthesis of many nanostructured and nano-sized MOFs has been carried out. ${ }^{6,7}$ The transformation in the structure of MOFs is contingent on conditions like $\mathrm{pH}$, molar ratio, solvents and temperature. ${ }^{8}$ MOFs have flexibility ${ }^{9}$ and a diverse range of applications ${ }^{10}$ including electrochemical applications, ${ }^{11}$ gas storage, ${ }^{12,13}$ separation, ${ }^{14}$ catalytic activity, ${ }^{15,16}$ heterogeneous catalysis, ${ }^{17,18}$ heavy metal removal, ${ }^{19}$ drug delivery, ${ }^{20,21}$ membrane desalination, ${ }^{22}$ water treatment, ${ }^{23}$ electrode materials for supercapacitance, ${ }^{24,25}$ ultrasonics, ${ }^{26}$ luminescence, ${ }^{27,28}$ energy storage, ${ }^{29}$ photocatalysis, ${ }^{30,31}$ adsorption, ${ }^{32}$ sensing, ${ }^{33}$ enzyme immobilization, ${ }^{34}$ bio-medicine, ${ }^{35}$ solid phase extraction/ analytical applications, ${ }^{36}$ dye/toxic materials removal, ${ }^{37-39}$ coordination chemistry, ${ }^{40}$ optics ${ }^{41}$ and optoelectronics which are attracting researchers. There have been reports of more than 20000 MOFs which are different from each other depending on their design, method of synthesis, structure, pore size, etc.

Department of Chemistry, Sri Guru Granth Sahib World University, Fatehgarh Sahib, Punjab, India. E-mail: kaushalsandeep33@gmail.com,

dhillonps2003@gmail.com
The shape, size and nature of pores in MOFs can be easily altered and this leads to rare chemical adaptability. Most of the reported MOFs have been fabricated from divalent or trivalent $3 p$ metal ions, 3d transition metals and lanthanides whereas the fabrication of MOFs from high-valent metal ions is still a big challenge. Furukawa et al. ${ }^{42}$ fabricated MOFs having a covalent bond between metal ions acting as nodes and organic ligands taken as spokes which combine to form open framework structures. The significant advances were also discussed, for constructing higher order mesoscopic superstructures that are composed of nanocrystals. These structures are divided into four categories: zero dimensional structures comprising hollow capsules, uni-dimensional structures like nanorods, bi-dimensional structures classified as thin films, membranes or patterns and three-dimensional structures made up of continuous and enlarged systems. ${ }^{43}$

Herein, the synthesis, structure and applications of MOFs based on first transition series elements have been discussed. Commonly used organic linkers in the frameworks are fumaric acid, oxalic acid, terephthalic acid, benzene-dicarboxylate, adipic acid, etc. In addition to organic linkers, some ionic liquids are also used for the fabrication of MOF composites. The commonly used ionic liquids for fabrication of composites are $\mathrm{N}$-alkylmethyl-imidazolium, $N$-alkyl-pyridinium, tetraalkyl-ammonium, tetraalkyl-phosphonium, etc. The reactions of most of the metal ions with numerous organic linkers are feasible and given in Fig. 1 and 2.

Here, we are considering metals of first transition series for fabrication of MOFs. These elements have a partially filled d-subshell or can result in cations with an incomplete subshell with general electronic configuration $(n-1) \mathrm{d}^{1-10} n \mathrm{~s}^{0-2}$. Later in this paper, MOFs of $\mathrm{Sc}, \mathrm{Ti}, \mathrm{V}, \mathrm{Cr}, \mathrm{Mn}, \mathrm{Fe}, \mathrm{Co}, \mathrm{Ni}, \mathrm{Cu}$ and $\mathrm{Zn}$ have been discussed. The discussion includes the capability of MOFs 


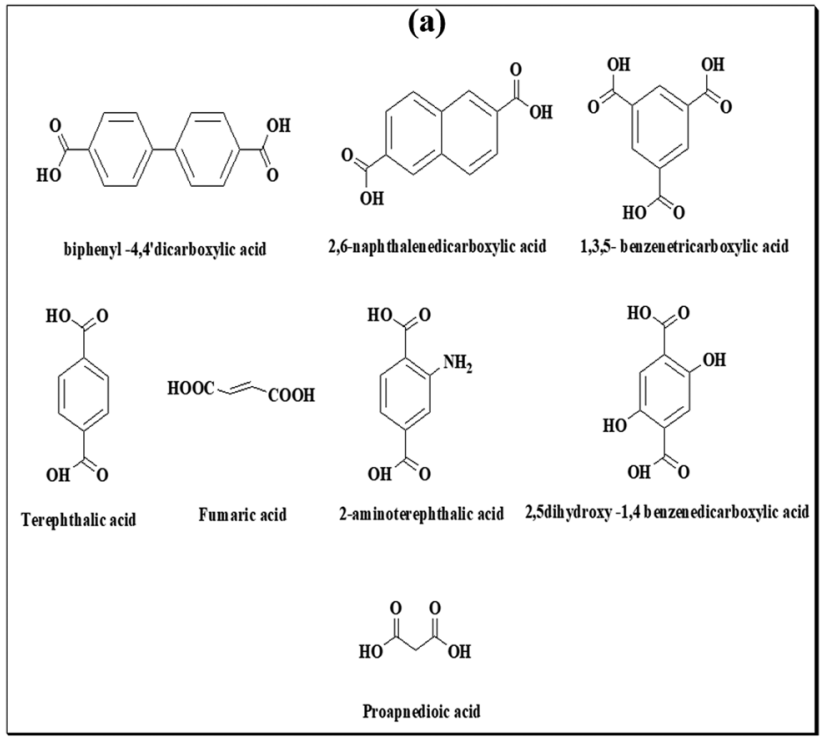

(b)
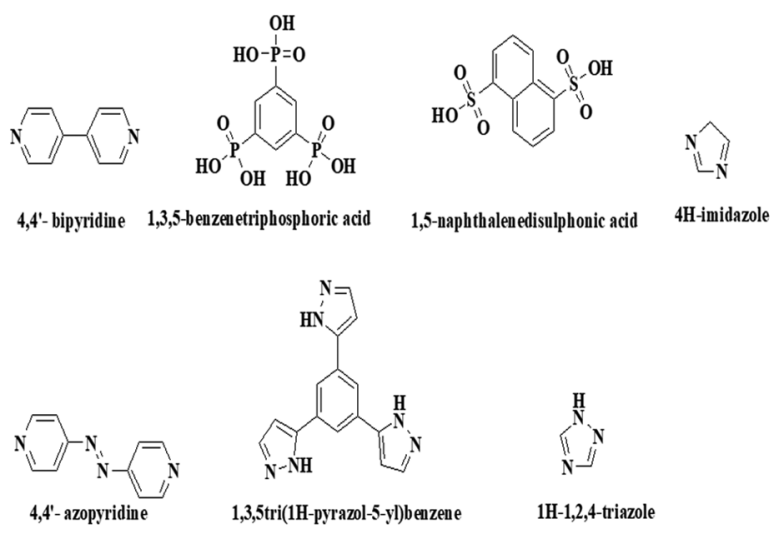

Fig. 1 Organic linkers containing (a) carboxylic functionality and (b) phosphorus, nitrogen and sulphur used for the preparation of MOFs.

for the environmental systems that may include sterilization, gas storage and separation, and gas fuel stockpiling. Thus, MOFs show their advantageous role in energy generation and storage. In this way, MOFs are leading to an ecologically sustainable and convenient future. ${ }^{44,45}$

\section{Synthetic approaches for metal organic frameworks}

Due to their certain functional and structural properties, MOFs have been presently perceived as an extensive collection of porous compounds. These frameworks are formed by connecting organic linkers and metal ion clusters/metal ions. Beyond question, another perception remarkably associated with MOFs conclusive design and properties is the chosen essential structural blocks known as secondary building units (SBUs). ${ }^{46}$ However, various other synthetic approaches and variables like pressure, temperature, $\mathrm{pH}$, time of reaction and solvent should also be scrutinized. Various distinctive synthetic routes viz.
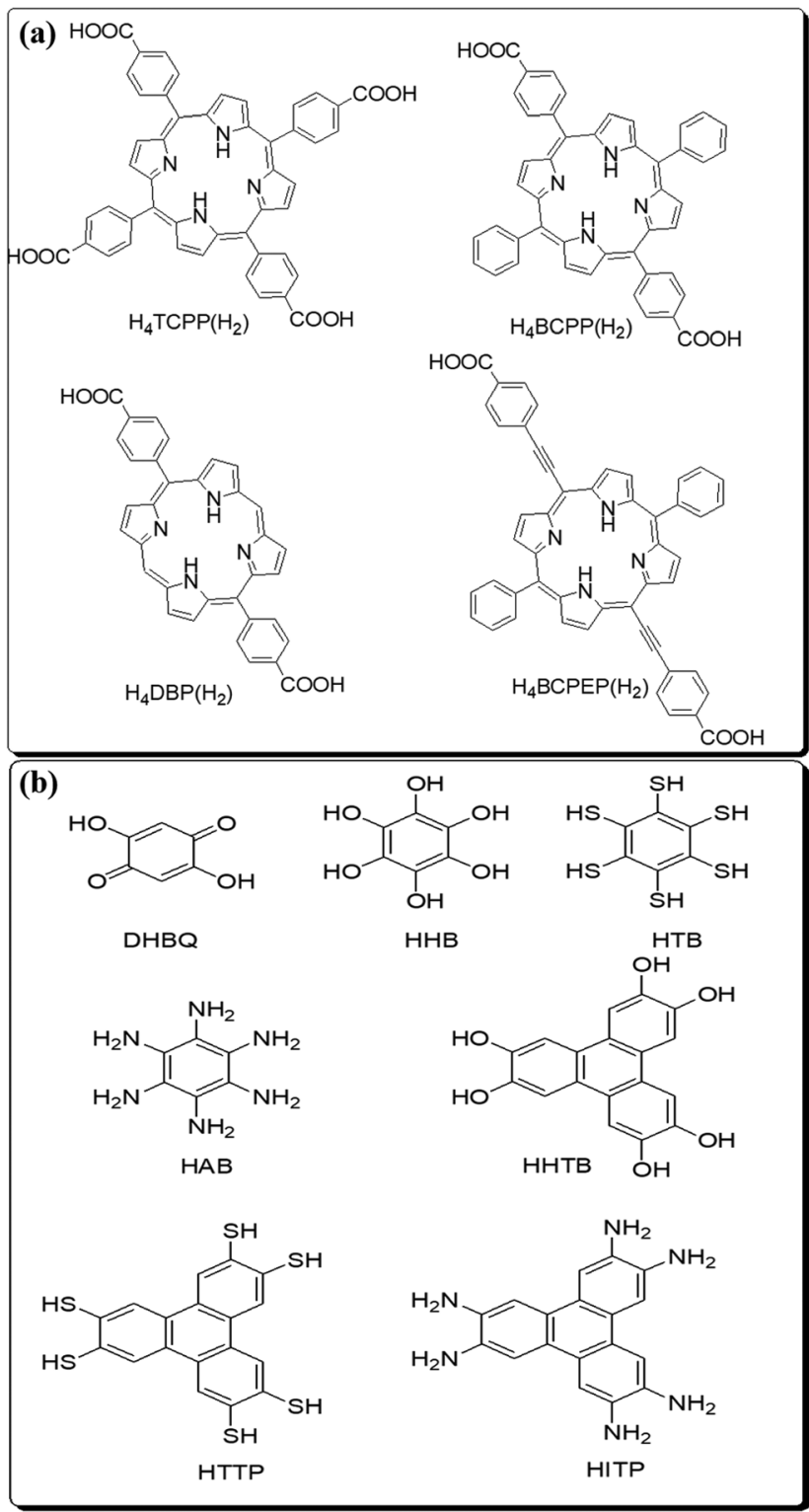

Fig. 2 Organic linkers with (a) conductive linkers and (b) porphyrin-based linkers used for the preparation of MOFs.

hydrothermal/solvothermal, diffusion, electrochemical, mechanochemical, microwave assisted heating and ultrasound can be used to construct MOFs trusting on the subsequent structures and features. $^{47,48}$

\section{Hydrothermal/solvothermal method}

The solvothermal technique is the most utilized strategy for the preparation of MOFs as it gives an assortment of morphologies. In this strategy, the reaction materializes between the metal salt and organic ligand in organic solvents or dissolvable mixtures. Hydrothermal reactions are accomplished at temperatures higher than the boiling point of solvent. It may be inferred that speedy reaction kinetics of hydrothermal reaction allows the construction of even MOF particles with higher crystallinity, 
and promptly acquires single crystals. Notwithstanding the advantageous features, this method unquestionably has a few constraints like necessity of solvent antecedents, creation of a lot of solvent waste and possibly harmful treatment of destructive metal salts within the sight of organic liquids. ${ }^{49}$

\section{Slow diffusion method}

The diffusion technique brings different species into interaction, step by step: (i) the first strategy is solvent liquid diffusion. In this method, two layers with different densities, the precipitant solvent constituting one layer and the other layer containing the product in a solvent, are formed. At the boundary, formation of crystals takes place by slow diffusion of the precipitant solvent into the other layer; (ii) the second strategy involves the step by step diffusion of reactants by overcoming the physical obstructions. The vital benefit of this technique is that single crystals suitable for XRD analysis can be easily obtained. The more time consuming nature of this method than other notable strategies is its major limitation..$^{50}$

\section{Electrochemical method}

In this method, metal ions are released by anodic dissolution into a reaction comprising organic linkers and electrolytes. The electrochemical method is applied for the synthesis of MOF powders on an industrial scale. Some of the advantages of this technique comprise the evading of anions like nitrates from metal salts, low temperature of reaction and tremendously rapid synthesis in comparison to solvothermal synthesis. A contradiction in thermal growth coefficients amongst the distinctive support structure and the MOF prompts this breaking. In this regard, MOFs display a negative thermal expansion coefficient. Therefore, contrasted with the solvothermal method, electrochemical techniques provide more variables for fine tuning by straightforward modification of the voltage. ${ }^{51}$

\section{Mechanochemical method}

Mechanochemical strategy involves the execution of chemical reaction with the assistance of mechanical power. In this method, chemical reactions and numerous physical phenomena could be carried out by mechanical force. In this method, mechanical cracking of intramolecular bonds is carried out and is followed by chemical synthesis. The main advantage of this method is that the reaction is performed at ambient temperature in the absence of harmful organic solvents. Another significant feature of this method is use of metal salts instead of metal oxides. However, this method has the disadvantage of undesirable product amorphization caused by neat milling. ${ }^{52}$

\section{Microwave method}

Microwave assisted synthesis is a rapid technique for fabrication of MOFs. On irradiation of the reaction mixture with microwaves for an hour or more, nanosized crystals are formed. The microwave assisted method is an indispensable strategy to perform synthesis at a rapid pace. The advantages of this method include great efficacy, fast reaction kinetics, phase selectivity, uniform particle morphology, particle size reduction, etc. ${ }^{53}$ However, this method usually can't yield crystals with adequate size for single X-ray analysis. ${ }^{54}$

\section{Sonochemical method}

In sonochemical synthesis, reaction mixture is exposed to ultrasound waves $(20 \mathrm{kHz}-10 \mathrm{MHz})$ and the molecules experience chemical change to yield compounds with innovative morphologies, crystal sizes and distinct properties. Ultrasonic radiation can create high temperatures and pressing factors in the reaction medium. The economical, usually fast, reproducible and environment friendly nature are the main advantages of this method. ${ }^{55}$ Just like microwave method, this method typically can't produce crystals with satisfactory size for single X-ray analysis.

\section{Scandium-based metal organic frameworks}

Scandium is the first member of first transition series and has silver white appearance. It may also appear yellow or pink due to different oxidation states of scandium. There is an emerging enthusiasm for utilization of Sc(III) centers for the fabrication of porous frameworks, since it is a moderately light metal which offers high porosity with large specific surface area, high hydrolytic and thermal stability of coordination framework with diverse functional properties and forms stable carboxylate complexes. Despite undeniable advantages and prospects, the science of scandium complexes and, specifically, scandium organic frameworks (SOFs) has inadequately evolved. An impressive limiting component is that scandium is a trace element and, correspondingly, scandium compounds are generally costly. ${ }^{56}$ Barsukova et al. reported solvothermal synthesis of three new coordination polymers based on scandium ions and 2,5-furandicarboxylate $\left(\mathrm{fdc}^{2-}\right)$ ligand i.e. $\left(\left(\mathrm{CH}_{3}\right)_{2} \mathrm{NH}_{2}\right)\left[\mathrm{Sc}\left(\mathrm{H}_{2} \mathrm{O}\right)_{2}(\mathrm{fdc})_{2}\right] \cdot 1,5 \mathrm{CH}_{3} \mathrm{CN}$ (1), $\left(\left(\mathrm{CH}_{3}\right)_{2} \mathrm{NH}_{2}\right)_{2}\left[\mathrm{Sc}(\mathrm{fdc})_{2}(\mathrm{HCOO})\right](2)$, and $\left[\mathrm{Sc}_{2}\left(\mathrm{H}_{2} \mathrm{O}\right)_{2}(\mathrm{fdc})_{3}\right]$ (3). It has been established that these MOFs retain their structure in aqueous media over an extensive $\mathrm{pH}$ range of 1-13. Furthermore, compounds 2 and $\mathbf{3}$ have also shown ligand-centered luminescence. ${ }^{57}$ In another study, properties of Sc- and Ti-based MOFs, $\left(\mathrm{C}_{6} \mathrm{H}_{3}\right)_{2}\left(\mathrm{~B}_{2} \mathrm{C}_{4} \mathrm{H}_{4}\right)_{3} \mathrm{M}_{6}\left(\mathrm{M}=\mathrm{Sc}\right.$, Ti), for storage of $\mathrm{H}_{2}$ were examined by density functional theory (DFT). It was revealed that each doped Sc atom is capable of adsorbing four $\mathrm{H}_{2}$ molecules, with average adsorption energy ranging from 0.21 to $0.34 \mathrm{eV} .^{58}$

Similarly, 3D porous bi-metallic frameworks of scandium metal ions along with lithium or sodium metal ions, coordinated to pyrimidine dicarboxylate were synthesized to investigate its capability to arrest $\mathrm{CO}_{2}$ at room temperature. A heat assisted solvent-free process was established to be most effective, yielding materials with nearly the same adsorption capacities 
as anticipated from Grand Canonical Monte Carlo (GCMC) calculations. The synthesized materials possessed high specific surface area, and systematic distribution of alkaline ions in the crystal structure. The ionic conductivity was also enhanced $\left(10^{-4} \mathrm{~S} \mathrm{~cm}^{-1}\right)$ by partial substitution of scandium ions with $\mathrm{Li}^{+}$and $\mathrm{Na}^{+}$ions. ${ }^{59}$ Pillai et al. synthesized and explored a series of functionalized scandium terephthalate MOFs for selective $\mathrm{CO}_{2}$ adsorption. The computational studies revealed that $\mathrm{Sc}_{2}\left(\mathrm{BDC} \mathrm{NO}_{2}\right)_{3}$ MOFs exhibited exceptional adsorption for $\mathrm{CO}_{2}$ over $\mathrm{N}_{2}$ and $\mathrm{CH}_{4}$, beating the vast majority of MOFs as well as other reported porous materials.

The sample exhibited very good water stability and can be easily regenerated at room temperature under vacuum. ${ }^{60}$ Khan et al. introduced scandium-triflate $\left(\mathrm{Sc}(\mathrm{OTf})_{3}\right)$ MOFs and carried out adsorptive desulfurization and denitrogenation of fuels. In comparison to sole MOFs, $\mathrm{Sc}(\mathrm{OTf})_{3}$ MOFs exhibited much better adsorption for benzothiophene (BT) from liquid fuel. Basic quinolone (QUI) was also adsorbed preferentially on acidic Sc(OTf) $)_{3}$ MOFs (Fig. 3). The improved adsorption might be attributed to interactions between acidic $\mathrm{Sc}(\mathrm{OTf})_{3}$ and basic adsorbates. The efficiency of the adsorbent was enhanced by solvent washing and thermal treatment. ${ }^{61}$

Graham et al. fabricated a scandium terephthalate MOF $\left(\mathrm{Sc}_{2}(\mathrm{BDC})_{3}, \mathrm{BDC}=1\right.$,4-benzenedicarboxylate $)$ and its derivative $\left(\mathrm{Sc}_{2}\left(\mathrm{NO}_{2}-\mathrm{BDC}\right)_{3}\right)$. The as-synthesized MOFs were employed for methanol uptake at high pressure. Diffraction experiments revealed that molecules of methanol occupied two sites, and one site was preferentially occupied in comparison to the other. The likely orientation of methanol molecules was controlled by H-bonding. ${ }^{62}$ Furthermore, Cabello and co-workers utilized variable-temperature infrared (VTIR) spectroscopy to report interactions between carbon dioxide and coordinatively unsaturated MIL-100(Sc) MOFs. The $\Delta H^{\circ}$ value was found to be $-48 \mathrm{~kJ} \mathrm{~mol}^{-1}$ which is the highest reported for adsorption of $\mathrm{CO}_{2}$ on MOFs comprising open metal sites. The corresponding $\Delta S^{\circ}$ value was found to be $-178 \mathrm{~J} \mathrm{~mol}^{-1} \mathrm{~K}^{-1}$ which displayed a positive correlation between $\Delta H^{\circ}$ and $\Delta S^{\circ}{ }^{63}$ Similarly, Mitchell et al. also reported porous MOFs with scandium and different linkers. The synthesized MOFs were used as catalysts in numerous reactions catalyzed by Lewis acid catalysts which are very

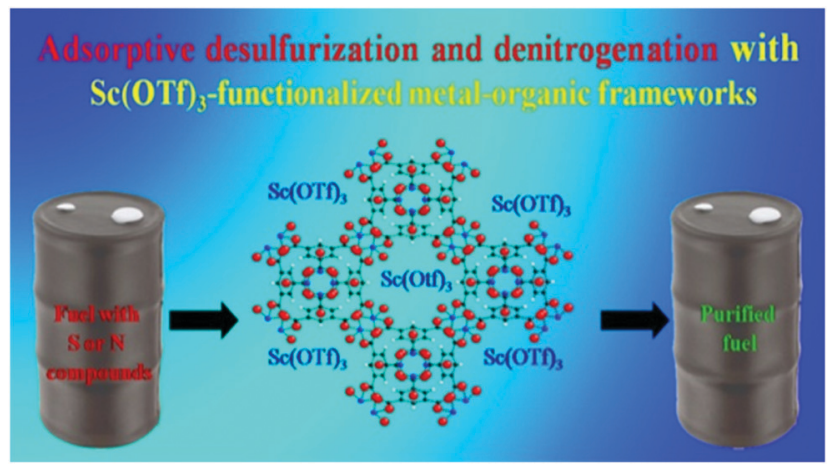

Fig. 3 Desulfurization and denitrogenation with scandium triflate MOF [reprinted with permission from ref. 61, Copyright (C) American Chemical Society, 2015]. significant in organic synthesis but have not been studied using MOF catalysts. ${ }^{64}$ Arean et al. reported the thermodynamics of hydrogen interaction with MIL-100(Sc) MOF with VTIR spectroscopy. The corresponding values of $\Delta H^{\circ}$ and $\Delta S^{\circ}$ were observed to be $-11.2( \pm 1) \mathrm{kJ} \mathrm{mol}^{-1}$ and $-120( \pm 10) \mathrm{J} \mathrm{mol}^{-1} \mathrm{~K}^{-1}$, respectively, in the temperature range of 80-125 $\mathrm{K}$. The enthalpy for adsorption of hydrogen was observed to be the highest on the MOFs reported so far. ${ }^{65}$

\section{Titanium-based metal organic frameworks}

Titanium is viewed as a most interesting contender for the development of MOFs with high chemical stability and structural diversity. Titanium is a tetravalent element in ionic form and is placed just above zirconium in the periodic table. The ionic radius of $\mathrm{Ti}^{4+}$ is smaller than $\mathrm{Zr}^{4+}$ and hence, $\mathrm{Ti}^{4+}$ shows stronger affinity for oxygen. Furthermore, the most attractive characteristic of titanium is its outstanding multifunctionality, typical redox activity, photochemical property and biocompatibility. Titanium-based MOFs exhibit comparatively higher stability in water. Still, the framework of titanium slowly breaks down in water within days which is attributed to the attack of $\mathrm{OH}^{-}$on $\mathrm{O}-\mathrm{Ti}-\mathrm{O}$ bond. An et al. enhanced the stability of titanium-based MOFs in water without affecting its other properties by employing Ti-ATA (ATA = 2-aminoterephthallate ion), a titanium-based MOF. ${ }^{66}$ Zhu et al. described titanium-based MOFs as a smart subclass of MOF family due to their encouraging stability, properties and inimitable structural features. ${ }^{67}$ Similarly, Zhang et al. synthesized Ti-based MOFs, MIL-125 and $\mathrm{NH}_{2}-\mathrm{MIL}-125$ solvothermally. As concentration of $\mathrm{Ti}$ was increased, particle size of MIL-125 decreased (Fig. 4). The catalytic properties of MOFs were investigated using $\mathrm{H}_{2} \mathrm{O}_{2}$ as an oxidant. In the
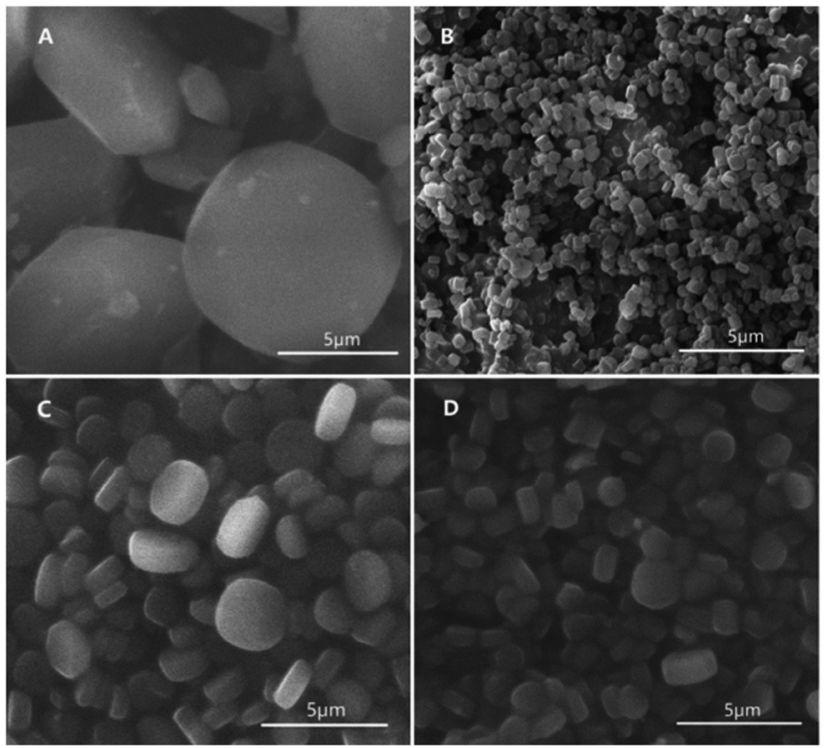

Fig. 4 SEM images of MIL-125-L (A), NH - MIL-125 (B), MIL-125-M (C), and MIL-125-S (D) [reprinted with permission from ref. 68, Copyright (C) Elsevier, 2018]. 
presence of methanol, both the $\mathrm{NH}_{2}$-MIL-125 and MIL-125 were highly stable, and maintained the framework structure on being recycled five times. ${ }^{68}$ Janek et al. synthesized tetranuclear titanium(Iv) oxo-complex with 4-aminobenzoate ligands. The DFT studies were employed to confirm the formation of $\left[\mathrm{Ti}_{4} \mathrm{O}_{2}(\mathrm{OiBu})_{10}(\mathrm{ABZ})_{2}\right]$ and $\left[\mathrm{Ti}_{6} \mathrm{O}_{6}(\mathrm{OiBu})_{6}(\mathrm{ABZ})_{6}\right]$ composites. The photodegradation of methylene blue (MB) dye in UV light was investigated in the presence of Ti-MOF-complex in a polystyrene matrix. ${ }^{69}$

A facile and scalable approach was used to fabricate porous anatase $\mathrm{TiO}_{2}$ and $\mathrm{Li}_{4} \mathrm{Ti}_{5} \mathrm{O}_{12}$ nano-tablets consisting of nanoparticles, grown from a Ti-MOF template. Both the nano-tablets exhibited outstanding electrochemical properties, and were employed as anode materials for lithium-ion batteries. $\mathrm{TiO}_{2}$ and $\mathrm{Li}_{4} \mathrm{Ti}_{5} \mathrm{O}_{12}$ delivered capacity up to $228 \mathrm{~mA} \mathrm{~h} \mathrm{~g} \mathrm{~g}^{-1}$ and $158 \mathrm{~mA} \mathrm{~h} \mathrm{~g}^{-1}$, respectively, at $0.1 \mathrm{~A} \mathrm{~g}^{-1}$. The outstanding electrochemical properties were attributed to the typical porous structure which augments active sites to lodge lithium ions and enhance ionic diffusion. ${ }^{70}$ Lian et al. constructed a distinct core-shell titanium-based MOF ( $\mathrm{Fe}_{3} \mathrm{O}_{4} @$ @ys@MIL125- $\mathrm{NH}_{2}$ ) and applied it as a magnetic adsorbent for fluoroquinolones from aqueous samples. The developed magnetic solid phase extraction (MSPE) method showed large linear concentration

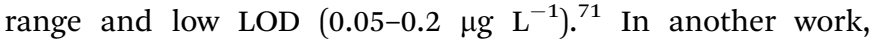
Ti-based MOFs were synthesized by addition of tetraethyl orthosilicate. The size of synthesized Ti-based MOFs was less by $42.78 \%$ as compared to that with traditional methods. Ibuprofen (IBU) was used to investigate the controlled release property of MOFs. Approximately $95 \%$ of IBU was released from MOFs after exposure to a phosphate buffered saline system for 24 h. $^{72}$ In another study, titanium-based MOF, MIL-125 was sulfated to increase its acidic property. The catalytic performance of raw and sulfated MIL-125 was investigated in esterification of acetic acid. It was observed that approximately $88.2 \%$ of acetic acid was converted to ester in $7 \mathrm{~h} .{ }^{73}$ Wang and co-workers synthesized titanium(Iv) ion-modified COFs with outstanding performance for detection and identification of trace phospho-peptides in the complex biological samples of milk and HeLa cells. ${ }^{74}$ It was revealed in another investigation that Ti-oxo clusters are highly selective and efficient towards photocatalysis, $\mathrm{CO}_{2}$ reduction and pollutant degradation due to their high optical response and photo-redox properties. ${ }^{75}$ In order to enhance the photocatalytic and degradation results, titanium-carboxylate molecular clusters and functional group tolerances of clusters were investigated by adding organic functionalities. During $\mathrm{CO}_{2}$ cycloaddition reaction, $80 \%$ of polypropylene oxide gets converted into cyclic carbonates. The degradation studies were performed on methylene blue (MB) dye and complete degradation was achieved in $4 \mathrm{~h}^{.}{ }^{76}$ George et al. reported microwave synthesis of titanium-based MOFs (Ti-BDC). The MOFs were observed to be photo-catalytically active (band gap energy $=3.14 \mathrm{eV}$ ), and effectively degraded $96.77 \%$ of $\mathrm{MB}$ dye in $6 \mathrm{~h}^{.77}$ Furthermore, a hydrothermal method was used to fabricate titanium-based MOFs (porous $\mathrm{NH}_{2}$-MIL-125) having high surface area $\left(1540 \mathrm{~m}^{2} \mathrm{~g}^{-1}\right)$. This MOF was successfully employed as a prospective photosensitizer and

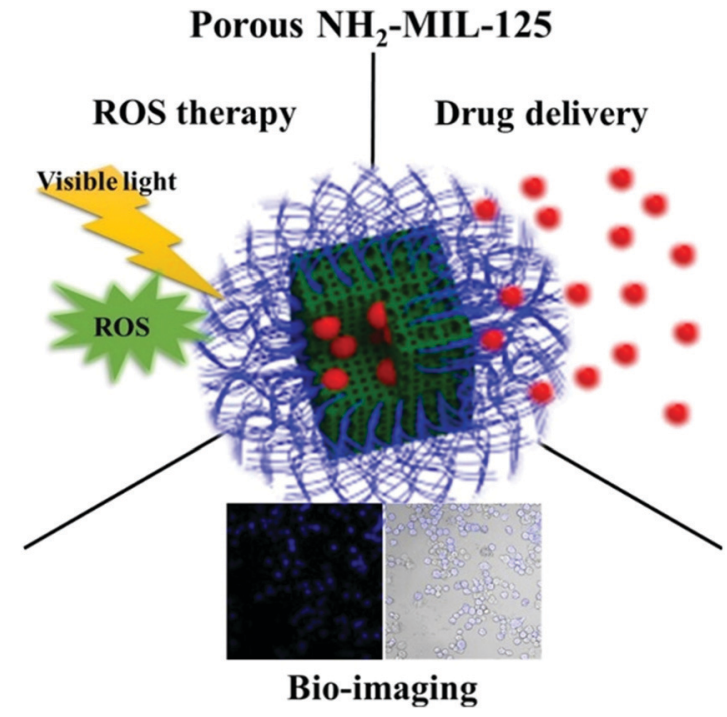

Fig. 5 Functioning of $\mathrm{NH}_{2}-\mathrm{MIL}-125$ (MOF) [reprinted with permission from ref. 78, copyright (C) Elsevier, 2017].

pH-responsive nano-carrier for cancer therapy, bio-imaging, drug delivery and ROS therapy (Fig. 5). Excellent results were reported during examination of breast cancer (MCF-7) cell line. ${ }^{78}$

$\mathrm{Fe}_{3} \mathrm{O}_{4} @ \mathrm{SiO}_{2} @ \mathrm{MOF} / \mathrm{TiO}_{2}$ nano-composite was prepared and utilized as an adsorbent for MSPE of tri-azole fungicides in water. The limit of detection was observed to be $0.19-1.20 \mathrm{ng} \mathrm{L}^{-1}$ for the selected fungicides. This method was employed to estimate the concentration of fungicides in real life water samples. ${ }^{79}$ Water splitting reaction and $\mathrm{CO}_{2}$ reduction was attained with Ti doped MOFs, followed by conversion of light energy into chemical energy. ${ }^{80}$ Guo and co-workers reported amine-functionalized MOFs ( $\mathrm{NH}_{2}$-MIL-125-Ti) which were used to prepare polysulfonebased mixed matrix membranes. The amalgamation of $\mathrm{NH}_{2}$ MIL-125-Ti in the membrane enhances $\mathrm{CO}_{2}$ permeability in comparison to that of the pure polymer membrane. ${ }^{81}$

\section{Vanadium based metal organic frameworks}

The research on MOFs of vanadium is very uncommon. The clusters and complexes are formed mainly with vanadium nodes. The catalytic activity of $\mathrm{VO}_{x}$ doped MIL-101(Cr) was studied in gas phase ethanol oxidative dehydrogenation and it was observed that this MOF catalyst displayed excellent selectivity towards acetaldehyde (up to $99 \%$ ) below $200{ }^{\circ} \mathrm{C}^{82}$ Wang and co-workers carried out the synthesis of $\mathrm{V} / \mathrm{UiO}-66-\mathrm{NH}_{2}$ and investigated its catalytic activity for hydroxylation of benzene to phenol using $\mathrm{O}_{2}$. A yield of $22.0 \%$ of phenol with high selectivity (98.1\%) was obtained using the fabricated MOFs in comparison to only 5.2\% yield with sole UiO66- $\mathrm{NH}_{2} \cdot{ }^{83}$ In another work, one pot in situ synthesis of $\mathrm{Li}_{3} \mathrm{~V}_{2}\left(\mathrm{PO}_{4}\right)_{3} /$ phosphorus-doped carbon (LVP/P-C) nanocomposites was carried out using hybrid vanadium MOF precursor. The nanocomposites exhibited a discharge capacity of $65 \mathrm{~mA} \mathrm{~h} \mathrm{~g}^{-1}$ at $10{ }^{\circ} \mathrm{C}$, and $90 \%$ of the capacity was retained after 1100 cycles. $^{84}$ 
Timofeev et al. reported isostructural metal-carboxylates MIL-100(M) and MIL-53(M) (M: V, Al, Fe and Cr) which were used in catalysis of condensation reaction of glycerol with acetone. It was observed that the materials with higher vanadium content exhibited enhanced activity and reusability at room temperature. ${ }^{85}$ Wang et al. fabricated microporous MIL-47 frameworks VO (1,4-benzenedicarboxylate) with $\mathrm{CS}_{2}$, tetrahydrothiophene, thiomorpholine and thioxane. The channel opening of framework was significantly expanded by intercalation with $\mathrm{CS}_{2}$ by breathing deformation mode, in contrast to numerous other molecules that typically lead to contraction of channel opening. With incorporation of $\mathrm{CS}_{2}$, maximum spherical void diameter increases to $8.0 \AA$ from $7.6 \AA$ of VO (1,4-benzenedicarboxylate) with empty channels. ${ }^{86}$ The development of more stable novel materials is required as extensive leaching of active $\mathrm{V}$ species is observed in vanadium-based solid catalysts in liquid phase oxidation reactions. Consequently, Kim et al. synthesized V-based MOFs by dispersion on a carbon support, of vanadium oxide and carbide species by pyrolysis of MIL-47(V) (Fig. 6). A number of carbon catalysts containing different surface and bulk phases of $\mathrm{V}$ were synthesized by affecting the phase transitions of $\mathrm{V}$ by altering the pyrolysis temperature. Vanadium carbide catalysts displayed better performance and increased stability as confirmed by lesser amounts of $\mathrm{V}$ leached $(<20 \%)$ in comparison to conventional V/AC (56\%) during the recycling runs. This investigation signified noteworthy advancement in the development of supported V catalysts, with decreased leaching in fluid-phase oxidation reactions in contrast to materials orchestrated by ordinary impregnation strategies. ${ }^{87}$

The electrochemical reaction of lithium with $\mathrm{MOF}, \mathrm{V}^{\mathrm{IV}}(\mathrm{O})(\mathrm{bdc})$ [MIL-47] was investigated by Kaveevivitchai et al. The large open channels present in the MOF can easily lodge small ions like $\mathrm{Li}^{+}$. The redox properties of vanadium(Iv) ions led to the use of this material as a rechargeable intercalation electrode in lithium batteries. The electrochemical properties of material were studied in $\mathrm{Li} \mid 1 \mathrm{M} \mathrm{LiPF}_{6}$ in ethylene carbonate and dimethyl carbonate $\mathrm{V}(\mathrm{O})(\mathrm{bdc})$ cells vs. $\mathrm{Li} / \mathrm{Li}^{+}$cathodes. $^{88}$ Farzaneh and Sadeghi reported a new heterogeneous catalyst $\mathrm{Fe}_{3} \mathrm{O}_{4} @ \mathrm{SiO}_{2} @ A P T M S @$ VMIL-101, synthesized by incorporation of $\mathrm{Fe}_{3} \mathrm{O}_{4}$ nanoparticles modified with sodium silicate and (3-aminopropyl) trimethoxysilane (APTMS) in V-MIL-101. The epoxidation reaction of allyl alcohols and alkenes with tert-butyl hydroperoxide was catalysed by the material with reasonably good yield. The material was stable and reusable, thus demonstrating its heterogeneous character. $^{89}$ MOFs having open metal sites are prospective adsorbents for the separation of gaseous mixtures. Yang and co-workers investigated open-metal sites $\mathrm{V}^{\mathrm{III}}$ on MIL-100V $\mathrm{V}^{\mathrm{III} / \mathrm{IV}}$ and MIL- $101 \mathrm{~V}^{\mathrm{III} / \mathrm{IV}}$ having $\mathrm{CO}_{2} / \mathrm{CH}_{4} / \mathrm{N}_{2} / \mathrm{O}_{2}$ adsorption capability. It was observed that the binding energy of single $\mathrm{O}_{2}$ on an openmetal $\mathrm{V}^{\mathrm{III}}$ site is reduced to $26.5 \mathrm{~kJ} \mathrm{~mol}^{-1}$ from $93.278 \mathrm{~kJ} \mathrm{~mol}^{-1}$ when the sites are occupied by $\mathrm{H}_{2} \mathrm{O}$. XPS pattern of $\mathrm{V} 2 \mathrm{p}$ indicated that on removal of water coating, V-MOF changed to MIL-100V $\mathrm{V}^{\mathrm{IV}}$ and MIL-101V $\mathrm{V}^{\mathrm{IV}}$ at $25{ }^{\circ} \mathrm{C}$ owing to the effect of $\mathrm{O}_{2} \cdot{ }^{90}$ Voort et al. reported V-based MOFs containing $\mathrm{V}^{\mathrm{III}}$ and $\mathrm{V}^{\mathrm{IV}}$ as metal nodes with their structure, porosity, stability and applications in oxidation catalysis and gas sorption. ${ }^{91}$ Two families of MOFs i.e. MIL-88 and MIL-101 constructed from transition metal (TM) clusters $(\mathrm{TM}=\mathrm{Cr}, \mathrm{Fe}$, or $\mathrm{Sc}$ ) have been recognized. Actually, these MOFs are polymorphs, fabricated from the same metal and organic linkers, but differ in the linking of components. ${ }^{92}$ McNamara et al. prepared a V-based MOF, MIL-47 and investigated its catalytic activity for oxidation of dibenzothiophene (DBT), benzothiophene,

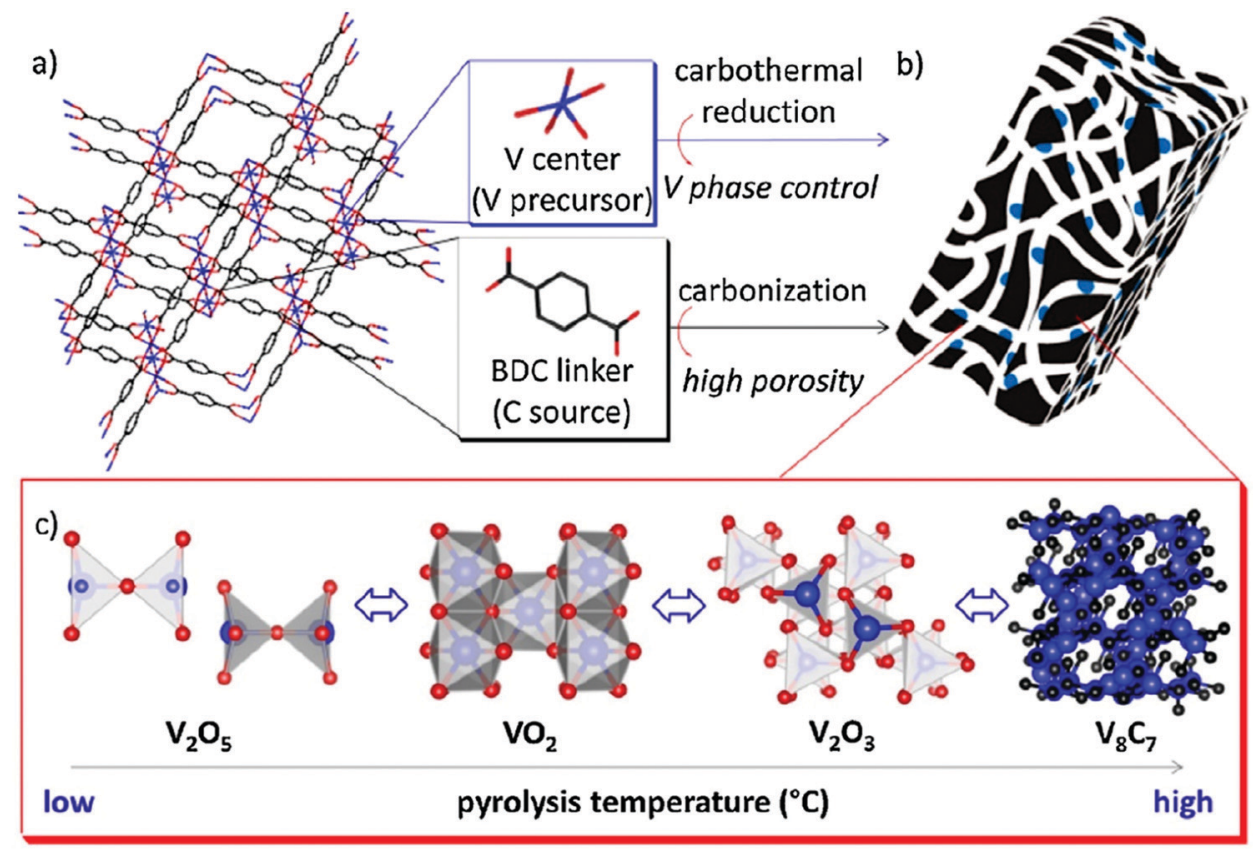

Fig. 6 Schematic representation of V-based MOFs on a carbon support via pyrolysis of MIL-47(V) [reprinted with permission from ref. 87, Copyright (C) Elsevier, 2016]. 
and thiophene. The activation energy for DBT oxidation on MIL-47 was observed to be $51 \mathrm{~kJ} \mathrm{~mol}^{-1}$. It was established that better catalytic activity of MIL-47 was not merely attributed to the partial availability of active sites of MOF but also to the nature of metal centre. $^{93}$ The MOF, V-MIL-47, was synthesized and employed to catalyze the epoxidation of cyclohexene in different solvents. On dissolving the MOF in water, considerable leaching of V-species was observed whereas negligible leaching of the oxidant was observed on dissolution in decane. The structural framework of V-MIL-47 was retained during consecutive runs. Extensive computational modelling studies were performed to establish that a number of reaction cycles are possible. ${ }^{94}$ Lieb et al. synthesized mesoporous vanadium(III) trimesate MIL-100(V) in hydrothermal conditions. The MIL-100(V) MOF exhibited higher adsorption capability and co-ordinatively unsaturated $\mathrm{V}$ sites in +3 and +4 oxidation states as indicated by the in situ IR studies after NO exposure. ${ }^{95}$ Rives et al. explored the self-diffusion of prolonged chain n-alkanes in MIL-47(V) MOF by joining quasi-elastic neutron scattering (QENS) and molecular dynamics (MD) simulations. The experimental diffusivities confirmed a non-monotonous reduction with growing chain length. ${ }^{96}$ Phan et al. amalgamated homogeneous catalysts having higher activity and heterogeneous catalysts for methane activation. Vanadium based MOFs (MIL-47 \& MOF-48) were observed to be chemically stable with high catalytic activity. Both the MOFs selectively transformed methane to acetic acid using $\mathrm{K}_{2} \mathrm{~S}_{2} \mathrm{O}_{8}$ as an oxidant. It was shown by isotopic labelling technique that both the methane molecules successfully transformed to acetic acid. The MOF catalysts were reusable and found to be catalytically active for a number of cycles while retaining their framework structures. ${ }^{97}$

\section{Chromium-based metal organic frameworks}

Chromium is the fourth transition metal and first element in group six. Chromium coordinates to various organic linkers and leads to generation of different types of MOFs which are utilized for gas separation, adsorption, catalytic activity, sensing, desalination, water treatment etc. In catalysis, controlling the interactions between active sites and substrates is crucial. The most prominent technique is to alter the active sites with a variety of compounds which, however, reduces substrate accessibility and, as a result, diminishes activity. Thus, the construction of heterogeneous catalysts with naked metal NPs that can simultaneously modulate substrate interactions is strongly desired. ${ }^{98}$ The surface naked metal NPs encapsulated onto MIL-101 achieved tunable interaction with the substrate and displayed outstanding catalytic activity and perfect selectivity. ${ }^{99}$ Zhao et al. carried out the synthesis of MIL-101(Cr) with massive porosity, using different additives as a modifier to regulate the morphology of MOFs. The addition of $\mathrm{NaOH}$ yielded MOFs with high porosity and particle size of about $87 \mathrm{~nm}$. The $\mathrm{CO}_{2}$ adsorption capacity exhibited by nano-sized MIL-101(Cr) was almost twice that of bulk MIL-101(Cr). ${ }^{100}$ Owing to their higher surface area and porosity, MOFs are fascinating materials for electrochemical applications,
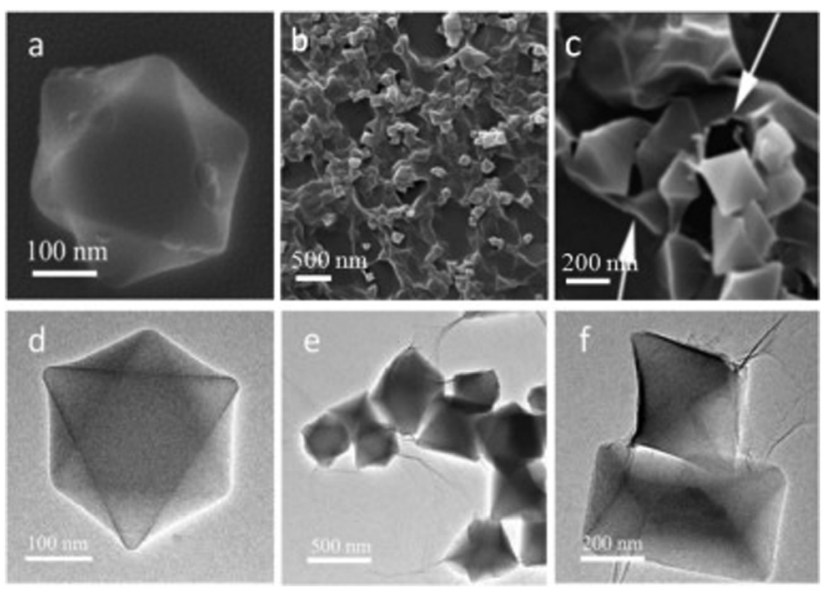

Fig. 7 (a-c) SEM and (d-f) TEM images of the MIL-101(Cr) arGO nanocomposite [reprinted with permission from ref. 101, Copyright (C) Elsevier, 2018].

but poor electrical conductivity impedes their utility. Zhang and co-workers fabricated a chromium terephthalate MOF MIL101(Cr) with reduced graphene oxide (rGO) (MIL-101(Cr)@rGO) nanocomposite (Fig. 7) which exhibited improved conductivity. The nanocomposite was employed for voltammetric monitoring of 4-nonylphenol in concentration range 0.1 to $12.5 \mu \mathrm{M}$, with 33 $\mathrm{nM}$ as the detection limit. ${ }^{101}$

Zare et al. immobilized Candida rugosa lipase with derivatives of chromium terephthalate MIL-101(Cr) and its three improved forms: amino MIL-101(Cr) $\left(\mathrm{NH}_{2}-\mathrm{MIL}\right)$, trichlorotriazine amino MIL-101(Cr) (TCT@ $\mathrm{NH}_{2}$-MIL) and glutaraldehyde amino MIL-101(Cr) (Glu@NH 2 -MIL). The MOFs CRL@Glu@ $\mathrm{NH}_{2}-\mathrm{MIL}$ displayed highest specific activity for enzymes. Nearly 80-90\% of enzyme activity was maintained after 35 days, demonstrating an outstanding storage stability of the immobilized CRLs. ${ }^{102}$ The leaking of liquid phase over the melting point and low thermal conductivity of phase change materials (PCMs) are significant hindrances that right now forestall the viable use of natural PCMs. Wang et al. fabricated a novel heterogeneous MOF by depositing Cr-MIL-101- $\mathrm{NH}_{2}$ MOF nanoparticles on the surface of CNTs (Fig. 8). The combination of CNTs and MOF nanoparticles resulted in the formation of a $3 \mathrm{D}$ and interpenetrating network. The fabricated PEG2000/CNT/Cr-MIL-101- $\mathrm{NH}_{2}$ composite exhibited better chemical and thermal cycling stability than PEG2000/Cr-MIL-101-NH ${ }_{2}$ PCM. $^{103}$

Dynamic adsorption behaviour of diverse volatile organic compounds (VOCs) in gas phase on improved M-MIL-101(Cr) and MIL-101/ $\mathrm{HNO}_{3}$ was explored with special emphasis on gasoline adsorption. The growth of VOCs and measurement of their dynamic adsorption behaviour and adsorption capacity was compared on both the MOFs. Better results were obtained with MIL-101(Cr) as it adsorbed $90.14 \%$ gasoline on regeneration after 4 cycles. ${ }^{104}$ Rostamnia et al. ${ }^{105}$ synthesized open metal site MOFs of MIL-100(Cr) which were used as a support for molybdenum complexes. The $\mathrm{MoO}\left(\mathrm{O}_{2}\right)_{2}$ complexes were coordinated on an ethylene diamine (En)-decorated MIL-100(Cr) pore cage $\left(\mathrm{MoO}\left(\mathrm{O}_{2}\right)_{2} @ \mathrm{En} / \mathrm{MIL}-100(\mathrm{Cr})\right)$ and were successfully used for a 

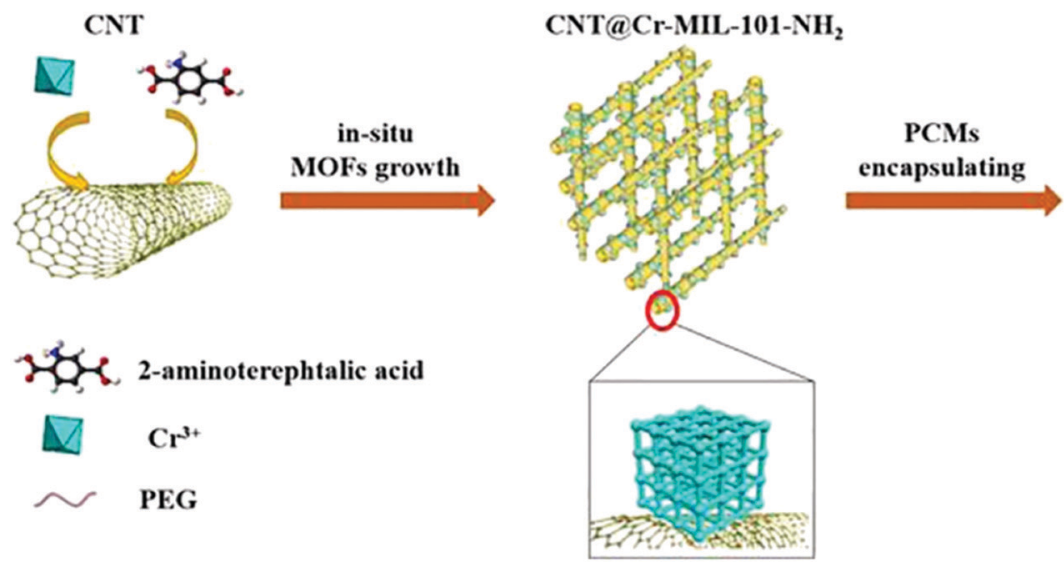

PEG/CNT@Cr-MIL-101-NH2

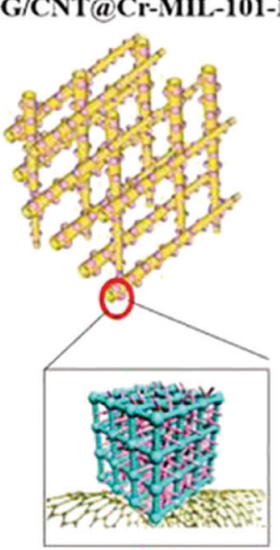

Fig. 8 Formation of the PCM composite through the CNT inserted MOFs [reprinted with permission from ref. 103, Copyright (C) Elsevier, 2018].

green thioether oxidation process, mediated by $\mathrm{H}_{2} \mathrm{O}_{2}(30 \%)$. The inimitable features like tremendously high surface area and porosity with a tuneable pore size make the MOFs an attractive material for adsorption of diverse trace pollutants from waste water. Azizi and co-workers synthesized and studied MIL-101(Cr) MOF as a proficient material for adsorption of diazinon with $92.5 \%$ removal from waste water at neutral $\mathrm{pH}$. The MOFs exhibited a mesoporous octahedral structure, crystallinity and high thermal stability. The use of Langmuir isotherm for adsorption and Thomas model for system behaviour was in conformity with the results obtained. ${ }^{106}$ Efficient removal of pyrethroids present in water and tea samples was achieved with the composite of MIL-101(Cr) with dispersive liquid-liquid microextraction. A linear range was achieved in concentration range $0.05-10.0 \mathrm{ng} \mathrm{mL}^{-1}$, with sensitivity and detection limit of $0.008-0.015 \mathrm{ng} \mathrm{mL}^{-1}$ and $0.028-0.050 \mathrm{ng} \mathrm{mL}^{-1}$, respectively. The technique was effectively employed for the estimation of pyrethroids in real life samples with acceptable recuperations. ${ }^{107} \mathrm{~A}$ new approach for development of multiple adsorption sites in MIL-101(Cr) for $\mathrm{CO}_{2}$ capture application was carried out by incorporating diethylenetriamine-based ionic liquid (DETA-Ac) by post-synthetic modification. High surface area and bulky cage size of MIL-101(Cr) led to better dispersion of ionic liquid, resulting in a higher number of sites for adsorption of $\mathrm{CO}_{2}$. The sole MIL-101(Cr) MOF adsorbed $1.22 \mathrm{mmol} \mathrm{g}^{-1}$ of $\mathrm{CO}_{2}$ whereas incorporation of DETA-Ac in MIL-101(Cr) MOF increased binding sites, and $2.46 \mathrm{mmol} \mathrm{g}^{-1}$ of $\mathrm{CO}_{2}$ was adsorbed. Cooperation of the composite and carbon dioxide resulted in high isosteric heat of adsorption. ${ }^{108}$ Zhao et al. introduced MIL-101(Cr) MOF as an adsorbent for removing elemental mercury from sintering flue gas. Results revealed that mercury removal efficiency was increased with increase in temperature and oxygen content ${ }^{109}$ (Fig. 9).

HF-free MIL-101(Cr) was synthesized hydrothermally and used for the fabrication of a highly sensitive humidity sensor with reasonably good response and recovery time. Thus, porous MIL-101(Cr) nanoparticles were established as efficient humidity sensors. ${ }^{110}$ The porous materials like MOFs have been widely used as adsorbents for hydrogen storage. Chromium(III) terephthalatebased MIL-101(Cr) is the most stable material among all the MOFs

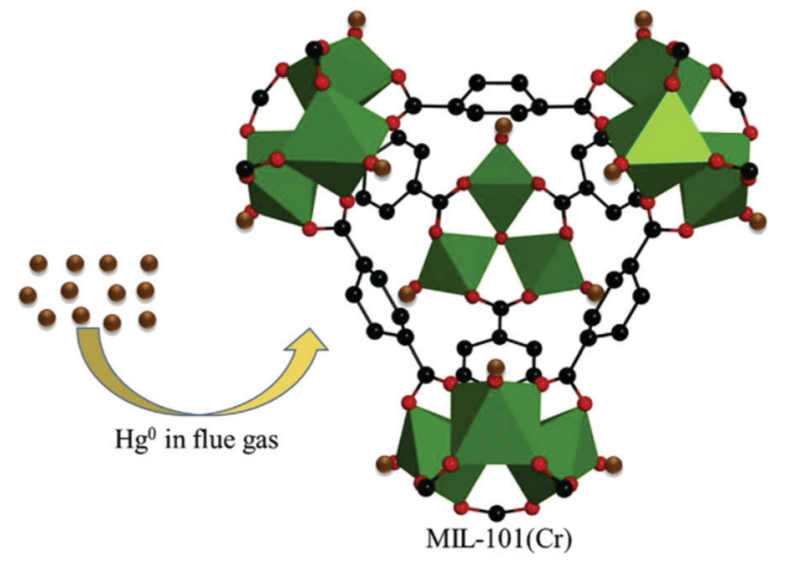

Fig. $9 \mathrm{Hg}$ removal from flue gas by the open metal site of MIL-101(Cr) [reprinted with permission from ref. 109, Copyright (C) Elsevier, 2018].

with good uptake capacity for hydrogen. Yu et al. fabricated MIL-101(Cr) MOFs with huge surface area, using carbon as a surface modifier. The hybrid MOF material was employed for hydrogen storage which exhibited a capacity of $67.4 \mathrm{~mol} \mathrm{~kg}^{-1}$ at $77 \mathrm{~K}$ and 100 bar. The adsorption was measured by volumetric and gravimetric techniques. ${ }^{111}$ Interpenetration of alkali metal ions in MIL-101(Cr) MOFs maximized the uptake of water. Iso-steric heat of adsorption was measured by the Van't Hoff equation. Doping of alkali metals (5\%) resulted in a decrease of hydrophobic length and increase in water uptake, depending upon the molecular mass of metal ions. ${ }^{112}$ Panchariya and co-workers prepared hybrid material of chromium(III) nitrate nonahydrate with terephthalic acid, and doping of carbon led to the fabrication of DAC/MIL-101 MOFs. Physical and chemical properties, stability and their applications were investigated to determine gas storage, adsorption and catalysis efficiency. ${ }^{113}$ Kayal et al. fabricated composite MAX-MIL using fluorine free hydrothermal reaction, by incorporating activated carbon in situ in MIL-101(Cr) MOFs. Furthermore, the adsorption of $\mathrm{CH}_{4}$ and $\mathrm{CO}_{2}$ on MAX-MIL and MIL-101(Cr) MOFs was compared, using gravimetric and volumetric uptakes. It was observed that the modified composite, MAX-MIL adsorbed higher amounts of $\mathrm{CH}_{4}$ and $\mathrm{CO}_{2}$ in comparison to the original 
MIL-101(Cr) MOFs. ${ }^{114}$ The shape selective MIL-101(Cr) MOFs were employed as a stationary phase in gas chromatography, to separate isomers of hydrocarbons on the basis of their binding efficiency and molecular mass. Elution of linear hydrocarbons, and xylenes i.e. meta-xylene, para-xylene and ortho-xylene was studied. ${ }^{115}$

Catalytic adsorption of radioiodine and iodine was performed with MIL-101 in cyclohexane, and 97.9\% elimination of iodine was attained. Advanced application of this reaction can be employed for controlling the amount of iodine during nuclear accidents involving radioiodine. ${ }^{116}$ Production of hydroxylacetone was discussed along with acetaldehyde and acetic acid from $10 \%$ oxidation of propylene glycol using tertiary butyl hydro-peroxide (TBHP) by a reaction catalysed by chromium-based MIL-101 and MIL-100 MOFs. The unsurpassed results were attained with MIL-101, employing acetonitrile as a solvent. It was observed that addition of molecular oxygen enhanced the reaction rate whereas the presence of radical chain scavengers generated a signified radical chain mechanism of oxidation process. ${ }^{117}$ Insertion of $\mathrm{NH}_{2}$ in chromium based MOFs (MIL-101) was tested for enhancement of its interaction with ibuprofen and nimesulide. The liberation of ibuprofen and nimesulide was $80 \%$ and $10 \%$, respectively, achieved in 8 days. The loading capacity of $\mathrm{NH}_{2}-\mathrm{MIL}-101(\mathrm{Cr})$ is much higher in comparison to MIL-(Cr). The drugs and matrix are joined by a hydrogen bond with the help of $\mathrm{NH}_{2}$. The release time of the drugs was extended by the matrix. ${ }^{118}$ Cr-MOFs were synthesised by utilization of waste PET bottles through one-pot conversion, originated from BDC acid linker. The prepared Cr-MOFs were employed for hydrogen storage applications with 1.8-2.1 wt\% hydrogen uptake. Ethylene glycol and terephthalic acid were formed by depolymerisation on addition of a catalyst. ${ }^{119}$ Differentiation was made between MIL-101(Cr), Selexsorb CDX, Selexsorb CD, silica gel and activated carbon for the sorption of nitrogen compounds using batch and fixed-bed set ups (Fig. 10). Langmuir and Freundlich models were used for the quantification of batch test, activated carbon and MIL-101(Cr). MIL-101(Cr) retained $85-90 \%$ stability by the utilisation of acetone even after 300 cycles and exhibited 2.3 times greater adsorption efficiency than other commercial adsorbents. $^{120}$

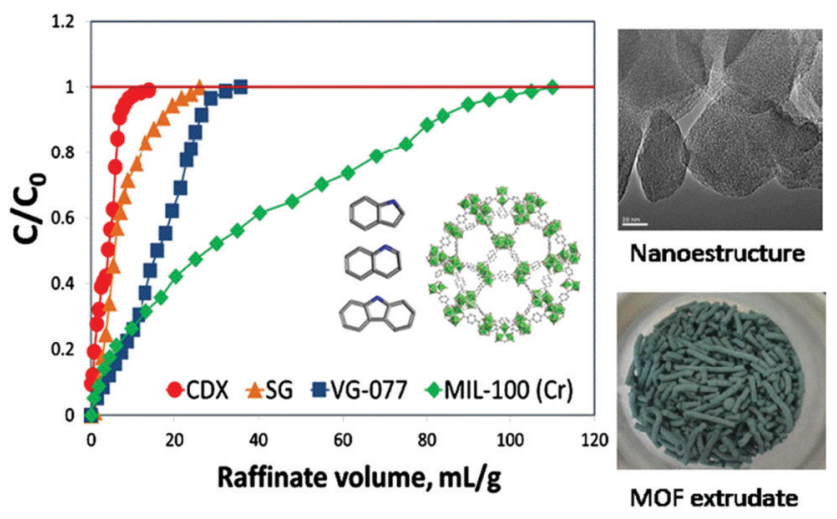

Fig. 10 Schematic representation of fabrication of MIL-100(Cr) [reprinted with permission from ref. 120, Copyright (C) Elsevier, 2016].
MIL-100(Fe, Cr) and MIL-101(Fe, Cr) MOFs were studied for isomerization of dicyclopentadiene from endo to exo dimers, contingent on the metal centre. MIL-100 possessed more acidic sites, high efficiency for recovery and reusability which contributed to its excellent catalytic performance.

\section{Manganese based metal organic frameworks}

Manganese is not present free in nature but is present within minerals. The ions of manganese act as co-factors for different types of enzymes. Manganese based MOFs with characteristic structural and electronic properties are fabricated mainly by a solvothermal method. Han et al. synthesized two new manganese based MOFs, $\left[\mathrm{Mn}_{2}(\mathrm{bpe})_{2}(4-\mathrm{Brip}) 2\right]_{n}(\mathbf{1})$ and $\left\{\left[\mathrm{Mn}_{3}\left(\mathrm{H}_{2} \mathrm{O}\right)_{2}(\mathrm{H}-\mathrm{bpp})_{2}\left(5^{-}\right.\right.\right.$ Brip) $\left.\left.{ }_{4}\right] \cdot \mathrm{H}_{2} \mathrm{O}\right\}_{n}$ (2) employing a hydrothermal method. Two new polymers were isolated from aromatic poly-carboxylate and $\mathrm{Mn}$ (II) ions with bipyridyl ethane or bipyridyl propane ligands. Complex 1 possessed a 3D 3-fold interpenetrating network whereas complex 2 contained 1D ladder-like chains. The chains were linked by $\mathrm{N}-\mathrm{H} \cdots \mathrm{O}$ and $\mathrm{O}-\mathrm{H} \cdots \mathrm{O}$ hydrogen bonds to form a $2 \mathrm{D}$ interlocked structure. ${ }^{121}$ Owing to their large surface area, simple synthesis methods and numerous applications, MOFs are considered as highly attractive materials. Recently, MOFs have earned global recognition in the field of hydrogen storage. Hu et al. evaluated interrelation between hydrogen storage capacities and structure of MOFs, with reference to surface area and pore size. ${ }^{122}$ Zhao et al. synthesized $\left[\mathrm{Mn}_{3}(\mathrm{HCOO})_{6}\right] \mathrm{DMF}$ MOF solvothermally, using Mn salt, formate ligand and DMF solvent. A neutral 3D network with fascinating $1 \mathrm{D}$ zig-zag channels was formed where the formate ligand formed a $\mu^{3}$-bridge to join three octahedral Mn(II) centers. The as-synthesized MOFs exhibited more exciting adsorption properties for $\mathrm{CO}_{2}$ than $\mathrm{N}_{2}$ under ambient conditions, with $\mathrm{CO}_{2}$ uptake of 57 and $43 \mathrm{~cm}^{3} \mathrm{~g}^{-1}$ at $273 \mathrm{~K}$ and $298 \mathrm{~K}$, respectively. $^{123}$ A new hybrid material CM-MIL-101 was employed for epoxidation of alkenes and hydroxylation of alkanes using sodium periodate. The results revealed that approximately $90-95 \%$ of alkenes were converted to ketones and alcohols. Mild reaction and easy work up conditions are the unique features of this catalyst. ${ }^{124}$

Thermal decomposition of cobalt-terephthalate and manganese MOF precursors was used for the fabrication of $\mathrm{Mn}_{3} \mathrm{O}_{4}, \mathrm{Co}_{3} \mathrm{O}_{4}$, and $\mathrm{Mn}_{2} \mathrm{O}_{3}$ NPs with average diameter of $60 \mathrm{~nm}, 40 \mathrm{~nm}$ and $80 \mathrm{~nm}$, respectively. These MOFs showed great stability and reusability towards olefin oxidation. Catalytic conversion of cyclohexene yields 80-95\% efficiency. ${ }^{125}$ A 3D manganese MOF namely, $[\mathrm{Mn}(\mathrm{L})(\mathrm{ndc})]_{n}$ was isolated using co-ligands of 2,6-naphthalenedicarboxylic acid (ndc) and 1,4-bis(5,6-dimethylbenzimidol-1-ylmethyl)benzene (L) which was employed for catalytic degradation of dye. For congo red solution, 85\% degradation was attained in 130 min. ${ }^{126} \mathrm{~A}$ series of some new Mn-MOFs was synthesized successfully under similar experimental conditions by manipulating the solvent systems. Characterization was made on the basis of XRD results showing variation in interconnections, layers of crystals and inversion center. The effect of solvents on structure 
was also discussed along with the feasibility of making MOF based SBUs. ${ }^{127}$

\section{Iron based metal organic frameworks}

Iron based MOFs having a periodic network structure are the hybrid solids formed by coordination of iron ions with organic ligands. Iron based MOFs are encouraging options in comparison to conventional heterogeneous catalysts because of their characteristic properties such as single iron sites, high porosity, and huge surface area which make available the active sites for reactants. Kailin et al. reported high yield conversions and better selectivity reactions within confined spaces of a micro-reactor. Furthermore, MOF catalysts were supported on the network of interconnecting channels. The huge surface area (i.e. $200000 \mathrm{~m}^{2} \mathrm{~m}^{-3}$ ) is best suited for deposition of the catalyst. ZIF-8, PdZIF-8 and FeBDC were synthesized and employed for Knoevenagel condensation reaction, selective hydrogenation reaction and acetalization reaction, respectively. ${ }^{128}$ Presently, applications of MOFs in agriculture and food processing have started to unfold, but still the toxicity of MOFs is of great concern. MOFs based on iron carboxylate (Fe-MOFs) exhibit low toxicity and hence, can be employed in food processing in controlled doses. Abdelhameed and co-workers reported porous Fe-MOFs modified with EDTA dianhydride (Fig. 11). It was observed that Fe-MOF-EDTA exhibited better activity as compared to other Fe-sources in improving the growth rate, chlorophyll content and antioxidant enzyme activities of Phaseolus vulgaris. ${ }^{129}$ The catalytic performance of iron based MOFs, namely Fe-MIL-101, Fe-MIL-100 and Fe-MIL-53 was compared for degradation of antibiotic tetracycline. It was observed that Fe-MIL-101 showed efficient removal of tetracycline (96.6\%) that was much better in comparison to that of Fe-MIL-100 (57.4\%) and Fe-MIL-53 (4.6\%) under similar experimental conditions.

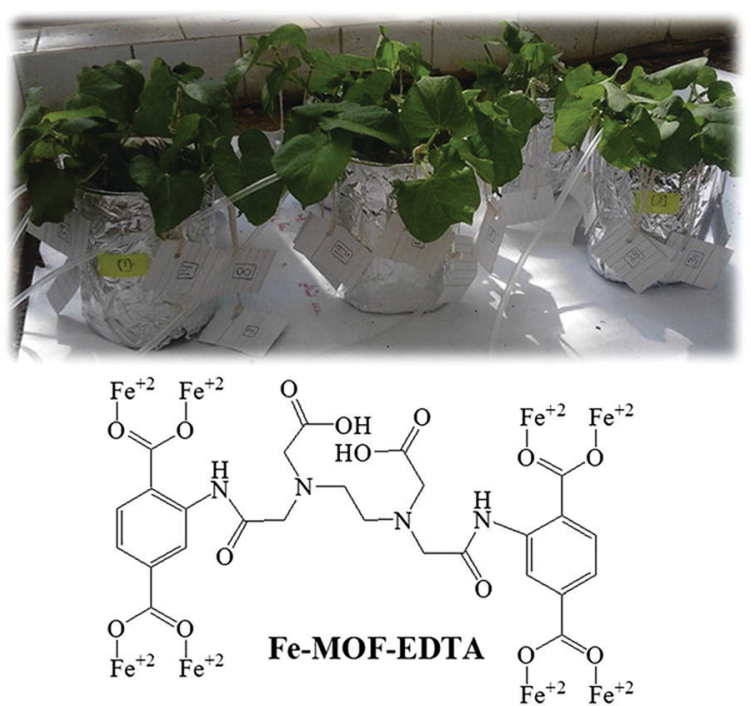

Fig. 11 Schematic representation of the fabrication of Fe-MOF-EDTA [reprinted with permission from ref. 129, Copyright (C) Elsevier, 2019].
It was also observed that there was significant improvement in photocatalytic degradation effect and adsorption properties with increase in time. ${ }^{130}$ Yuan et al. fabricated $\mathrm{H}_{2} \mathrm{~N}-\mathrm{Fe}-\mathrm{MIL}-$ 88B@OMC composites through in situ growth of $\mathrm{H}_{2} \mathrm{~N}$-Fe-MIL-88B MOFs on ordered mesoporous carbon (OMC) by a hydrothermal method. Addition of OMC resulted in enlargement of specific surface area, lowering of electron transfer resistance, decrease of size, drastic improvement in electrochemical performance and enhancement of electro-catalytic activity for reducing $p$-nitrotoluene and oxidizing hydrazine. Hence, $\mathrm{H}_{2} \mathrm{~N}$-Fe-MIL-88B@OMC was used for fabrication of an efficient sensor for detection of $p$-nitrotoluene and hydrazine. The sensor exhibited extensive linear range with limit of detection at $8 \mu \mathrm{M}$ and $5.3 \mathrm{nM}$ for $p$-nitrotoluene and hydrazine, respectively, under ambient conditions. ${ }^{131}$ A synthetic method for preparation of hierarchically spinel $\mathrm{Ni}_{x} \mathrm{Co}_{1-x} \mathrm{Fe}_{2} \mathrm{O}_{4}$ micro-tubes by using iron-based MOFs and inorganic acetate salts of nickel and cobalt involving combined solvent evaporation and annealing technique was used for synthesizing MOFs with adjustable sensing properties. The obtained composite exhibited high sensitivity and magnificent reproducibility for estimation of acetone vapors at $120{ }^{\circ} \mathrm{C} .{ }^{132}$ Insertion of $\mathrm{Cu}$ (II) species in iron-based MOFs having large surface area reduced $\mathrm{Cu}$ (II) species to $\mathrm{Cu}(\mathrm{I})$. It was observed that $\mathrm{Cu}(\mathrm{I})$ doped MOFs displayed high $\mathrm{CO} / \mathrm{CO}_{2}$ selectivity and improved $\mathrm{CO}$ working ability of $1.61 \mathrm{mmol} \mathrm{g}^{-1}$. It was also revealed that this new composite can easily separate $\mathrm{CO} / \mathrm{CO}_{2}$ mixtures under forceful flow conditions and can be efficiently reformed under mild conditions. ${ }^{133}$ The synthesis of iron based MOFs doped with bismuth was carried out by addition of $\mathrm{Bi}$ (III) and MIL-101(Fe) by solvothermal method in a Teflon-lined autoclave. The new mesoporous compound exhibited enhanced uptake of iodide ions from aqueous solution. The composite displayed a fast adsorption rate that was affected by the $\mathrm{pH}$ of solution. During catalyst and iodide ion interactions, equilibrium was achieved in $20 \mathrm{~min}$ at neutral $\mathrm{pH}$ and $200 \mathrm{mg} \mathrm{g}^{-1}$ concentration of iodide ions. ${ }^{134}$ MOFs are used as heterogeneous photocatalysts, due to pores in their structures and large surface area, especially for gaseous pollutants. Pollutant gases such as nitric oxides can be oxidized by iron-based MOFs as photocatalysts. It was also observed that an iron organic framework (MIL-101) is extraordinarily stable and removed $60-70 \% \mathrm{NO}_{x}$ gases under normal reaction conditions ${ }^{135}$ (Fig. 12).

To enhance the adsorption property of iron MOFs for selenite $[\mathrm{Se}(\mathrm{Iv})]$, Fe-MOFs were modified by grafting $\mathrm{Al}^{3+}$ ions,

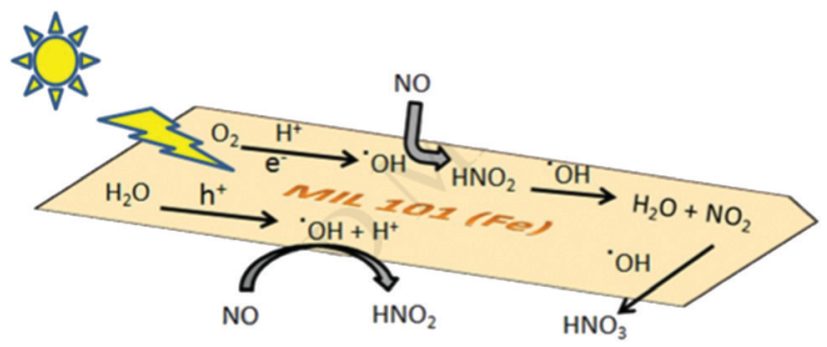

Fig. 12 Application of MOFs as a photocatalyst for the removal of pollutant gases [reprinted with permission from ref. 135, Copyright (C) Elsevier, 2019]. 
leading to $\mathrm{Al} \&$ Fe-MOFs. Hydrolysis of $\mathrm{Al} \&$ Fe-MOFs was carried out at $\mathrm{pH}$ range $3.0-7.0$ which led to an increase in adsorption capacity by $77 \%$ and the efficiency of specific surface area for Se(Iv) was increased by $112 \%$, in Al@Fe-MOFs as compared to Fe-MOFs. ${ }^{136}$ Being inexpensive and having high specific capacity, Li-S batteries have significant prospects for future energy storage. The main limitation in advancement of $\mathrm{Li}-\mathrm{S}$ batteries is the low conductivity of sulfur and volume extension in the lithiation/delithiation process. High chemical adsorption among metal oxides and polysulfides encouraged the use of $\mathrm{Fe}_{3} \mathrm{O}_{4} / \mathrm{C}$ composite obtained from Fe-MOFs as a proficient sulfur host in $\mathrm{Li}-\mathrm{S}$ batteries. Immobilization of sulfur and inhibition of dissipation of poly-sulfides can be carried out through the $\mathrm{Fe}_{3} \mathrm{O}_{4} / \mathrm{C}$ composite due to chemical bonding between iron ions and poly-sulfides, and an interaction between oxygen anion and lithium ion. Initially, specific capacity of the battery was observed to be $1324 \mathrm{~mA} \mathrm{~h} \mathrm{~g}^{-1}$ at a current density of $0.05 \mathrm{C}$, and after 300 cycles, $642 \mathrm{~mA} \mathrm{~h} \mathrm{~g}^{-1}$ specific capacity was retained at a current density of $1.0 \mathrm{C}$. This difference and maintenance upon charging and discharging is put up on the buffer layers which are provided from the carbon component and improve the electrical conductivity as well. ${ }^{137}$ An electrochemical biosensor based on Fe-MOFs was fabricated for signal-on detection of T4 polynucleotide kinase (PNK). Immobilization of Fe-MOFs on the electrode surface is the consequence of hybridization of Fe-MOFs \& AuNPs to modify single stranded DNA to produce double stranded DNA. Electrochemical signal can be produced on the electrode surface by generation of Prussian blue through the reaction of $\mathrm{Fe}^{3+}$ in MOFs with $\mathrm{K}_{4} \mathrm{Fe}(\mathrm{CN})_{6} \cdot{ }^{138}$ In order to produce sulfate radicals for degradation of organic contaminants, ferrocene is considered as a suitable catalyst for activating oxone. However, direct use of ferrocene in aqueous solutions may cause tough retrieval and aggregation. Ferrocene can be immobilized on some substrates without much effort. These substrates displayed small surface areas and did not offer meaningful contributions to catalytic happenings. Zhang et al. specifically selected a Fe-MOF, MIL-101, as a support to immobilize ferrocene chemically. The modified ferrocene-MIL (Fc-MIL) was synthesized by Schiff base reaction in which ferrocene-carboxaldehyde reacts with amine functionalized MOFs (namely, MIL-101- $\mathrm{NH}_{2}$ ) (Fig. 13). Experimental studies on catalytic activity of oxone for dye degradation were taken into account. The results displayed that Fc-MIL presented higher catalytic activity and smaller activation energy. ${ }^{139}$

Qin et al. established a synergistic approach to oxidize anethole selectively with $\mathrm{H}_{2} \mathrm{O}_{2}$ and tert-butyl hydroperoxide, using ionic liquid and $\mathrm{Cu}-$ or Fe-based MOFs. Nearly 95\% selectivity was achieved over Cu-BTC-1 (BTC: benzene-1,3,5tricarboxylate) with $5.0 \mathrm{~mol} \%$ [C12mim] Cl, employing $\mathrm{H}_{2} \mathrm{O}_{2}$ as an oxidant. It was observed that the synergic effect of Cu-BTC-1/ [C12mim]Cl was responsible for enhanced reactivity. ${ }^{140}$ It was reported that 2 -substituted benzothiazoles can be synthesized under visible light irradiation through oxidative condensation between alcohols and o-amino thiophenols. MIL-100 and MIL-68, two iron-based MOFs were observed to be active for this reaction. Higher concentration of long-lived positive holes in MIL-68 can be photo-generated over MIL-100. Thus, MIL-100 displayed

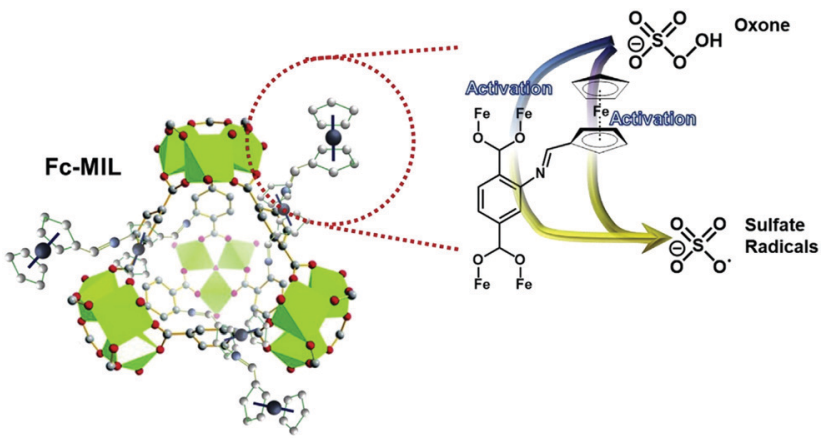

Fig. 13 Ferrocene modified MOF gives sulfate radicals and oxone on activation [reprinted with permission from ref. 139, Copyright (C) Elsevier, 2018].

superior catalytic performance with $92.1-94.6 \%$ selectivity and 74.8-91.5\% catalytic conversion. ${ }^{141}$ Nikseresht and co-workers reported esterification of oleic acid with different alcohols in high yield under ultrasonic irradiation. The reaction was achieved with a heterogeneous catalyst which was invented using heteropoly acid and Fe-based MOF (MIL-53 Fe). ${ }^{142}$ Liu et al. developed a one-step Fe-based catalyst (Fe-MIL-88B) which exhibited better catalytic execution for converting $\mathrm{CO}_{2}$ to hydrocarbons. At $773 \mathrm{~K}$ temperature, magnetite was achieved whereas the increase in temperature to $973 \mathrm{~K}$ resulted in metallic iron as the prominent phase. The varied performance of catalysts was due to the formation of different iron species under given reaction parameters. ${ }^{143}$ MOFs have transformed the probable applications of nano porous materials. The most advanced applications of MOFs are their use as supports for enzyme immobilization (Fig. 14). An in situ approach for the synthesis of MOFs has been quite encouraging due to many reasons: (i) enzyme immobilization is achieved in a single step; (ii) it is quick; (iii) it is highly effective in encapsulation capacity; (iv) enzymes are completely engaged without any leaching; and (v) the action of engaged enzymes can be significantly preserved. ${ }^{144}$

Fenton reaction is considered a proficient method for degrading highly toxic pollutants. Due to reusability and non-production of sludge, heterogeneous Fenton-like catalysts provide an encouraging substitute to homogeneous catalysts. However, these catalysts normally exhibit little activity towards production of $\mathrm{OH}$ because of their restricted visible active sites as well as exertion in reduction of $\mathrm{Fe}(\mathrm{III})$ to $\mathrm{Fe}(\mathrm{II})$. Hence, Cong et al. utilized iron-based MOFs

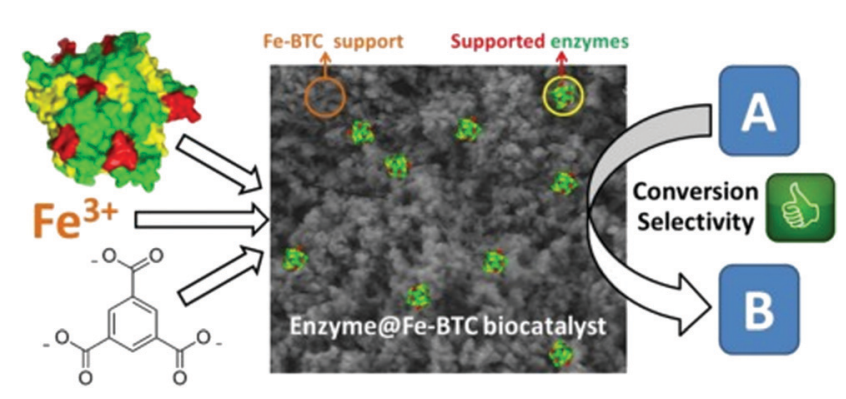

Fig. 14 Graphical representation of the synthesis of Fe-BTC MOF [reprinted with permission from ref. 144, Copyright (C) Elsevier, 2018]. 
(MIL-88-B-Fe) as a heterogeneous catalyst for degradation of pollutants. MIL-88B-Fe exhibited three times higher catalytic activity than $\mathrm{Fe}_{2} \mathrm{O}_{3}, \alpha-\mathrm{FeOOH}$, and $\mathrm{Fe}_{3} \mathrm{O}_{4}$, traditional catalysts and MIL-53-Fe and MIL-101-Fe, the other iron-based MOFs. The combined form of MIL-88-B-Fe and $\mathrm{H}_{2} \mathrm{O}_{2}$ was capable of efficiently degrading $99 \%$ of phenol. ${ }^{145}$ The adsorption capability of iron-based MOFs having square paddle-wheel cage structure for a $\mathrm{H}_{2}$ molecule was studied. It was observed that the adsorption of $\mathrm{H}_{2}$ molecules occurred on Fe active sites of the MOFs by interaction of d-orbitals of the MOF and sigma orbital of a $\mathrm{H}_{2}$ molecule. The interactions were studied by DFT. ${ }^{146}$ A superficial approach was established for the production of mesoporous material comprising an $\mathrm{Fe}_{3} \mathrm{O}_{4}$ core in a carbon nano disk shell employing Fe-MOF as a precursor. To affirm the presence of $\mathrm{Fe}_{3} \mathrm{O}_{4}$ nanoparticles in carbon matrix FeMCNA-300, $\mathrm{N}_{2}$ adsorption and X-ray diffraction techniques were used. Approximately, 84\% degradation of methylene blue dye was achieved in 15 min under ultra-sonication with FeMCNA-300 at the conditions of maximum iron draining. ${ }^{147}$ Ehsan et al. fabricated Fe-based MOFs (MIL-101 Fe and MIL-88 Fe) as novel catalysts for synthesizing ethyl benzene by alkylation of benzene with ethanol. The performance of catalyst at fixed benzene to ethanol ratio at different temperatures was also observed. MIL-88 demonstrated better performance in comparison to MIL-101(Fe) for conversion of reactants (ethanol-100\%, benzene-72\%) and ethylbenzene selectivity $(76 \%)$ at $175{ }^{\circ} \mathrm{C}$ temperature. ${ }^{148}$

Due to tunability of the pore aperture and structure, MOFs are attractive materials for various applications. Araya et al. successfully synthesized a three-dimensional MIL-53(Fe) MOF 4 by reacting Fe-MOF with BDC linker, followed by the formation of composites with Amberlite IRA 200 and Amberlite IRA 900. The synthesized MOF composites AMIL-53(Fe) and DMIL-53(Fe) were used for degrading organic contaminants photocatalytically. By adjusting the ratio of resin to MOF, $96 \%$ of the dye was degraded in 120 min under visible light. ${ }^{149}$ A crystalline Fe-based MOF-235 was fabricated and used for heterogeneous catalysis of a cyclo-condensation reaction of 1,2-diamines and ketones to form 1,5-benzodiazepines. ${ }^{150}$ A study showed the immobilization application of MOFs by growth of a 3-D Fe-based MOF (MIL-100) on $\mathrm{Fe}_{3} \mathrm{O}_{4}$ compound. It resulted in the formation of a core-shell microsphere, having large surface area and magnetic characteristics, and is considered as the commendable option for enzyme immobilization. The initial activity of enzyme was $>65 \%$, and after 10 catalytic cycles, the activity was found to be $60 \%$ over $6 \mathrm{~h}$. This synthesis of highly dispersed compound is an economically convenient, surfactant free and green synthesis. ${ }^{151}$ Anbia and co-workers synthesized iron terephthalate, MOF-235 hydrothermally that was used for gas adsorption. Among $\mathrm{CH}_{4}$, $\mathrm{H}_{2}$ and $\mathrm{CO}_{2}$ gases, maximum adsorption capacity and selectivity was shown for $\mathrm{CH}_{4}$. The presence of more open metal sites and large pore volume were responsible for better adsorption of $\mathrm{CH}_{4}$ on MOF-235. The higher selectivity of MOF for $\mathrm{CH}_{4}$ as compared to other two gases, advocated that MOF-235 was a good adsorbent for separation of $\mathrm{CH}_{4}$ from gaseous mixtures. ${ }^{152}$ The removal of methyl orange, methylene blue or other harmful dyes from contaminated water was carried out via adsorption on iron terephthalate (MOF-235). It was observed that adsorption of dyes was a spontaneous and endothermic process. Furthermore, with the adsorption of MB and MO dyes, entropy also increased. ${ }^{153}$

\section{Cobalt based metal organic frameworks}

MOFs of cobalt display excellent applications such as adsorption, catalysis, sensing, heavy metal removal, electrical conductivity, etc. due to their highly crystalline and porous hybrid structure. Cobalt based MOFs can be synthesized by hydrothermal, solvothermal or wet impregnation techniques. The post-synthetic technique which allows the formation of desired structure can be used for fabrication of well-defined structural crystalline MOFs. Peters et al. synthesized cobalt-based MOF, NU-1000 combined with linker naphthalene dicarboxylate for blocking small cavities where cobalt oxide clusters grow (Fig. 15). For oxidative dehydrogenation of propane, cobalt oxide cluster acts as an excellent catalyst at $230{ }^{\circ} \mathrm{C} .{ }^{154}$

Furthermore, intensification of catalytic activity of cobaltbased MOF, Co-MOF-74@NDHPI doped with NDHPI under mild conditions was detected. The modification resulted in high selectivity of the catalyst for oxidation of toluene where molecular oxygen acted as a primary oxidant. Experimental studies showed the successful synthesis of benzoic alcohol, benzaldehyde and benzoic acid with 18\%, 48\% and $34 \%$ selectivity, respectively and conversion of toluene was found to be $16 \%{ }^{155}$ Various electrochemical techniques were employed for insertion of titanium carbide in cobalt-based MOFs on nickel foam. The advantages of titanium carbide-based Co-MOF as the binder free supercapacitor electrode, increasing active sites and promoting fast ion transport, provide a new way for further

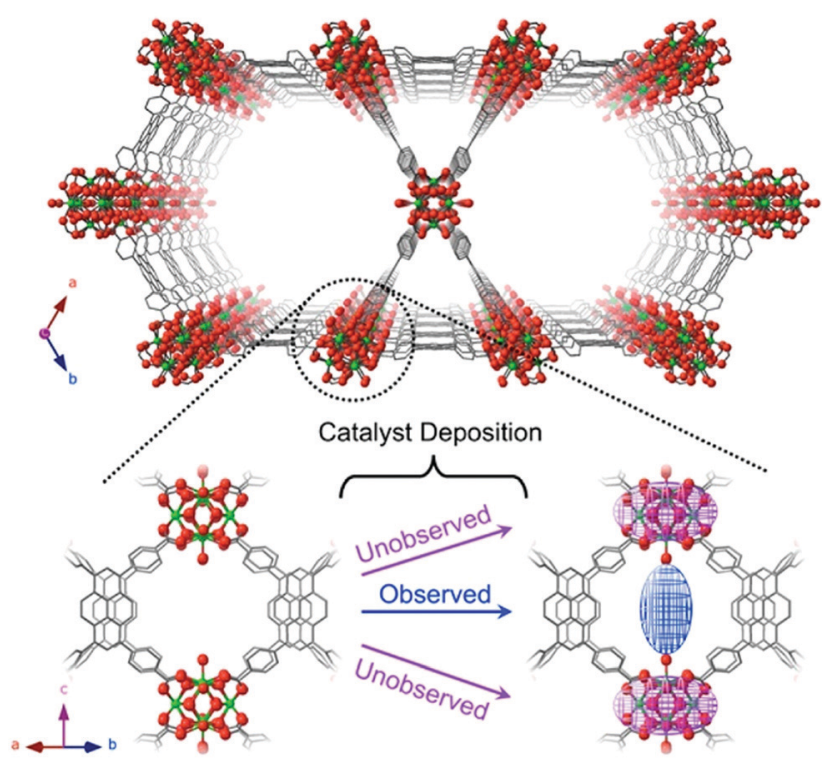

Fig. 15 Assembly of NU-1000 with stress on observed electron density of metal ions after post-synthetic anchoring of metal sites [reprinted with permission from ref. 154, Copyright (C) American Chemical Society, 2018]. 
research on such composites as it has high gravimetric capacitance. ${ }^{156} \mathrm{~A}$ distinct MOF with 2-D structure was prepared by coordination of cobalt ions with bis-carboxyphenyl-triazole and bis-imidazolebenzene. On interaction with graphene, the MOF gave well organized electro-catalytic hydrogen evolution reaction (HER) with overpotential of $125 \mathrm{mV} \cdot{ }^{157}$ An investigation on the convenient ultrasonic technique for synthesis of cobalt terephthalate-based MOF nano-sheets having oxygen vacancies was carried out. The synthesized novel MOFs exhibited higher anodic performance that enhanced their application in sodium ion batteries. The improved working of batteries was attributed to increased ion dispersion rate and reversible sodium ion storage by the induction of electric field through oxygen vacancies. ${ }^{158}$ Jiang et al. fabricated a single phase Co/Mn-MOF- 74 composite by a hydrothermal method. The catalytic activity at low temperature was demonstrated by using it as a control catalyst for industrial $\mathrm{NH}_{3}$-SCR $\mathrm{NO}_{x}$ degradation with $96 \%$ efficiency. Studies showed that morphology of Co/Mn-MOF-74 was affected by the incorporation of Co ions. ${ }^{159}$ The MOFs are also used as outstanding electrode materials in supercapacitors. Co/Ni-MOF and Ni-MOF was fabricated hydrothermally by altering the proportion of nickel. The MOF with a dandelion like hollow structure displayed splendid specific capacitance with $75 \%$ activity retention after 5000 cycles. Experimental studies showed enhancement in electrochemical properties and improved morphology of the MOFs. ${ }^{160}$ High porosity and surface area make the MOF a fascinating electrode material for energy storage and conversion. Zhu et al. reported a layered Co-based MOF on a nickel foam support (Co-MOF/NF) which was used as a high-performing electrode in supercapacitors. Furthermore, Co-MOF/NF demonstrated a very high specific capacitance $\left(13.6 \mathrm{~F} \mathrm{~cm}^{-2}\right)$ at $2 \mathrm{~mA} \mathrm{~cm}^{-2}$ in $2 \mathrm{M} \mathrm{KOH}$ which was higher in comparison to other MOFs. ${ }^{161}$

Yu et al. fabricated a Co-based MOF that was carbonized and then acid etched to get mesoporous carbon, to use it as a lithium-sulfur (Li-S) battery cathode scaffold. After etching, mesoporous carbon displayed an enhancement in porosity and/ or in sulfur-loading amount. In comparison to the composite-1 cathode, composite-2 $\left(1 \mathrm{C}=1675 \mathrm{~mA} \mathrm{~g}^{-1}\right)$ delivered a high discharge capacity of $925.1 \mathrm{~mA} \mathrm{~h} \mathrm{~g}^{-1}$ in second cycle and maintained a specific value of $781.1 \mathrm{~mA} \mathrm{~h} \mathrm{~g}^{-1}$ in 140th cycle. ${ }^{162}$ Enzymes, the catalysts of nature, are highly selective and efficient. In recent times, MOFs have attained great consideration as an interesting porous support for immobilizing enzymes. However, their handling and separation is still challenging, owing to less density and higher dispersion of enzyme-MOF composites. The magnetic-MOF can be a probable contender due to its advanced structural design, coupled with magnetic characteristics. Definitely fabricated magnetic-MOFs have unique properties like adjustable composition, huge surface area and speedy collection, making them a prospective candidate for immobilizing enzymes. ${ }^{163}$ In recent years, MOFs have been considered advantageous materials for electrocatalysis. However, electrocatalytic performance and stability of synthesized MOFs was diminished by their low conductance. Murthy and co-workers prepared a cobalt hydroxide functionalized multi-walled carbon nanotube (MWCNT) composite with improved electro activity using Co-MOF, ZIF-67 templates. The composite was used in the fabrication of a MWCNTs-Co(OH) $)_{2}$ modified glassy carbon electrode (GCE) for estimation of hydrazine and hydrogen peroxide. The MWCNTs-Co $(\mathrm{OH})_{2} / \mathrm{GCE}$ based sensor demonstrated linear range, detection limit and sensitivity, comparable with that reported earlier for sensing of hydrazine and hydrogen peroxide. ${ }^{164}$ The enhanced activity, selectivity, stability and synergic effect of dissimilar components than single component earned extensive attention. Yu et al. fabricated mesoporous hybrid dual-metal MOFs (Co/Fe-MOF, Fe-MOF, and Co-MOF) and studied their electrochemical properties in an ionic liquid (IL)/supercritical $\mathrm{CO}_{2}$ (SC)/surfactant emulsion system. It was revealed that due to coexistence of two metals, Co/Fe-MOF displayed 4 times higher specific capacitance $\left(319.5 \mathrm{~F} \mathrm{~g}^{-1}\right.$ at $\left.1 \mathrm{~A} \mathrm{~g}^{-1}\right)$ as well as superior cycling stability compared to that of single metal Co-MOF and Fe-MOF. ${ }^{165}$ In alkaline medium, electrocatalysis of glucose was performed with Co-MOF by using cobalt ions and terephthalic acid on nickel foam. Selective and sensitive examination of glucose through the production and development of nonnoble metal nano-array arrangement was found to exhibit $10886 \mu \mathrm{A} \mathrm{mM}^{-1} \mathrm{~cm}^{-2}$ sensitivity and $1.3 \mathrm{nM}$ detection limit. The results revealed that a Co-MOF/NF compound has longrange stability and powerful reproducibility. ${ }^{166}$ Owing to the ill use of antibiotics in creature farming and horticulture, it is profoundly important to estimate anti-microbials in biological systems by a straightforward, easy, and rapid strategy. Liu et al. fabricated a novel nano-construction, Co-MOF@TPN-COF using Co-MOF and terephthalonitrile-(TPN-COF) which was utilized as an aptasensor for sensing commonly used $\beta$-lactam antibiotic, ampicillin (AMP). The aptasensor exhibited a very low detection limit of $0.217 \mathrm{fg} \mathrm{mL}^{-1}$ in concentration range $1.0 \mathrm{fg} \mathrm{mL}^{-1}-2.0 \mathrm{ng} \mathrm{mL} \mathrm{m}^{-1}$. $^{167}$ The electrode property of cobalt MOF was enhanced by doping it with heteroatoms which can be further used in lithium sulfur (Li-S) batteries. By arranging the activation time and addition of a small number of clews of polymer nano belts, physiochemical properties of the doped MOFs were altered. The areal mass loading was enhanced by co-doping of the MOF defined carbon arrangement which contains cobalt and oxygen containing groups in matrix medium. This hybrid material showed transformation in activity efficiency from 1300.69 to $1020.6 \mathrm{~mA} \mathrm{~h} \mathrm{~g}^{-1}$ for 0.1 and 0.5 current density after several catalytic revolutions. ${ }^{168}$ The novel microporous and mesoporous cobalt-based MOF was synthesized in reduced reaction time with a simple method at low temperature. The as-synthesized lithium-ion batteries electrode displayed a high discharge capacity and respectable cyclability with a high coulombic efficiency. The micropores and mesopores of particles in materials provide sufficient space for loading and diffusion of electrolyte which is responsible for enhanced electrochemical performance. ${ }^{169}$ A slow evaporation technique was used for the preparation of cobalt pyridine-dicarboxylate MOF. L-Cysteine was detected with the help of cobalt pyridine-dicarboxylate. High resistance was used for observation of signals at $\mathrm{pH} 4$. The slow evaporation technique was used for preparation of $\left\{\left(\mathrm{C}_{5} \mathrm{H}_{5} \mathrm{NH}\right)\left[\mathrm{Co}\left(\mathrm{C}_{7} \mathrm{H}_{4} \mathrm{NO}_{4}\right)\left(\mathrm{C}_{7} \mathrm{H}_{3} \mathrm{NO}_{4}\right)\right] \cdot\left(\mathrm{C}_{7} \mathrm{H}_{5} \mathrm{NO}_{4}\right) \cdot\left(\mathrm{H}_{2} \mathrm{O}\right)\right\}_{n}$ composite 
bonded through covalent and non-covalent bonds. ${ }^{170}$ Mehak et al. investigated electrochemical oxidation of methanol in an alkaline medium employing Co-MOF and its composites with GO (Co-MOF-71/GO). The composite presented exceptional peak current density $\left(29.1 \mathrm{~mA} \mathrm{~cm}^{-2}\right)$ at lower potential $(0.1 \mathrm{~V})$. The boosted activity and stability was accredited to the synergy between the MOF and GO substrate. ${ }^{171}$ In another study, Co-MOF designed by coordination of cobalt ions with benzene-tricarboxylic acid in the presence of tri-ethylamine and nonanoic acid Co@NPC-900 displayed many advantageous properties like large surface area, proper pore sizes, highly ordered arrangement and diverse constitutions with various organic linkers, and was utilized for catalytic reaction of oxygen reduction and oxygen evolution. ${ }^{172}$ Two types of nano-crystals of $\mathrm{Co}_{3} \mathrm{O}_{4}$ were designed by indirect solid state thermolysis of cobalt terephthalate MOF (MOF-71). The MOF possessed an energy band gap of $3.7 \mathrm{eV}$ and displayed outstanding stability by retaining $85 \%$ capacitance after 2000 revolutions, excellent energy density and electrochemical properties. ${ }^{173}$ DFT calculations were performed for investigation of M-MOF-74 ( $\mathrm{M}=\mathrm{Mg}$, Co or Mn). Experimental data indicated structural design, band gap energies and many other properties of MOFs. The results showed that primarily, ionic bonds and covalent bonds were observed between the metal cations and oxygen atoms. Cobalt and magnesium MOFs also possessed hydrogen bonds. ${ }^{174}$ Choi et al. reported isostructural 3-D, Co(II) and $\mathrm{Cd}(\mathrm{II})$ MOFs using rigid 1,4-naphthalenedicarboxylate (1,4-NDC) as linkers. The 3-dimensional framework was generated by coupling of 1-dimensional chains which were formed by the bridging of metal ions with ligand. The performance of synthesized MOF as a catalyst in cyanosilylation reaction of aromatic aldehydes was investigated, and approximately $50 \%$ improved results were obtained compared to previously reported data. ${ }^{175}$ The attraction for MOFs has increased owing to their probable use in high efficiency energy storage. Liu and co-workers synthesized cobalt based MOFs using tetrafluoroterephthalic acid as a linker. The MOF, with large specific capacitance and splendid cycling stability, was used as an electrode in supercapacitors (Fig. 16). The properties of Co-MOF like enough space for storage, suitable pore sizes and dispersion of electrolytes lead to its outstanding electrochemical behavior. The electrode had a specific capacitance of $2474 \mathrm{~F} \mathrm{~g}^{-1}$

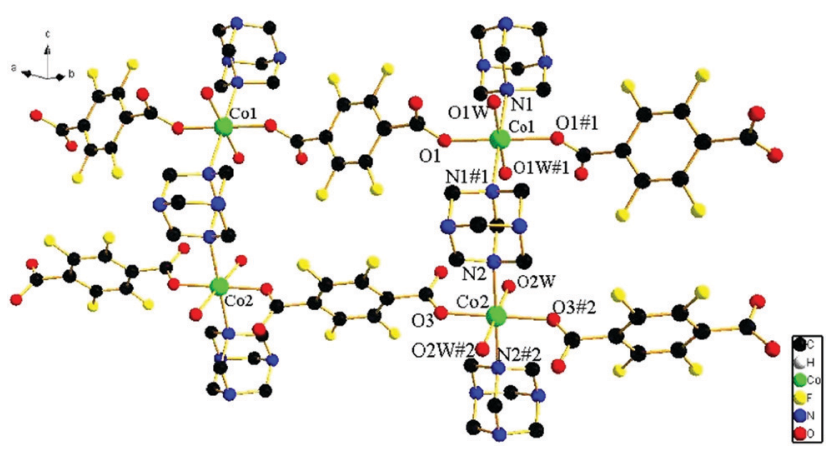

Fig. $162 \mathrm{D}$ view of Co-LMOF [reprinted with permission from ref. 176 Copyright (C) American Chemical Society, 2016]

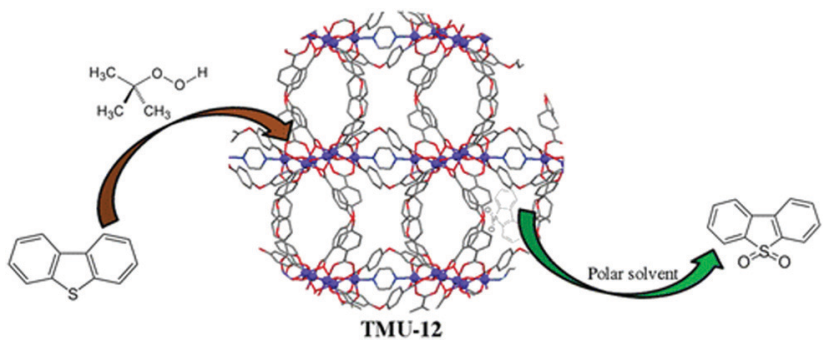

Fig. 17 Cobalt metal organic frameworks as catalysts in the oxidative desulfurization [reprinted with permission from ref. 177, Copyright (C) Royal Society of Chemistry, 2015].

at $1 \mathrm{~A} \mathrm{~g}^{-1}$ current density, and about $94.3 \%$ capacity was retained after 2000 cycles. $^{176}$

Co-MOF was used as a catalyst for oxidative desulfurization reaction under mild conditions (Fig. 17). Cobalt MOFs were fabricated solvothermally by the coordination of cobalt metal ions with dicarboxylate ligand. Model oil to be desulfurized, was generated by mixing dibenzothiophene in $n$-hexane. Production of the corresponding sulfone from oxidation was confirmed by FT-IR and mass analysis techniques, and $500 \mathrm{ppm}$ of sulfur was removed with $75.2 \%$ efficiency in $8 \mathrm{~h}^{177}$

Trends in structural, catalytic and magnetic properties of microporous cobalt $\mathrm{MOF},\left[\mathrm{Co}_{3}(\mathrm{lac})_{2}(\mathrm{pybz})_{2}\right] \cdot 3 \mathrm{DMF}$ and its derivatives prepared by ligand exchange or solvent exchange were investigated. The effect of water, DMF and other solvents on the crystal structure of MOF was studied by crystallographic technique. Upon interaction with water molecules, adsorption efficiency of Co-MOF for $\mathrm{CH}_{4}, \mathrm{CH}_{3} \mathrm{OH}, \mathrm{C}_{6} \mathrm{H}_{6}$ and $\mathrm{I}_{2}$ gets reduced whereas post synthetic changes in structure showed transformation from antiferromagnetic to ferromagnetic. ${ }^{178}$ Response of MOFs towards adsorption of gases, separation and even storage of gases in both humid and aqueous medium was studied. Almost all the MOFs are unstable in an aqueous medium whereas few such MOFs are known which show water stability. XRD, BET and $\mathrm{N}_{2}$ adsorption studies were carried out to determine the stability of MOFs, and a useful collaboration of data was reported for advancements in MOFs. ${ }^{179}$ The supercapacitor properties of cobalt MOF, synthesized from cobalt metal ion and benzene-dicarboxylate in DMF solvent, were investigated. Porous cobalt hydroxide was produced by the surface hydrolysis of Co-MOF in a basic medium. The newly formed porous cobalt hydroxide is active, and has excellent pseudo capacitance and electro-catalytic activity. Large nanoscale porosity was introduced into the products because of conformal transformation. ${ }^{180}$ In current energy gadgets, efficient hydrogen evolution by electrocatalytic water splitting offers a lot of potential. Wang et al. reported that localized surface plasmon resonance (LSPR) excitation of $\mathrm{Au}$ nanorods efficiently boosted the hydrogen evolution property of CoFe-MOF nanosheets. Studies performed suggest that improved hydrogen evolution is mostly due to the injection of hot electrons from $\mathrm{Au}$ nanorods into CoFe-MOF nanosheets which raises the Fermi level of CoFeMOF nanosheets, allowing for the reduction of $\mathrm{H}_{2} \mathrm{O}$ and a lower activation energy for HER. ${ }^{181}$ 


\section{Nickel based metal organic frameworks}

Nickel is a lustrous, metallic and silver-white metal with a slight golden tinge. The enzyme of nickel like urease is used in some organisms. The MOF of $\mathrm{Ni}$ is formed quickly at room temperature. Arul et al. reported solvothermal fabrication of nickel-based MOFs capped with polyvinylpyrrolidone (Ni-MOF-PVP). Drop casting technique was used for fabrication of a GC electrode of as synthesized Ni-MOF-PVP material which was used for selective estimation of nitrobenzene (NB). It was observed that with increase in concentration $(0.2 \mu \mathrm{M}-1 \mathrm{mM})$, amperometric current response of NB increased with a detection limit of $97 \mathrm{nM}$. The proposed electrode was used to determine NB in samples of tap and lake water. ${ }^{182}$ The pore size and surface structure of nickel-based MOFs can be regulated via a simple, cost-effective and environment friendly method by using three different molecular lengths of carboxylic acids. Large surface area and pore characteristics promote easy dispersion of electrolyte ions on the framework. Moreover, it was doped with carbon nano-fibers for increasing electrochemical performance. It exhibited high power density $\left(1064.7 \mathrm{~W} \mathrm{~kg}^{-1}\right)$ and specific capacity $\left(250.6 \mathrm{~mA} \mathrm{~h} \mathrm{~g}^{-1}\right)$ corresponding to $1 \mathrm{~A} \mathrm{~g}^{-1}$ current density. During the catalytic process of 5000 cycles, $92 \%$ capacity was retained. ${ }^{183}$ Electrochemical bio-sensing application of the electro-active nickel MOFs, having large surface area and modified structural properties, was examined by $\mathrm{Wu}$ et al. Ni-MOFs were mixed with tricarboxytriphenylamine, tri-phenylamine and $\mathrm{Ni}_{4} \mathrm{O}_{4}$ for electrochemical sensing of thrombin. High selectivity and sensitivity with detection limit of $0.016 \mathrm{pM}$ in the $0.05 \mathrm{pM}-50 \mathrm{nM}$ range was observed in the synthesized electro-active MOFs ${ }^{184}$ (Fig. 18).

The coordination of nickel metal ion with terephthalic acid was carried out by solvothermal synthesis. The synthesized composite had a 3-D flower like structure, and its chemical stability and electrochemical activity were enhanced by ultrasonic method. A non-enzymatic electrochemical glucose sensor, with a detection limit of $4.6 \mu \mathrm{M}$ over a large concentration range $(20 \mu \mathrm{M}-4.4 \mathrm{mM})$, was developed by the modification of Ni-MOF with a glassy carbon electrode. ${ }^{185}$ The synthesis of a stable crystalline 3-D mesoporous network by coordination of a metal ion with poly-dentate organic linkers was performed through a solvothermal pathway. Nickel metal ions were coordinated with terephthalic acid using DMF solvent. X-ray studies were carried out to evaluate the crystalline nature and crystallite size. Catalytic adsorption of $\mathrm{NO}_{2}$ with different molar ratios was studied to analyze the composition of designed MOFs. The band gap was

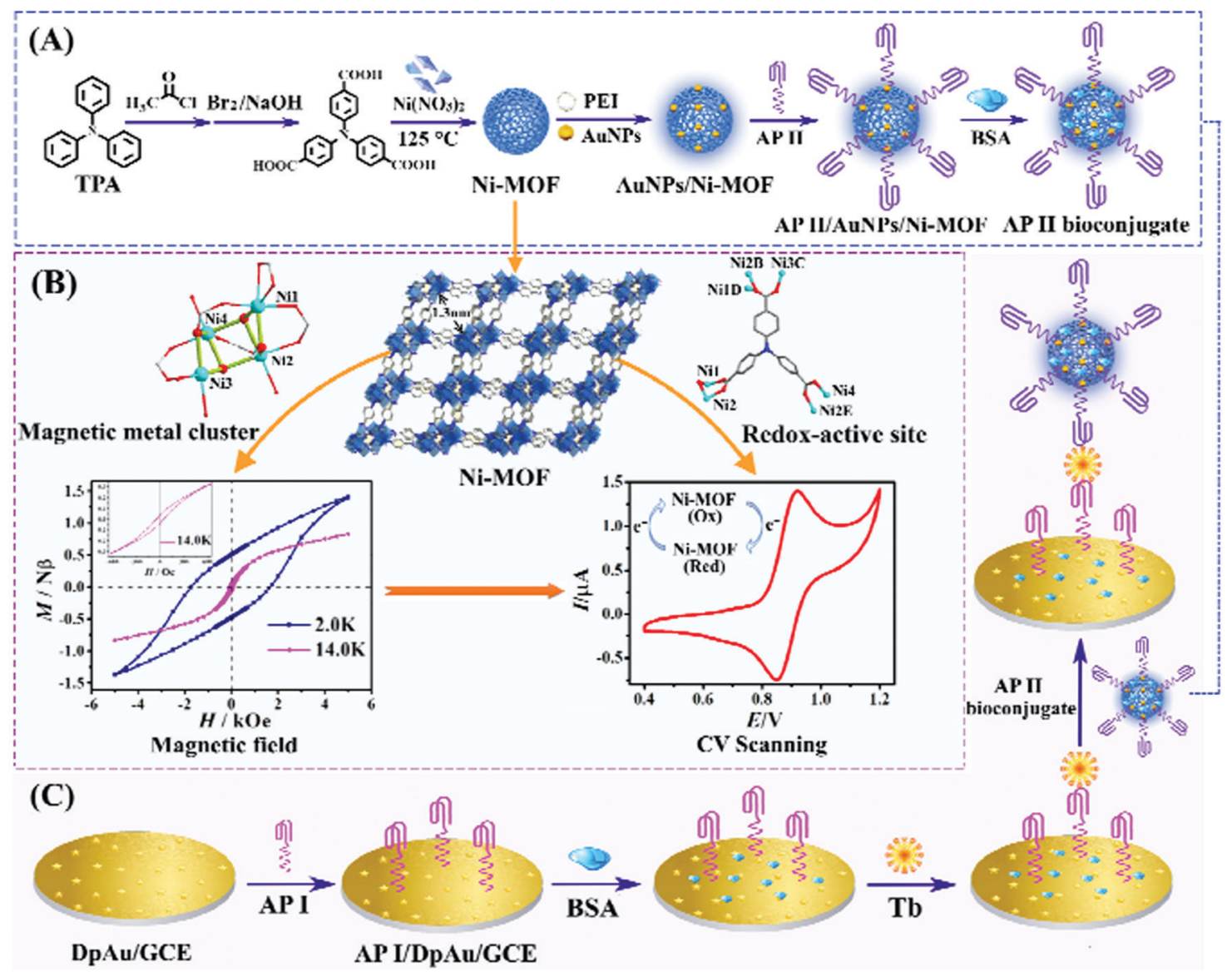

Fig. 18 Graphic demonstration of (A) preparation of AP II bioconjugate signal probe, (B) structural affected magnetic and electrochemical properties of $\mathrm{Ni}-\mathrm{MOF}$ and (C) fabrication procedure of the electrochemical aptasensor for Tb detection [reprinted with permission from ref. 184, Copyright (C) Elsevier, 2019]. 
observed to be approximately $3.94 \mathrm{eV}$ from UV-vis studies. ${ }^{186}$ Oxidation of tetramethylbenzidine in the presence of $\mathrm{H}_{2} \mathrm{O}_{2}$ was examined with Ni-MOF. Nickel MOF is also useful for food environment analysis and in clinical medicine. In addition, a Ni-MOF nanosheet was used to design a $\mathrm{H}_{2} \mathrm{O}_{2}$ colorimetric sensor having a detection limit of $8 \mathrm{nM}$ over a large concentration range $(0.04-160 \mu \mathrm{M}) .{ }^{187}$ Hierarchical porous nickel MOF, with a perfect pore size and specific surface area was fabricated by the coordination of nickel ions with trimesic acid. By varying the concentration of trimesic acid and nickel ions, different morphologies of nickel MOFs were obtained. The studies revealed that Ni-MOF has powerful specific capacitance of $649 \mathrm{~F} \mathrm{~g}^{-1}$, electrochemical properties, $63.4 \%$ rate capability and $70 \%$ retention of activity. ${ }^{188}$ Microwave accelerated hydrothermal method was employed for the polymerization of coordinated 3-D MOFs of nickel metal (Ni-MOF). The experimental investigations indicated excellent surface area $\left(5131 \mathrm{~m}^{3} \mathrm{~g}^{-1}\right)$, presence of drilling open pores with radius $4.2-10.1 \AA$ and stabilization of a 3-D structure by various hydrogen bonds (inter and intra-molecular). ${ }^{189}$ The low biodegradability of industrial dye effluents makes them profoundly harmful and carcinogenic for both human and aquatic lives, and thus, they are considered unfavorable for the biodiversity of environment. Ezugwu et al. reported the capability of cationic Ni-MOFs for adsorbing charged and neutral dye molecules. Nickel metal ions and bis-carboxyphenyl-imidazolium chloride were used for the synthesis of cationic nickel MOF which was used for preferential elimination of methyl orange (81.08\%) and congo red dyes (98.65\%) by adsorption. ${ }^{190}$ An investigation of the synthesis of porous $\mathrm{Ni}_{2} \mathrm{P} / \mathrm{C}$ composite from microwave accelerated hexagonal rods of nickel MOF was carried out. The newly prepared composite has long-term stability, highly porous arrangement, powerful electrocatalytic activity and strong electrical conductivity. The hydrogen evolution reaction (HER) was catalyzed by the electrocatalytically active $\mathrm{Ni}_{2} \mathrm{P} / \mathrm{C}$ composite at a potential of $-64 \mathrm{mV}$ and possessed capacity for long term stability. ${ }^{191} \mathrm{He}$ et al. reported hexagonal micro-rods of MOF-74-Ni prepared with a fast and facile microwave-assisted method and applied the material as a predecessor for the generation of a porous $\mathrm{Ni}_{2} \mathrm{P} / \mathrm{C}$ composite. The assynthesized $\mathrm{Ni}_{2} \mathrm{P} / \mathrm{C}$ displayed exceptional electrocatalytic activity for the HER. The structure of generated NiO can be optimized by varying some features of nickel MOF such as pore size, thermal behavior, specific surface area and intrinsic structural properties. ${ }^{192}$

Synthesis of MOFs with nickel, cobalt and zinc ions, using benzene-tricarboxylic acid as a ligand, was carried out for the determination of the morphological effect on electrochemical applications and electrochemistry. XRD, FT-IR, SEM and electrochemical techniques were employed for determination of structure. Studies revealed that three MOFs have some properties similar to each other. Investigation on ponceau-4R gave the detection limit of $80 \mathrm{pM}$ in $0.5-150 \mathrm{nM}$ concentration range. ${ }^{193}$ The gravimetric-type gas sensing application of Ni-MOF-74 was explored with resonant cantilever sensors in the ultrasensitive examination of carbon monoxide. Ni-MOF-74 with nanoporous structure and huge surface area holds great adsorption capacity for CO gas and it might be due to definite interaction among $\mathrm{Ni}^{2+}$ in Ni-MOF-74 crystal and CO molecules (Fig. 19).

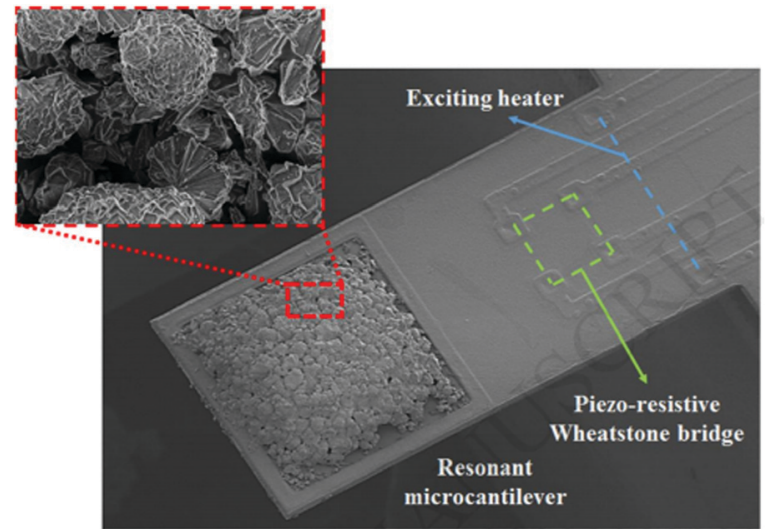

Fig. 19 MOF-loaded resonant microcantilever sensor [reprinted with permission from ref. 194, Copyright (C) Elsevier, 2018].

It has been observed that the gravimetric sensor developed by doping of Ni-MOF-74 on the resonant microcantilever, exhibited highly sensitive detection of $\mathrm{CO}$ at a trace level with less than $10 \mathrm{ppb}$ (parts per billion in volume) detection limit. In addition, the sensor also exhibited outstanding reproducibility and long lasting stability. ${ }^{194}$ In addition to copper or iron-based MOFs, nickel MOF has high thermal stability for the catalytic activity of $\mathrm{NH}_{3}$-SCR. Heat treatment in $\mathrm{N}_{2}$ atmosphere was carried out to enhance its catalytic performance and $92 \%$ of catalytic NO conversion was achieved in temperature range of 275-440 ${ }^{\circ} \mathrm{C} .{ }^{195}$ Wang et al. synthesized a flower-shaped MWCNTs/nickel-trimesic acid composite (MWCNTs@Ni/TA) by a solvothermal method. It was revealed that the existence of carboxyl functionalized MWCNTs helped to transform the shape of solid spherical Ni/TA. Electrochemical studies have shown that in comparison to spherical Ni(TA), flower-shaped composite achieved higher specific capacity as well as improved rate capability. ${ }^{196}$ In another study, a flexible carbon cloth substrate was employed to grow $\mathrm{Co}_{3} \mathrm{O}_{4} / \mathrm{Ni}$-based MOFs by a two-step hydrothermal method. The synthesized MOFs were employed as electrode materials and exhibited a brilliant specific capacity and good cycling stability. ${ }^{197}$ The effectively peeled nanosheets from a conductive $2 \mathrm{D}-\mathrm{MOF} \mathrm{Ni}{ }_{3}(\mathrm{HITP})_{2}$ were found to be a proficient co-catalyst for $\mathrm{CO}_{2}$ decrease in a cross breed photocatalytic framework under visible light brightening, exhibiting $97 \%$ selectivity and $3.45 \times 10^{4} \mu \mathrm{mol} \mathrm{g}^{-1} \mathrm{~h}^{-1}$ yield of carbon monoxide. Active sites for redox reaction and powerful conductivity for charge transfer are advantageous. This work gave fundamental insights into future structure and advancement of more powerful MOFs for $\mathrm{CO}_{2}$ reduction. ${ }^{198}$ Nickel-based Ni-MOF-74 was blended by a solvothermal strategy. Ni-MOF-74 showed excellent catalytic properties for immediate arylation of azoles by means of $\mathrm{C}-\mathrm{H}$ initiation while other Ni-based MOFs, nickel-based heterogeneous frameworks, and homogeneous partners showed lower catalysis. ${ }^{199}$ Tran et al. synthesized a Ni-MOF and MWCNTs based Ni-MOF/MWCNTs catalyst for non-enzymatic urea detection. The electrode with Ni-MOF/ MWCNTs presented a tremendous sensitivity $\left(685 \mu \mathrm{A} \mathrm{mM}{ }^{-1} \mathrm{~cm}^{-2}\right.$, LOD $3 \mu \mathrm{M}$ ) with $10 \mathrm{~s}$ response time. ${ }^{200} \mathrm{Qu}$ et al. reported 
nickel-based $\mathrm{MOF},\left[\mathrm{Ni}(\mathrm{L})(\mathrm{DABCO})_{0.5}\right]$ where $\mathrm{L}$ represents a functionalized BDC (1,4-benzenedicarboxylic acid) linker and DABCO represents 1,4-diazabicyclo [2.2.2]-octane. MOF capacitors exhibited brilliant performance as electrode materials. The Ni-DMOF-ADC electrode had a specific capacitance of 552 at $1 \mathrm{~A} \mathrm{~g}^{-1}$ current density and $438 \mathrm{~F} \mathrm{~g}^{-1}$ at $20 \mathrm{~A} \mathrm{~g}^{-1}$ current density. ${ }^{201} \mathrm{Xu}$ et al. established a superficial and effective onestep solvothermal method for the synthesis of a magnetic and porous Ni@MOF-74(Ni) [ $\left.\mathrm{Ni}_{2}(\mathrm{DOBDC})\right]$ [(DOBDC = 2,5-dihydroxyterephthalate)] composite. The as-prepared Ni@MOF-74(Ni) composite showed magnetic characteristics as well as high porosity, making the composite a competent contender for dye removal and targeted drug delivery systems. The composite displayed an adsorption capacity of $177.8 \mathrm{mg} \mathrm{g}^{-1}$ and $4.1 \mathrm{mg} \mathrm{g}^{-1}$ for rhodamine $\mathrm{B}$ and ibuprofen, respectively. ${ }^{202} \mathrm{~A}$ nickel(II) pillared paddle wheel MOF was prepared via amalgamation of solvent-assisted linker exchange and transmetallation. The MOF showed boosted $\mathrm{N}_{2}$ sorption performance in comparison to the isostructural $\mathrm{Zn}$ (II) counterpart. ${ }^{203}$ Because of their ultrahigh activity and selectivity, single-atom catalysts (SACs) are of tremendous interest. As it is challenging to make model SACs using a generic synthetic technique, distinguishing between the activity of different single-atom catalysts is difficult. Beginning from multivariate MOFs, a comprehensive technique for the production of single-atom metals implanted in $\mathrm{N}$-doped carbon $\left(\mathrm{M}_{1}-\mathrm{N}-\mathrm{C} ; \mathrm{M}=\mathrm{Fe}, \mathrm{Co}, \mathrm{Ni}\right.$, and $\left.\mathrm{Cu}\right)$ has been established. When used in electrocatalytic $\mathrm{CO}_{2}$ reduction, $\mathrm{Ni}_{1}-\mathrm{N}-\mathrm{C}$ demonstrated a very high $\mathrm{CO}$ faradaic efficiency (FE) of up to $96.8 \%$ which considerably outperformed other materials. ${ }^{204}$

\section{Copper based metal organic frameworks}

Copper is a soft and ductile metal with red orange metallic luster. Like zinc, copper is also present in trace amounts in plants and animals. MOF of copper is used in gas separation, catalysis, and super-capacitors. Cu-Based MOF can be synthesized by a solvent free method. The synthesis of novel copperbased MOFs was carried out by the addition of bioproduct itaconic acid, and the fabricated MOF acted as an outstanding $\mathrm{CO}_{2}$ adsorbent. The MOF was grown with dissimilar chemical formulae using diverse synthetic approaches and solvent mixtures or use of additives that may act as pore shape templating agents. On the basis of comprehensive description, Cu-IA MOF synthesized on a water-ethanol mixture reported the highest conversion and $\mathrm{CO}_{2}$ capture. ${ }^{205}$ Wang et al. introduced $\mathrm{Mg} / \mathrm{Al}$ layered double hydroxide (LDH) nanosheets as modulators for growth of HKUST-1 which is deprived of either pore blockage or loss of crystallinity (Fig. 20). The addition of LDH to HKUST-1 via a hydrothermal process caused phase change from octahedron (110) facets to tetrakaidecahedron (100) and (111) facets. Consequently, BET surface area and micropore volume increased significantly. HKUST-1 exhibited high acetylene uptake of $275 \mathrm{~cm}^{3}$ (STP) g $\mathrm{g}^{-1}$ at room temperature and $1 \mathrm{~atm}^{206}$

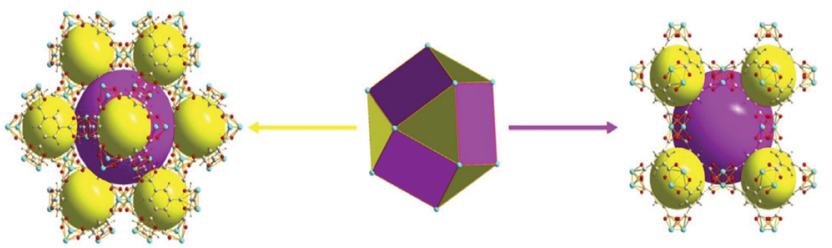

Fig. 20 Unit cells of HKUST-1 [reprinted with permission from ref. 206, Copyright (C) Elsevier, 2019].

Lincke $e$ t al. prepared and explored the crystal structure of a copper-based MOF. PXRD technique was used to confirm phase purity of the material whereas TD-PXRD and coupled DTATG-MS analysis confirmed its stability up to $230{ }^{\circ} \mathrm{C} .{ }^{207}$ The catalytic property of copper-based MOF (Cu-MOF-74) was also examined. An acid catalyzed reaction of anisole was carried out for its Friedel-Crafts acylation. Effects of various parameters like temperature, acylating agent and solvent were studied on Cu-MOF. The MOF exhibited an extraordinary catalytic performance for anisole alteration and $p$-MAP yield. Furthermore, the structural MOF-74 phase was conserved when dilute acetyl chloride was used as an acylating agent. ${ }^{208}$ In another work, a graphene doped copper-based MOF composite was fabricated and employed for adsorption of ammonia at room temperature, under dry and moist conditions. In a dry environment, composites with lesser quantity of GO were adjudged improved adsorbents of ammonia in comparison to those having more quantity of GO. In moist environments, adsorbed ammonia caused the breakdown of MOF structure and release of active groups. ${ }^{209}$ The sonochemical synthesis of guanine-Cu-MOF was reported by using copper metal ions and biphenyldicarboxylic organic ligand, followed by doping of guanine. Their effect on oprD gene expression was determined by a broth micro-dilution method. Minimum inhibitory concentration (MIC) was observed to be $400 \mu \mathrm{g} \mathrm{mL} \mathrm{m}^{-1}$, and minimum bactericidal concentration was $400 \mu \mathrm{g} \mathrm{mL} \mathrm{L}^{-1}$ of $P$. aeruginosa strains. ${ }^{210}$ Some other transition metal-based MOFs reported for various catalytic activities are listed in Table 1.

\section{Zinc based metal organic frameworks}

Zinc is a silver-grey colored compound which is present in small amounts in humans, animals, plants and microorganisms. The central nervous system is functionalized by zinc homeostasis. Zinc MOFs can be synthesized by a hydrothermal method. Sensing of compounds and adsorption of gases are major applications of zinc MOFs. Li and co-workers reported aggregation induced emission enhancement (AIEE) of AuNCs in a liquid phase via incarceration of AuNCs by in situ formed Zn-MOF. Glutathione capped AuNCs (GSH-AuNCs) were prepared by reduction of $\mathrm{Au}^{3+}$ by glutathione. $\mathrm{Zn}^{2+}$ could meaningfully improve fluorescence of GSH-AuNCs with the accumulation of 2-methylimidazole which was credited to the formation of Zn-MOF. A fluorogenic sensor was proposed for detection of $\mathrm{Zn}^{2+}$ in concentration range of $12.3 \mathrm{nM}-24.6 \mu \mathrm{M}$, with $6 \mathrm{nM}$ as the detection limit. The fabricated sensor was used for efficient estimation of zinc in human serum, milk, water, 
Table 1 Some transition metal-based MOFs for different catalytic activities

\begin{tabular}{llll}
\hline Transition metal based MOFs & Method of synthesis & Morphology & Catalytic activity \\
\hline Cu-MOF & Solvothermal & Cubic & Synthesis of tacrine derivative \\
Ti-MOF & Solvothermal & Spherical & Hydrogen evolution reaction \\
Ni-MOF & Hydrothermal & Nanosheets & Hydrogen evolution reaction \\
Ni-MOF & Sonication & Stacked layers with smooth surface & Catalyst during glucose sensing \\
Mn-MOF & Solvothermal & Aggregated nanotubes & Electrode material for charge storage 215 \\
Zr-Fu MOF & Solvothermal & Undefined shape & 216 \\
Zr-Fu MOF & Solvothermal & Needle like structure & Adsorption of CO \\
Mn-MOF & Electrochemical, solvothermal & Removal of nitrates and phosphates 217 \\
Zn-MOF & Hexagonal rods & Adsorption of gases \\
Fe-MOF & Solvothermal & Flower like & Reduction of Cr(vI) \\
Co-Fe MOF & Solvothermal & Octahedral & 219 \\
Co-MOF & Ultrasonic & Flake like & Reduction of $N_{2}$ \\
& Solvothermal & Block structure & Oxygen evolution reaction \\
\end{tabular}

and zinc sulphate syrup. ${ }^{223}$ Rodríguez et al. reported the synthesis of Zn-MOF (4,4'-bipyridyl and zinc acetate). The MOF was doped with $\mathrm{Eu}^{3+}$ or $\mathrm{Tb}^{3+}$ in different proportions. The doped Zn-MOFs exhibited characteristic red and green emission conforming to $\mathrm{Eu}^{3+}$ and $\mathrm{Tb}^{3+}$ ions, respectively. On varying the ratio of $\mathrm{Eu}^{3+}$ and $\mathrm{Tb}^{3+}$, the color of emission by lanthanide doped Zn-MOFs changed from red to orange-yellow-green. ${ }^{224}$ Duan et al. reported $\left\{\left[\mathrm{Zn}(\mathrm{apc})_{2}\right] \cdot \mathrm{H}_{2} \mathrm{O}\right\}_{n}(\mathbf{1})$ and $\left[\mathrm{Zn}(\mathrm{apc})_{2}\left(\mathrm{H}_{2} \mathrm{O}\right)_{2}\right]$ (2), with a multi-functional ligand 2-aminopyrimidine-5-carboxylic acid (Hapc). XRD investigations revealed that structure- 1 consisted of an interpenetrating pillared-layer 3D framework (point symbol $\{83\} 2\{86\})$, conforming to tfa topology whereas structure-2 possessed a 3D framework based on $\mathrm{Zn}(\mathrm{apc})_{2}\left(\mathrm{H}_{2} \mathrm{O}\right)_{2}$, interlocked by hydrogen bonds. ${ }^{225}$ In another work, $\mathrm{Zn}$-based MOF, $\left\{\left[\left(\mathrm{CH}_{3}\right)_{2} \mathrm{NH}_{2}\right]_{2}\right.$ $\left.\left[\mathrm{Zn}_{5}(\mathrm{TDA})_{4}(\mathrm{TZ})_{4}\right] \cdot 4 \mathrm{DMF}\right\}_{n}(\mathbf{1})\left(\mathrm{H}_{2} \mathrm{TDA}=\right.$ thiophene-2,5-dicarboxylic acid and HTZ = $1 H$-1,2,4-triazole) was prepared and characterized by mixed-ligand strategy. The as-synthesized material was used for detection of aniline, benzaldehyde, $\mathrm{Cr}_{2} \mathrm{O}_{7}{ }^{2-}$ and $\mathrm{CrO}_{4}{ }^{2-226} \mathrm{~A} \mathrm{Zn}$ based MOF, $\left\{\left[\left[\mathrm{Zn}_{7}(\mathrm{BPS})_{4}(\mathrm{OH})_{6}\left(\mathrm{H}_{2} \mathrm{O}\right)_{2}\right] \cdot 5 \mathrm{H}_{2} \mathrm{O}\right]_{n}\right\},\left(\mathrm{H}_{2} \mathrm{BPS}=4,4^{\prime}-\right.$ bibenzoic acid-2, $2^{\prime}$-sulfone), containing wavy and infinite chain SBUs, was synthesized solvothermally. The solid-state emission spectra indicated strong luminescence emission bands at room temperature. ${ }^{227}$ A 3D web-like carbon material C-Zn-MOF-74@ CNFs was synthesized. It exhibited high electro-catalytic activity for the oxygen reduction reaction (ORR) by direct carbonization of a composite (Zn-MOF-74@CNFs) having Zn-MOF-74s grown on a carbon nano-fiber (CNF) web (Fig. 21). The solvothermal method was used to grow hexagonal pillar shaped Zn-MOF-74s with 300-600 $\mathrm{nm}$ diameter along with the CNF web. The calculated $n$ value corresponding to this composite was 3.94 at $0.4 \mathrm{~V}$ for the ORR. ${ }^{228}$

In a study, synthesis of zinc-based MOFs through green and facile synthetic methods was discussed. The nano MOF containing biocompatible metal ions, i.e. zinc(II) and benzene 1,3,5-tricarboxylic acid $\left(\mathrm{H}_{3} \mathrm{BTC}\right)$ as a linker to form [Zn-3(BTC)(2)] using electroand sonochemical methods was compared. The electrochemical method generated a bigger particle size $(c a .18 .43 \pm 8.10 \mu \mathrm{m})$ than the sonochemical method ( $c a .87 .63 \pm 22.86$ and $112.23 \pm$ $28.87 \mathrm{~nm}$, for 30 and $60 \mathrm{~min}$, respectively). Slow-release of ibuprofen was conducted in a phosphate buffered saline system at $37{ }^{\circ} \mathrm{C}$ and $\mathrm{pH} 7.4 .^{229}$ Yadav et al. reported zinc-containing MOF-5(Zn) and MOF-5W(Zn) systems, followed by incorporation of silver which were employed in electrochemical oxidation of accumulated nitrophenols. The electrochemical and structural

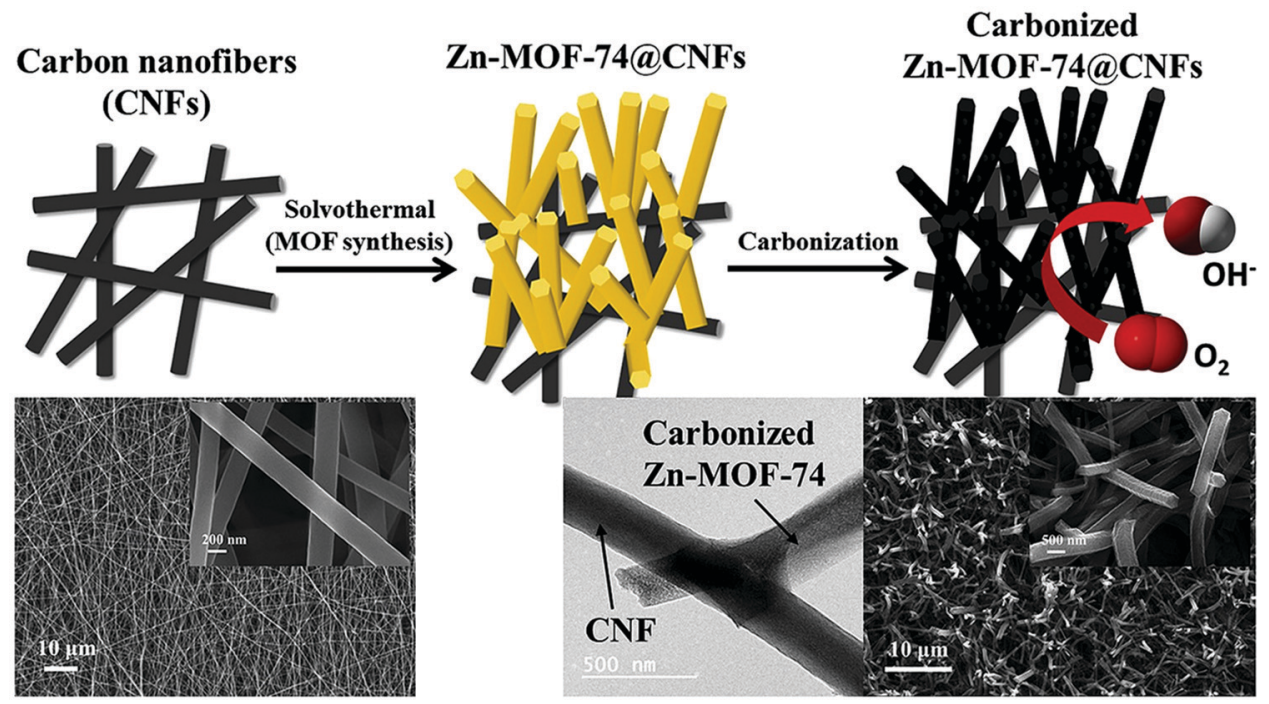

Fig. 21 Outline of the synthesis of C-Zn-MOF-74@CCNFs [reprinted with permission from ref. 228, Copyright (C) Elsevier, 2018]. 
characterization revealed that silver is present in Ag@MOF$5(\mathrm{Zn})$ in metallic form. The incorporation of silver changed the electrochemical oxidation performance towards nitrophenols in MOF-5(Zn) from "inactive" to "active". ${ }^{230}$ Wang et al. synthesized monodisperse MOF-5 crystals having tunable pore sizes and shapes. The synthesis comprised base-tuned nucleation and surfactant-modulated facet development of MOF-5. Under augmented reaction conditions, monodisperse MOF-5 cubes, truncated cubes, truncated octahedra, and octahedra were obtained with high reproducibility. ${ }^{231}$ Mohammad et al. investigated adsorption of aqueous tetracycline (TC) by MOF-5, synthesized at room temperature. The MOF has cubic arrangement, $84.3 \%$ crystallinity, thermal stability up to $450{ }^{\circ} \mathrm{C}$ and about $2510 \mathrm{~m}^{2} \mathrm{~g}^{-1}$ BET surface area with both the micro- and mesocavities. The as-synthesized material was employed for adsorptive removal of TC antibiotics, and nearly $96 \%$ of TC was removed successfully (adsorption capacity $=233 \mathrm{mg} \mathrm{g}^{-1}$ ). ${ }^{232}$ Mixed matrix membranes (MMMs) were fabricated by the introduction of MOFs, to investigate their separation properties for $\mathrm{H}_{2}, \mathrm{CO}_{2}$ and $\mathrm{CH}_{4}$ gases. There was no direct connection between the gas adsorption capacities of MOFs and degree of permeation of these gases over the MMMs. The most adsorbed gas $\left(\mathrm{H}_{2}\right)$ infused gradually over MMMs which could be used for separation of $\mathrm{H}_{2}$ from $\mathrm{CO}_{2} \cdot{ }^{233,234}$ In summary, MOFs have shown various applications such as energy storage, catalytic degradation, electrical conductivity and charge storage. The green and facile synthesis method was used for the preparation of zinc-p-phenylenediamine which was used for energy storage. ${ }^{235}$ The liberation of U(vI) in the atmosphere with extensive application of radionucleotides has been established. The MOF of zinc was formed by the solvothermal method, and used for the sorption of $\mathrm{U}(\mathrm{vI})$ which is spontaneous and endothermic, contingent upon $\mathrm{pH}$ and free from ionic strength. The researchers showed the sorption capacity (237) at pH 5 and room temperature. FTIR and XPS showed attribution to oxygen containing functional groups. ${ }^{236}$ The regulation of selectivity towards aldehydes in aromatic alcohol oxidation utilizing molecular oxygen under gentle conditions remains a major concern. Chen et al. ${ }^{237}$ fabricated Pt/PCN-224(M) (M = Zn, Ni, Co, Mn and 2H) composites by incorporating $\mathrm{Pt}$ nanocrystals and porphyrinic MOFs. Due to the strongest diamagnetism with $\mathrm{d}^{10}$ configuration of $\mathrm{Zn}^{2+}$ among different metals existing in a porphyrin center in the MOF, PCN$224(\mathrm{Zn})$ demonstrates the greatest ability for $\mathrm{O}_{2}$ activation and ${ }^{1} \mathrm{O}_{2}$ production among all the PCN-224(M) MOFs investigated.

\section{Conclusions and future prospects}

Until now, different uses of MOFs have been scrutinized as they display unique structural features, high flexibility, low cost, and high productivity. Especially on an industrial scale, MOFs illustrate promising results in waste water treatment innovations. The adaptability of structural and electronic characteristics provides the likelihood to plan materials which can be both acceptable adsorbents and effective photodegradation catalysts. Based on their large porosity, crystallinity and surface area,
MOFs are used for waste disposal, gas storage, catalytic reactions, sensing and separation procedures. Notwithstanding the turn of events and the refinements, new engineered MOFs face difficulties that come from the science of these materials and their upcoming applications. Furthermore, the possibility of extensive execution of MOFs in waste water treatment is encouraging but requires more investigation, mainly considering scaling up application to study their performance under real life conditions. Although great progress has been achieved over the past few years for fabrication of MOF materials with intrinsic catalytic activity and MOFsupported metal nanoparticles, we believe that the limitations of these systems in terms of chemical and thermal vulnerability are still a great question mark with reference to consumption. The extraordinary characteristics exhibited by MOFs have encouraged researchers to use these in numerous catalytic reactions and usually, these MOF-intervened catalysts yield better results than their conventional counterparts. However, regardless of these outstanding characteristics of MOFs, there is still a lot of opportunity to get better, and an incredible number of chemistries to be investigated. The majority of reactions over MOFs are explored for photocatalysis, electrocatalysis, thermal organic catalysis, water splitting, and the $\mathrm{CO}_{2} \mathrm{RR}$. Hence, extension to other catalytic procedures should be looked into by the scientific community. Also, hardly any works have reported profound examinations of the morphological changes occurring during pyrolysis. These examinations are vital as the morphology, particle size, porosity, and composition significantly rely upon the pyrolysis conditions. Thus, to highlight the change of MOFs into desired materials, in situ operando methods like in situ TEM must be achieved during pyrolysis. Finally, expansion of the MOF fabrication strategies is additionally an unquestionable requirement to get ready for the large-scale manufacturing of these promising designs. Given the outstanding characteristics of MOFs, we emphatically believe that MOFs will keep on getting broad consideration sooner rather than later, and every one of these issues will be tended to by the catalysis community.

\section{Conflicts of interest}

There are no conflicts to declare.

\section{References}

1 S. Qiu, M. Xue and G. Zhu, Metal-organic framework membranes: from synthesis to separation application, Chem. Soc. Rev., 2014, 43, 6116-6140.

2 S. Yuan, L. Feng, K. Wang, J. Pang, M. Bosch, C. Lollar, Y. Sun, J. Qin, X. Yang, P. Zhang, Q. Wang, L. Zou, Y. Zhang, L. Zhang, Y. Fang, J. Li and H. C. Zhou, Stable MetalOrganic Frameworks: Design, Synthesis, and Applications, Adv. Mater., 2018, 30, 1704303.

3 I. Ahmed and S. H. Jhung, Composites of metal-organic frameworks: preparation and application in adsorption, Mater. Today, 2014, 17, 136-146. 
4 W. Li, Metal-organic framework membranes: production, modification, and applications, Prog. Mater. Sci., 2019, 100, 21-63.

5 L. Jiao, J. Y. R. Seow, W. S. Skinner, Z. U. Wang and H. L. Jiang, Metal-organic frameworks: structures and functional applications, Mater. Today, 2019, 27, 43-68.

6 S. S. Nadar, N. Varadan, O. S. Suresh, P. Rao, D. J. Ahirrao and $\mathrm{S}$. Adsare, Recent progress in nanostructured magnetic framework composites (MFCs): synthesis and applications, J. Taiwan Inst. Chem. Eng., 2018, 91, 653-677.

7 N. A. Khan, Z. Hasan and S. H. Jhung, Beyond pristine metal-organic frameworks: preparation and application of nanostructured, nanosized, and analogous MOFs, Coord. Chem. Rev., 2018, 376, 20-45.

8 R. Seetharaj, P. V. Vandana, P. Arya and S. Mathew, Dependence of solvents, $\mathrm{pH}$, molar ratio and temperature in tuning metal organic framework architecture, Arab. J. Chem., 2019, 12, 295-315.

9 S. K. Elsaidi, M. H. Mohamed, D. Banerjee and P. K. Thallapally, Flexibility in metal-organic frameworks: a fundamental understanding, Coord. Chem. Rev., 2018, 358, 125-152.

10 N. P. Singh and A. Kumar, Metal Organic Framework and Its Application: A Review, Comput. Biol. Chem., 2016, 1, 10-18.

11 Y. Xu, Q. Li, H. Xue and H. Pang, Metal-organic frameworks for direct electrochemical applications, Coord. Chem. Rev., 2018, 376, 292-318.

12 Y. He, F. Chen, B. Li, G. Qian, W. Zhou and B. Chen, Porous metal-organic frameworks for fuel storage, Coord. Chem. Rev., 2018, 373, 167-198.

13 B. Wang, L. H. Xie, X. Wang, X. M. Liu, J. Li and J. R. Li, Applications of metal-organic frameworks for green energy and environment: new advances in adsorptive gas separation, storage and removal, Green Energy Environ., 2018, 3, 191-228.

14 J. R. Li, J. Sculley and H. C. Zhou, Metal-Organic Frameworks for Separations, Chem. Rev., 2012, 112, 869-932.

15 Y. S. Kang, Y. Lu, K. Chen, Y. Zhao, P. Wang and W. Y. Sun, Metal-organic frameworks with catalytic centers: from synthesis to catalytic application, Coord. Chem. Rev., 2019, 378, 262-280.

16 Y. Pan, Y. Qian, X. Zheng, S. Q. Chu, Y. Yang, C. Ding, X. Wang, S. H. Yu and H. L. Jiang, Precise fabrication of single-atom alloy co-catalyst with optimal charge state for enhanced photocatalysis, Natl. Sci. Rev., 2021, 8, nwaa224.

17 Y. Wen, J. Zhang, Q. Xu, X. T. Wu and Q. L. Zhu, Pore surface engineering of metal-organic frameworks for heterogeneous catalysis, Coord. Chem. Rev., 2018, 376, 248-276.

18 L. Zhu, X. Q. Liu, H. L. Jiang and L. B. Sun, Metal-Organic Frameworks for Heterogeneous Basic Catalysis, Chem. Rev., 2017, 117, 8129-8176.

19 J. Kim, J. S. Oh, K. C. Park, G. Gupta and C. Y. Lee, Colorimetric detection of heavy metal ions in water via Metal-Organic Framework, Inorg. Chim. Acta, 2019, 486, 69-73.

20 L. Wang, M. Zheng and Z. Xie, Nanoscale metal-organic frameworks for drug delivery: a conventional platform with new promise, J. Mater. Chem. B, 2018, 6, 707-717.
21 A. Ma, Z. Luo, C. Gu, B. Li and J. Liu, Cytotoxicity of a metal-organic framework: drug delivery, Inorg. Chem. Commun., 2017, 77, 68-71.

22 M. Kadhom and B. Deng, Metal-organic frameworks (MOFs) in water filtration membranes for desalination and other applications, Appl. Mater. Today, 2018, 11, 219-230.

23 P. Kumar, V. Bansal, K. H. Kim and E. E. Kwon, Metalorganic frameworks (MOFs) as futuristic options for wastewater treatment, J. Ind. Eng. Chem., 2018, 62, 130-145.

24 W. Du, Y. L. Bai, J. Xu, H. Zhao, L. Zhang, X. Li and J. Zhang, Advanced metal-organic frameworks (MOFs) and their derived electrode materials for supercapacitors, J. Power Sources, 2018, 402, 281-295.

25 S. Sundriyal, H. Kaur, S. K. Bhardwaj, S. Mishra, K. H. Kim and A. Deep, Metal-organic frameworks and their composites as efficient electrodes for supercapacitor applications, Coord. Chem. Rev., 2018, 369, 15-38.

26 C. Vaitsis, G. Sourkouni and C. Argirusis, Metal Organic Frameworks (MOFs) and ultrasound: a review, Ultrason. Sonochem., 2019, 52, 106-119.

27 T. N. Nguyen, F. M. Ebrahim and K. C. Stylianou, Photoluminescent, upconversion luminescent and nonlinear optical metal-organic frameworks: from fundamental photophysics to potential applications, Coord. Chem. Rev., 2018, 377, 259-306.

28 K. M. Buschbaum, F. Beuerle and C. Feldmann, MOF based luminescence tuning and chemical/physical sensing, Microporous Mesoporous Mater., 2015, 216, 171-199.

29 L. Wang, Y. Han, X. Feng, J. Zhou, P. Qi and B. Wang, Metal-organic frameworks for energy storage: batteries and supercapacitors, Coord. Chem. Rev., 2016, 307, 361-381.

30 Y. Li, H. Xu, S. Ouyang and J. Ye, Metal-organic frameworks for photocatalysis, Phys. Chem. Chem. Phys., 2016, 18, 7563-7572.

31 A. Dhakshinamoorthy, A. M. Asiri and H. Garcia, Metalorganic framework (MOF) compounds: photocatalysts for redox reactions and solar fuel production, Angew. Chem., Int. Ed., 2016, 55, 5414-5445.

32 N. C. Burtch, H. Jasuja and K. S. Walton, Water Stability and Adsorption in Metal-Organic Frameworks, Chem. Rev., 2014, 114, 10575-10612.

33 K. Vikrant, V. Kumar, Y. S. Ok, K. H. Kim and A. Deep, Metal-organic framework (MOF)-based advanced sensing platforms for the detection of hydrogen sulfide, $\operatorname{Tr} A C$, Trends Anal. Chem., 2018, 105, 263-281.

34 Y. Hu, L. Dai, D. Liu, W. Du and Y. Wang, Progress \& prospect of metal-organic frameworks (MOFs) for enzyme immobilization (enzyme/MOFs), Renewable Sustanable Energy Rev., 2018, 91, 793-801.

35 P. Horcajada, R. Gref, T. Baati, P. K. Allan, G. Maurin, P. Couvreur, G. Ferey, R. E. Morris and C. Serre, MetalOrganic Frameworks in Biomedicine, Chem. Rev., 2012, 112, 1232-1268.

36 Z. Y. Gu, C. X. Yang, N. Chang and X. P. Yan, MetalOrganic Frameworks for Analytical Chemistry: From Sample Collection to Chromatographic Separation, Acc. Chem. Res., 2012, 45, 734-745. 
37 A. Ayati, M. N. Shahrak, B. Tanhaei and M. Sillanpää, Emerging adsorptive removal of azo dye by metal-organic frameworks, Chemosphere, 2016, 160, 30-44.

38 J. M. Yang, R. J. Ying, C. X. Han, Q. T. Hu, H. M. Xu, J. H. Li, Q. Wang and W. Zhang, Adsorptive removal of organic dyes from aqueous solution by a Zr-based metal-organic framework: effects of Ce(III) doping, Dalton Trans., 2018, 47, 3913-3920.

39 F. Rouhani, F. R. Masuleh and A. Morsali, Highly Electroconductive Metal-Organic Framework: Tunable by Metal Ion Sorption Quantity, J. Am. Chem. Soc., 2019, 141, 11173-11182.

40 C. Petit and T. J. Bandosz, Exploring the coordination chemistry of MOF-graphite oxide composites and their applications as adsorbents, Dalton Trans., 2012, 41, 4027-4035.

41 L. R. Mingabudinova, V. V. Vinogradov, V. A. Milichko, E. Hey-Hawkins and A. V. Vinogradov, Metal-organic frameworks as competitive materials for non-linear optics, Chem. Soc. Rev., 2016, 45, 5408-5431.

42 S. Furukawa, J. Reboul, S. Diring, K. Sumida and S. Kitagawa, Structuring of metal-organic frameworks at the mesoscopic/ macroscopic scale, Chem. Soc. Rev., 2014, 43, 5700-5734.

43 F. Rouhani, A. Morsali and P. Retailleau, Simple One-Pot Preparation of a Rapid Response AIE Fluorescent MetalOrganic Framework, ACS Appl. Mater. Interfaces, 2018, 10(42), 36259-36266.

44 B. M. Connolly, J. P. Mehta, P. Z. Moghadam, A. E. H. Wheatley and D. Fairen-Jimenez, From synthesis to applications: metal-organic frameworks for an environmentally sustainable future, Curr. Opin. Green Sustainable Chem., 2018, 12, 47-56.

45 F. Rouhani, B. Gharib and A. Morsali, Solvent switching smart metal-organic framework as a catalyst of reduction and condensation, Inorg. Chem. Front., 2019, 6, 2412-2422.

46 M. Safaei, M. M. Foroughi, N. Ebrahimpoor, S. Jahani, A. Omedi and M. Khatami, A review on metal-organic frameworks: Synthesis and applications, Trac, Trends Anal. Chem., 2019, 118, 401-425.

47 A. Kumari, S. Kaushal and P. Singh, Bimetallic metal organic frameworks heterogeneous catalysts: design, construction, and applications, Mater. Today Energy, 2021, 20, 100667.

48 B. O. Rubio, H. Ghasempour, V. Guillerm, A. Morsali, J. Juanhuix, I. Imaz and D. Maspoch, Net-Clipping: An Approach to Deduce the Topology of Metal-Organic Frameworks Built with Zigzag Ligands, J. Am. Chem. Soc., 2020, 142, 9135-9140.

49 T. F. Yi, L. J. Jiang, J. Shu, C. B. Yue, R. S. Zhu and H. B. Qiao, Recent development and application of $\mathrm{Li}_{4} \mathrm{Ti}_{5} \mathrm{O}_{12}$ as anode material of lithium-ion battery, J. Phys. Chem. Solids, 2010, 71(9), 1236-1242.

50 S. R. Halper, L. Do, J. R. Stork and S. M. Cohen, Topological Control in Heterometallic Metal-Organic Frameworks by Anion Templating and Metalloligand Design, J. Am. Chem. Soc., 2006, 128(47), 15255-15268.

51 Y. Wu, A. Kobayashi, G. J. Halder, V. K. Peterson, K. W. Chapman, N. Lock, P. D. Southon and C. J. Kepert,
Negative Thermal Expansion in the Metal-Organic Framework Material $\mathrm{Cu}_{3}(1,3,5 \text {-benzenetricarboxylate) })_{2}$, Angew. Chem., Int. Ed., 2008, 47, 8929-8932.

52 M. Klimakow, P. Klobes, K. Redemann and F. Emmerling, Characterization of mechanochemically synthesized MOFs, Microporous Mesoporous Mater., 2012, 154, 113-118.

53 N. A. Khan and S. H. Jhung, Synthesis of metal-organic frameworks (MOFs) with microwave or ultrasound: rapid reaction, phase-selectivity, and size reduction, Coord. Chem. Rev., 2015, 285, 11-23.

54 Z. Ni and R. I. Masel, Rapid Production of Metal-Organic Frameworks via Microwave-Assisted Solvothermal Synthesis, J. Am. Chem. Soc., 2006, 128, 12394-12395.

55 S. A. Razavi, M. Y. Masoomi and A. Morsali, Ultrasonic assisted synthesis of a tetrazine functionalized MOF and its application in colorimetric detection of phenylhydrazine, Ultrason. Sonochem., 2017, 37, 502-508.

56 M. O. Barsukova, S. A. Sapchenko, D. N. Dybtsev and V. P. Fedin, Scandium-organic frameworks: progress and prospects, Russ. Chem. Rev., 2018, 87(11), 1139-1167.

57 M. O. Barsukova, D. G. Samsonenko, A. A. Sapianik, S. A. Sapchenko and V. P. Fedin, Influence of synthetic conditions on the formation of thermally and hydrolytically stable Sc-based metal-organic frameworks, Polyhedron, 2018, 144, 219-224.

58 L. Zhao, B. Z. Xu, J. Jia and H. S. Wu, A newly designed Sc-decorated covalent organic framework: a potential candidate for room-temperature hydrogen storage, Comput. Mater. Sci., 2017, 137, 107-112.

59 J. Cepeda, S. P. Yáñez, G. Beobide, O. Castillo, E. Goikolea, F. Aguesse, L. Garrido, A. Luque and P. A. Wright, Scandium/ Alkaline Metal-Organic Frameworks: Adsorptive Properties and Ionic Conductivity, Chem. Mater., 2016, 28, 2519-2528.

60 R. S. Pillai, V. Benoit, A. Orsi, P. L. Llewellyn, P. A. Wright and G. Maurin, Highly selective $\mathrm{CO}_{2}$ capture by small pore Scandium-based metal-organic frameworks, J. Phys. Chem. C, 2015, 119, 23592-23598.

61 N. A. Khan and S. H. Jhung, Scandium-Triflate/Metal-Organic Frameworks: Remarkable adsorbents for Desulfurization and Denitrogenation, Inorg. Chem., 2015, 54, 11498-11504.

62 A. J. Graham, A. M. Banu, T. Düren, A. Greenaway, S. C. Mckellar, J. P. S. Mowat, K. Ward, P. A. Wright and S. A. Moggach, Stabilization of Scandium Terephthalate MOFs against Reversible Amorphization and Structural Phase Transition by Guest Uptake at Extreme Pressure, J. Am. Chem. Soc., 2014, 136, 8606-8613.

63 C. P. Cabello, P. Rumori and G. T. Palomino, Carbon dioxide adsorption on MIL-100(M) (M = Cr, V, Sc) metalorganic frameworks: IR spectroscopic and thermodynamic studies, Microporous Mesoporous Mater., 2014, 190, 234-239.

64 L. Mitchell, B. Gonzalez-Santiago, J. P. S. Mowat, M. E. Gunn, P. Williamson, N. Acerbi, M. L. Clarke and P. A. Wright, Remarkable Lewis acid catalytic performance of the scandium trimesate metal organic framework MIL-100(Sc) for C-C and $\mathrm{C}=\mathrm{N}$ bond-forming reactions, Catal. Sci. Technol., 2013, 3, 606-617. 
65 C. O. Areán, C. P. Cabello and G. T. Palomino, Infrared spectroscopic and thermodynamic study on hydrogen adsorption on the metal organic framework MIL-100(Sc), Chem. Phys. Lett., 2012, 521, 104-106.

66 Y. An, Y. Liu, Z. Wang, P. Wang, Z. Zheng, Y. Dai, X. Qin, X. Zhang, M. Whangbo and B. Huang, Stabilizing the titanium-based metal organic frameworks in water by metal cations with empty or partially-filled d orbitals, J. Colloid Interface Sci., 2019, 533, 9-12.

67 J. Zhu, P. Li, W. Guo, Y. Zhao and R. Zou, Titanium-based metal-organic frameworks for photocatalytic applications, Coord. Chem. Rev., 2018, 359, 80-101.

68 Y. Zhang, G. Li, L. Kong and H. Lu, Deep oxidative desulfurization catalyzed by Ti-based metal-organic frameworks, Fuel, 2018, 219, 103-110.

69 M. Janek, T. M. Muziol and P. Piszczek, The structure and photocatalytic activity of the tetranuclear titanium(Iv) oxocomplex with 4-aminobenzoate ligands, Polyhedron, 2018, 141, 110-117.

70 J. Wang, S. Dong, Z. Yadi, Z. Chen, S. Jiang, L. Wu and X. Zhang, Metal-organic framework derived titaniumbased anode materials for lithium ion batteries, NanoStruct. Nano-Objects, 2018, 15, 48-53.

71 L. Lian, X. Zhang, J. Hao, J. Lv, X. Wang, B. Zhu and D. Lou, Magnetic solid-phase extraction of fluoroquinolones from water samples using titanium-based metal-organic framework functionalized magnetic microspheres, J. Chromatogr. A, 2018, 1579, 1-8.

72 Y. Xie, X. Liu, X. Ma, Y. Duan, Y. Yao and Q. Cai, Small Titanium-based MOFs prepared with the introduction of tetraethyl orthosilicate and their potential for use in drug delivery, ACS Appl. Mater. Interfaces, 2018, 10, 13325-13332.

73 E. Yilmaz, E. Sert and F. S. Atalay, Synthesis and sulfation of titanium based metal organic framework; MIL-125 and usage as catalyst in esterification reactions, Catal. Commun., 2017, 100, 48-51.

74 H. Wang, F. Jiao, F. Gao, Y. Lv, Q. Wu, Y. Zhao, Y. Shen, Y. Zhang and X. Qian, Titanium(Iv) ion-modified covalent organic frameworks for specific enrichment of phosphopeptides, Talanta, 2017, 166, 133-140.

75 H. L. Nguyen, The chemistry of titanium-based metalorganic frameworks, New J. Chem., 2017, 41, 14030-14043.

76 S. Kim, D. Sarkar, Y. Kim, M. H. Park, M. Yoon, Y. Kim and M. Kim, Synthesis of functionalized titanium-carboxylate molecular clusters and their catalytic activity, J. Ind. Eng. Chem., 2017, 53, 171-176.

77 P. George, N. R. Dhabarde and P. Chowdhury, Rapid synthesis of Titanium based Metal Organic framework (MIL-125) via microwave route and its performance evaluation in photocatalysis, Mater. Lett., 2017, 186, 151-154.

78 A. Rengaraj, P. Puthiaraj, N. Heo, H. Lee, S. K. Hwang, S. Kwon, W. Ahn and Y. Huh, Porous $\mathrm{NH}_{2}$-MIL-125 as an efficient nano-platform for drug delivery, imaging and ROS therapy utilised Low-Intensity Visible light exposure system, Colloids Surf., B, 2017, 160, 1-10.
79 H. Su, Y. Lin, Z. Wang, Y. E. Wong, X. Chen and T. D. Chan, Magnetic metal-organic framework-titanium dioxide nanocomposite as adsorbent in the magnetic solid-phase extraction of fungicides from environmental water samples, J. Chromatogr. A, 2016, 1466, 21-28.

80 R. Navarro, M. Carboni and D. Meyer, Photosensitive titanium and zirconium Metal Organic Frameworks: Current research and future possibilities, Mater. Lett., 2016, 166, 327-338.

81 X. Guo, H. Huang, Y. Ban, Q. Yang, Y. Xiao, Y. Li, W. Yang and C. Zhong, Mixed matrix membranes incorporated with amine-functionalized titanium-based metal-organic framework for $\mathrm{CO}_{2} / \mathrm{CH}_{4}$ separation, J. Membr. Sci., 2015, 478, 130-139.

82 R. Bulánek, P. Čičmanec, J. Kotera and I. Boldog, Efficient oxidative dehydrogenation of ethanol by $\mathrm{VO}_{x}$ @MIL-101: On par with $\mathrm{VO}_{x} / \mathrm{ZrO}_{2}$ and much better than MIL-47(V), Catal. Today, 2019, 324, 1-19.

83 W. Wang, N. Li, H. Tang, Y. Ma and X. Yang, Vanadium oxyacetylacetonate grafted on UiO-66- $\mathrm{NH}_{2}$ for hydroxylation of benzene to phenol with molecular oxygen, Mol. Catal., 2018, 453, 113-120.

84 Z. Wang, W. He, X. Zhang, Y. Yue, J. Liu, C. Zhang and L. Fang, Multilevel structures of $\mathrm{Li}_{3} \mathrm{~V}_{2}\left(\mathrm{PO}_{4}\right)_{3} /$ phosphorousdoped carbon nanocomposites derived from hybrid V-MOFs for long-life and cheap lithium ion battery cathodes, J. Power Sources, 2017, 366, 9-17.

85 M. N. Timofeeva, V. N. Panchenko, N. A. Khan, Z. Hasan, I. P. Prosvirin, S. V. Tsybulya and S. H. Jhung, Isostructural metal-carboxylates MIL-100(M) and MIL-53(M) (M: V, Al, Fe and $\mathrm{Cr}$ ) as catalysts for condensation of glycerol with acetone, Appl. Catal., A, 2017, 529, 167-174.

86 X. Wang and A. J. Jacobson, Framework deformation of the microporous vanadium benzenedicarboxylate MIL-47 upon absorption of organosulfur molecules, Microporous Mesoporous Mater., 2016, 219, 112-116.

87 J. Kim, N. D. McNamara and J. C. Hicks, Catalytic activity and stability of carbon supported $\mathrm{V}$ oxides and carbides synthesized via pyrolysis of MIL-47(V), Appl. Catal., A, 2016, 517, 141-150.

88 W. Kaveevivitchai and A. J. Jacobson, Exploration of vanadium benzenedicarboxylate as a cathode for rechargeable lithium batteries, J. Power Sources, 2015, 278, 265-273.

89 F. Farzaneh and Y. Sadeghi, Immobilized V-MIL-101 on modified $\mathrm{Fe}_{3} \mathrm{O}_{4}$ nanoparticles as heterogeneous catalyst for epoxidation of allyl alcohols and alkenes, J. Mol. Catal. A: Chem., 2015, 398, 275-281.

90 J. Yang, Y. Wang, L. Li, Z. Zhang and J. Li, Protection of open-metal V(III) sites and their associated $\mathrm{CO}_{2} / \mathrm{CH}_{4} / \mathrm{N}_{2} / \mathrm{O}_{2} /$ $\mathrm{H}_{2} \mathrm{O}$ adsorption properties in mesoporous V-MOFs, J. Colloid Interface Sci., 2015, 456, 197-205.

91 P. V. D. Voort, K. Leus, Y. Liu, M. Vandichel, V. V. Speybroeck, M. Waroquier and S. Biswas, Vanadium metal-organic frameworks: structures and applications, New J. Chem., 2014, 38, 1853-1867.

92 F. Carson, J. Su, A. E. Platero-Prats, W. Wan, Y. Yun, L. Samain and X. Zou, Framework isomerism in Vanadium 
Metal-Organic Frameworks: MIL-88B(V) and MIL-101(V), Cryst. Growth Des., 2013, 13, 5036-5044.

93 N. D. McNamara, G. T. Neumann, E. T. Masko, J. A. Urban and J. C. Hicks, Catalytic performance and stability of (V) MIL-47 and (Ti) MIL-125 in the oxidative desulfurization of heterocyclic aromatic sulfur compounds, J. Catal., 2013, 305, 217-226.

94 K. Leus, M. Vandichel, Y. Liu, I. Muylaert, J. Musschoot, S. Pyl, H. Vrielinck, F. Callens, G. B. Marin, C. Detavernier, P. V. Wiper, Y. Z. Khimyak, M. Waroquier, V. V. Speybroeck and P. V. D. Voort, The coordinatively saturated vanadium MIL-47 as a low leaching heterogeneous catalyst in the oxidation of cyclohexene, J. Catal., 2012, 285, 196-207.

95 A. Lieb, H. Leclerc, T. Devic, C. Serre, I. Margiolaki, F. Mahjoubi, J. S. Lee, A. Vimont, M. Daturi and J. S. Chang, MIL-100(V) - A mesoporous vanadium metal organic framework with accessible metal sites, Microporous Mesoporous Mater., 2012, 157, 18-23.

96 S. Rives, H. Jobic, F. Ragon, T. Devic, C. Serre, G. Ferey, J. Ollivier and G. Maurin, Diffusion of long chain n-alkanes in the metal-organic framework MIL-47(V): a combination of neutron scattering experiments and molecular dynamics simulations, Microporous Mesoporous Mater., 2012, 164, 259-265.

97 A. Phan, A. U. Czaja, F. Gándara, C. B. Knobler and O. M. Yaghi, Metal-Organic Frameworks of Vanadium as Catalysts for Conversion of Methane to Acetic Acid, Inorg. Chem., 2011, 50, 7388-7390.

98 L. Li, Z. Li, W. Yang, Y. Huang, G. Huang and H. L. Jiang, Integration of Pd nanoparticles with engineered pore walls in MOFs for enhanced catalysis, Chem., 2021, 7, 686-698.

99 Y. Z. Chen, B. Gu, T. Uchida, J. Liu, X. Liu, B. J. Ye, Q. Xu and H. L. Jiang, Location determination of metal nanoparticles relative to a metal-organic framework, Nat. Commun., 2019, 10, 1-10.

100 T. Zhao, S. Li, L. Shen, Y. Wang and X. Yang, The sized controlled synthesis of MIL-101(Cr) with enhanced $\mathrm{CO}_{2}$ adsorption property, Inorg. Chem. Commun., 2018, 96, 47-51.

101 Y. Zhang, P. Yan, Q. Wan and N. Yang, Integration of chromium terephthalate metal-organic frameworks with reduced graphene oxide for voltammetry of 4-Nonylphenol, Carbon, 2018, 134, 540-547.

102 A. Zare, A. Bordbar, F. Jafarian and S. Tangestaninejad, Candida rugosa lipase immobilization on various chemically modified Chromium terephthalate MIL-101, J. Mol. Liq., 2018, 254, 137-144.

103 J. Wang, X. Huang, H. Gao, A. Li and C. Wang, Construction of CNT@Cr-MIL-101- $\mathrm{NH}_{2}$ hybrid composite for shape-stabilized phase change materials with enhanced thermal conductivity, Chem. Eng. J., 2018, 350, 164-172.

104 M. Shafiei, M. S. Alivand, A. Rashidi, A. Samimi and D. Mohebbi-Kalhori, Synthesis and adsorption performance of a modified micro-mesoporous MIL-101(Cr) for VOCs removal at ambient conditions, Chem. Eng. J., 2018, 341, 164-174.

105 S. Rostamnia and F. Mohsenzad, Nanoarchitecturing of open metal site Cr-MOFs for oxodiperoxo molybdenum complexes $[\mathrm{MoO}(\mathrm{O} 2) 2 @ E n / \mathrm{MIL}-100(\mathrm{Cr})]$ as promising and bifunctional catalyst for selective thioether oxidation, Mol. Catal., 2018, 445, 12-20.

106 S. M. Mirsoleimani-azizi, P. Setoodeh, F. Samimi, J. Shadmehr, N. Hamedi and M. R. Rahimpour, Diazinon removal from aqueous media by mesoporous MIL-101(Cr) in a continuous fixed-bed system, J. Environ. Chem. Eng., 2018, 6, 4653-4664.

107 N. Lu, X. He, T. Wang, S. Liu and X. Hou, Magnetic solidphase extraction using MIL-101(Cr)-based composite combined with dispersive liquid-liquid microextraction based on solidification of a floating organic droplet for the determination of pyrethroids in environmental water and tea samples, Microchem. J., 2018, 137, 449-455.

108 C. Chen, N. Feng, Q. Guo, Z. Li, X. Li, J. Ding, L. Wang, H. Wan and G. Guan, Surface engineering of a chromium metal-organic framework with bifunctional ionic liquids for selective $\mathrm{CO}_{2}$ adsorption: synergistic effect between multiple active sites, J. Colloid Interface Sci., 2018, 521, 91-101.

109 S. Zhao, J. Mei, H. Xu, W. Liu, Z. Qu, Y. Cui and N. Yan, Research of mercury removal from sintering flue gas of iron and steel by the open metal site of MIL-101(Cr), J. Hazard. Mater., 2018, 351, 301-307.

110 J. Zhang, L. Sun, C. Chen, M. Liu, W. Dong, W. Guo and S. Ruan, High performance humidity sensor based on metal organic framework MIL-101(Cr) nanoparticles, J. Alloys Compd., 2017, 695, 520-525.

111 Z. Yu, J. Deschamps, L. Hamon, P. K. Prabhakaran and P. Pré, Hydrogen adsorption and kinetics in MIL-101(Cr) and hybrid activated carbon-MIL-101(Cr) materials, Int. J. Hydrogen Energy, 2017, 42, 8021-8031.

112 H. W. B. Teo, A. Chakraborty and S. Kayal, Post synthetic modification of MIL-101(Cr) for S-shaped isotherms and fast kinetics with water adsorption, Appl. Therm. Eng., 2017, 120, 453-462.

113 D. K. Panchariya, R. K. Rai, S. K. Singh and E. A. Kumar, Synthesis and characterization of MIL-101 incorporated with Darco type Activated Charcoal, Mater. Today, 2017, 4, 388-394.

114 S. Kayal and A. Chakraborty, Activated carbon (type Maxsorb-III) and MIL-101(Cr) metal organic framework based composite adsorbent for higher $\mathrm{CH}_{4}$ storage and $\mathrm{CO}_{2}$ capture, Chem. Eng. J., 2018, 334, 780-788.

115 H. Belarbi, L. Boudjema, C. Shepherd, N. Ramsahye, G. Toquer, J. Chang and P. Trens, Adsorption and separation of hydrocarbons by the metal organic framework MIL101(Cr), Colloids Surf., A, 2017, 520, 46-52.

116 T. Assaad and B. Assfour, Metal organic framework MIL101 for radioiodine capture and storage, J. Nucl. Mater., 2017, 493, 6-11.

117 V. V. Torbina, I. D. Ivanchikova, O. A. Kholdeeva, I. Y. Skobelev and O. V. Vodyankina, Propylene glycol oxidation with tertbutyl hydroperoxide over Cr-containing metal-organic frameworks MIL-101 and MIL-100, Catal. Today, 2016, 278, 97-103.

118 I. M. P. Silva, M. A. Carvalho, C. S. Oliveira, D. M. Profirio, R. B. Ferreira, P. P. Corbi and A. L. B. Formiga, Enhanced 
performance of a metal-organic framework analogue to MIL-101(Cr) containing amine groups for ibuprofen and nimesulide controlled release, Inorg. Chem. Commun., 2016, 70, 47-50.

119 J. Ren, X. Dyosiba, N. M. Musyoka, H. W. Langmi, B. C. North, M. Mathe and M. S. Onyango, Green synthesis of chromium-based metal-organic framework (Cr-MOF) from waste polyethylene terephthalate (PET) bottles for hydrogen storage applications, Int. J. Hydrogen Energ., 2016, 41, 18141-18146.

120 D. Kim, H. Kim and D. Cho, Catalytic performance of MIL$100(\mathrm{Fe}, \mathrm{Cr})$ and MIL-101(Fe, $\mathrm{Cr}$ ) in the isomerization of endo- to exo-dicyclopentadiene, Catal. Commun., 2016, 73, 69-73.

121 M. Han, S. Li, L. Ma and L. Wang, Syntheses, structures and properties of two manganese(II) metal-organic frameworks based on bromoisophthalate and bipyridyl-type co-ligands, Inorg. Chem. Commun., 2012, 20, 340-345.

122 J. Rydén, S. Öberg, M. Heggie, M. Rayson and P. Briddon, Hydrogen storage in the manganese containing metalorganic framework MOF-73, Microporous Mesoporous Mater., 2013, 165, 205-209.

123 Y. Zhao, H. Yang, F. Wang and Z. Du, A microporous manganese-based metal-organic framework for gas sorption and seperation, J. Mol. Struct., 2014, 1074, 19-21.

124 F. Zadehahmadi, S. Tangestaninejad, M. Moghadam, V. Mirkhani, I. Mohammadpoor-Baltork, A. R. Khosropour and R. Kardanpour, Manganese(III) tetrapyridylporphyrinchloromethylated MIL-101 hybrid material: a highly active catalyst for oxidation of hydrocarbons, Appl. Catal., A, 2014, 477, 34-41.

125 F. Ashouri, M. Zare and M. Bagherzadeh, Manganese and cobalt-terephthalate metal-organic frameworks as a precursor for synthesis of $\mathrm{Mn}_{2} \mathrm{O}_{3}, \mathrm{Mn}_{3} \mathrm{O}_{4}$ and $\mathrm{Co}_{3} \mathrm{O}_{4}$ nanoparticles: active catalysts for olefin heterogeneous oxidation, Inorg. Chem. Commun., 2015, 61, 73-76.

126 X. Wang, Y. Yu, D. Huan, K. V. Hecke and G. Cui, An unprecedented 3D manganese(II) MOF displaying $(4,5)$ connected xah topology, Inorg. Chem. Commun., 2015, 61, 24-26.

127 Y. Niu, L. Cui, J. Han and X. Zhao, Solvent-mediated secondary building units (SBUs) diversification in a series of MnII-based metal-organic frameworks (MOFs), J. Solid State Chem., 2016, 241, 18-25.

128 K. He, W. Han and K. L. Yeung, Preparation and performance of catalytic MOFs in microreactor, J. Taiwan Inst. Chem. Eng., 2019, 98, 85-93.

129 R. M. Abdelhameed, R. E. Abdelhameed and H. A. Kamel, Iron-based metal-organic-frameworks as fertilizers for hydroponically grown Phaseolus vulgaris, Mater. Lett., 2019, 237, 72-79.

130 D. Wang, F. Jia, H. Wang, F. Chen, Y. Fang, W. Dong, G. Zeng, X. Li, Q. Yang and X. Yuan, Simultaneously efficient adsorption and photocatalytic degradation of tetracycline by Fe-based MOFs, J. Colloid Interface Sci., 2018, 519, 273-284.
131 S. Yuan, X. Bo and L. Guo, In situ growth of iron-based metal-organic framework crystal on ordered mesoporous carbon for efficient electrocatalysis of $p$-nitrotoluene and hydrazine, Anal. Chim. Acta, 2018, 1024, 73-83.

132 S. Wu, X. Li, Y. Xu, J. Wu, Z. Wang, Y. Han and X. Zhang, Hierarchical spinel $\mathrm{Ni}_{x} \mathrm{Co}_{1-x} \mathrm{Fe}_{2} \mathrm{O}_{4}$ microtubes derived from Fe-based MOF for high-sensitive acetone sensor, Ceram. Int., 2018, 44, 19390-19396.

133 A. Kim, T. Yoon, S. Kim, K. Cho, S. Han and Y. Bae, Creating high $\mathrm{CO} / \mathrm{CO}_{2}$ selectivity and large $\mathrm{CO}$ working capacity through facile loading of $\mathrm{Cu}(\mathrm{I})$ species into an iron-based mesoporous metal-organic framework, Chem. Eng. J., 2018, 348, 135-142.

134 W. Xu, W. Zhang, J. Kang and B. Li, Facile synthesis of mesoporous Fe-based MOFs loading bismuth with high speed adsorption of iodide from solution, J. Solid State Chem., 2019, 269, 558-565.

135 H. P. Nguyen, M. Matsuoka, T. H. Kim and S. W. Lee, Iron(III)based metal-organic frameworks as potential visible lightdriven catalysts for the removal of $\mathrm{NO}_{x}$ : a solution for urban air purification, J. Photochem. Photobiol., 2018, 367, 429-437.

136 R. Wang, H. Xu, K. Zhang, S. Wei and D. Wu, High-quality $\mathrm{Al} @ \mathrm{Fe}-\mathrm{MOF}$ prepared using Fe-MOF as a micro-reactor to improve adsorption performance for selenite, J. Hazard. Mater., 2019, 364, 272-280.

137 L. Fan, H. Wu, X. Wu, M. Wang, J. Cheng, N. Zhang, Y. Feng and K. Sun, Fe-MOF derived jujube pit like $\mathrm{Fe}_{3} \mathrm{O}_{4} / \mathrm{C}$ composite as sulfur host for lithium-sulfur battery, Electrochim. Acta, 2019, 295, 444-451.

138 L. Cui, J. Hu, C. Li, C. Wang and C. Zhang, An electrochemical biosensor based on the enhanced quasi-reversible redox signal of prussian blue generated by self-sacrificial label of iron metal-organic framework, Biosens. Bioelectron., 2018, 122, 168-174.

139 M. Zhang, M. Yang, S. Tong and K. A. Lin, Ferrocenemodified iron-based metal-organic frameworks as an enhanced catalyst for activating oxone to degrade pollutants in water, Chemosphere, 2018, 213, 295-304.

140 H. Qin, X. Jiang, H. Huang, W. Liu, J. Li, Y. Xiao, L. Mao, Z. Fu, N. Yu and D. Yin, Ionic liquid-assisted catalytic oxidation of anethole by copper- and iron-based metal organic frameworks, Mol. Catal., 2017, 440, 158-167.

141 D. Wang, J. Albero, H. Garcia and Z. Li, Visible-light-induced tandem reaction of $o$-aminothiophenols and alcohols to benzothiazols over Fe-based MOFs: influence of the structure elucidated by transient absorption spectroscopy, J. Catal., 2017, 349, 156-162.

142 A. Nikseresht, A. Daniyali, M. Ali-Mohammadi, A. Afzalinia and A. Mirzaie, Ultrasound-assisted biodiesel production by a novel composite of Fe(III)-based MOF and phosphotangestic acid as efficient and reusable catalyst, Ultrason. Sonochem., 2017, 37, 203-207.

143 J. Liu, A. Zhang, M. Liu, S. Hu, F. Ding, C. Song and X. Guo, Fe-MOF-derived highly active catalysts for carbon dioxide hydrogenation to valuable hydrocarbons, J. CO2 Util., 2017, 21, 100-107. 
144 V. Gascon, M. B. Jimenez, R. M. Blanco and M. SanchezSanchez, Semi-crystalline Fe-BTC MOF material as an efficient support for enzyme immobilization, Catal. Today, 2018, 304, 119-126.

145 C. Gao, S. Chen, X. Quan, H. Yu and Y. Zhang, Enhanced Fenton-like catalysis by iron-based metal organic frameworks for degradation of organic pollutants, J. Catal., 2017, 356, 125-132.

146 M. K. Agusta, A. G. Saputro, V. V. Tanuwijaya, N. N. Hidayat and H. K. Dipojono, Hydrogen adsorption on Fe-based metal organic frameworks: DFT study, Procedia Eng., 2017, 170, 136-140.

147 M. Angamuthu, G. Satishkumar and M. V. Landau, Precisely controlled encapsulation of $\mathrm{Fe}_{3} \mathrm{O}_{4}$ nanoparticles in mesoporous carbon nanodisk using iron based MOF precursor for effective dye removal, Microporous Mesoporous Mater., 2017, 251, 58-68.

148 E. Rahmani and M. Rahmani, Alkylation of benzene over Fe-based metal organic frameworks (MOFs) at low temperature condition, Microporous Mesoporous Mater., 2017, 249, 118-127.

149 T. Araya, M. Jia, J. Yang, P. Zhao, K. Cai, W. Ma and Y. Huang, Resin modified MIL-53(Fe) MOF for improvement of photocatalytic performance, Appl. Catal., B, 2017, 203, 768-777.

150 T. D. Le, K. D. Nguyen, V. T. Nguyen, T. Truong and N. T. S. Phan, 1,5-Benzodiazepine synthesis via cyclocondensation of 1,2-diamines with ketones using ironbased metal-organic framework MOF-235 as an efficient heterogeneous catalyst, J. Catal., 2016, 333, 94-101.

151 J. Wang, G. Zhao and F. Yu, Facile preparation of $\mathrm{Fe}_{3} \mathrm{O}_{4} @$ MOF core-shell microspheres for lipase immobilization, J. Taiwan Inst. Chem. Eng., 2016, 69, 139-145.

152 M. Anbia, V. Hoseini and S. Sheykhi, Sorption of methane, hydrogen and carbon dioxide on metal-organic framework, iron terephthalate (MOF-235), J. Ind. Eng. Chem., 2012, 18, 1149-1152.

153 E. Haque, J. W. Jun and S. H. Jhung, Adsorptive removal of methyl orange and methylene blue from aqueous solution with a metal-organic framework material, iron terephthalate (MOF-235), J. Hazard. Mater., 2011, 185, 507-511.

154 A. W. Peters, K. Otake, A. E. Platero-Prats, Z. Li, M. R. DeStefano, K. W. Chapman, O. K. Farha and J. T. Hupp, Site-directed synthesis of cobalt oxide clusters in a metalorganic framework, ACS Appl. Mater. Interfaces, 2018, 10, 15073-15078.

155 O. Pliekhov, O. Pliekhova, U. L. Stangar and N. Z. Logar, The Co-MOF-74 modified with $N, N^{\prime}$-Dihydroxypyromellitimide for selective, solvent free aerobic oxidation of toluene, Catal. Commun., 2018, 110, 88-92.

156 R. Ramachandran, K. Rajavel, W. Xuan, D. Lin and F. Wang, Influence of $\mathrm{Ti}_{3} \mathrm{C}_{2} \mathrm{~T}_{x}$ (MXene) intercalation pseudocapacitance on electrochemical performance of Co-MOF binder-free electrode, Ceram. Int., 2018, 44, 14425-14431.

157 J. Tian, M. Fu, D. Huang, X. Wang, Y. Wu, J. Y. Lu and D. Li, A new 2D $\mathrm{Co}_{5}$-cluster based MOF: crystal structure, magnetic properties and electrocatalytic hydrogen evolution reaction, Inorg. Chem. Commun., 2018, 95, 73-77.

158 C. Li, Q. Yang, M. Shen, J. Ma and B. Hu, The electrochemical $\mathrm{Na}$ intercalation/extraction mechanism of ultrathin cobalt(II) terephthalate-based MOF nanosheets revealed by synchrotron X-ray absorption spectroscopy, Energy Storage Mater., 2018, 14, 82-89.

159 H. Jiang, Y. Niu, Q. Wang, Y. Chen and M. Zhang, Singlephase $\mathrm{SO}_{2}$-resistant to poisoning Co/Mn-MOF-74 catalysts for $\mathrm{NH}_{3}$-SCR, Catal. Commun., 2018, 113, 46-50.

160 S. Gao, Y. Sui, F. Wei, J. Qi, Q. Meng, Y. Ren and Y. He, Dandelion-like nickel/cobalt metal-organic framework based electrode materials for high performance supercapacitors, J. Colloid Interface Sci., 2018, 531, 83-90.

161 G. Zhu, H. Wen, M. Ma, W. Wang, L. Yang, L. Wang, X. Shi, $\mathrm{X}$. Cheng, X. Sun and Y. Yao, A self-supported hierarchical Co-MOF as a supercapacitor electrode with ultrahigh areal capacitance and excellent rate performance, Chem. Commun., 2018, 54, 10499-10502.

162 F. Yu, H. Zhou and Q. Shen, Modification of cobaltcontaining MOF-derived mesoporous carbon as an effective sulfur-loading host for rechargeable lithium-sulfur batteries, J. Alloys Compd., 2019, 772, 843-851.

163 S. S. Nadar and V. K. Rathod, Magnetic-metal organic framework (magnetic-MOF): a novel platform for enzyme immobilization and nanozyme applications, Int. J. Biol. Macromol., 2018, 120, 2293-2302.

164 N. M. Umesh, K. K. Rani, R. Devasenathipathy, B. Sriram, Y. Liu and S. Wang, Preparation of Co-MOF derived $\mathrm{Co}(\mathrm{OH})_{2} /$ multiwalled carbon nanotubes as an efficient bifunctional electro catalyst for hydrazine and hydrogen peroxide detections, J. Taiwan Inst. Chem. Eng., 2018, 93, 79-86.

165 H. Yu, H. Xia, J. Zhang, J. He, S. Guo and Q. Xu, Fabrication of Fe-doped Co-MOF with mesoporous structure for the optimization of supercapacitor performances, Chin. Chem. Lett., 2018, 29, 834-836.

166 Y. Li, M. Xie, X. Zhang, Q. Liu, D. Lin, C. Xu, F. Xie and $\mathrm{X}$. Sun, Co-MOF nanosheet array: a high-performance electrochemical sensor for non-enzymatic glucose detection, Sens. Actuators, B, 2019, 278, 126-132.

167 X. Liu, M. Hu, M. Wang, Y. Song, N. Zhou, L. He and Z. Zhang, Novel nanoarchitecture of Co-MOF-on-TPN-COF hybrid: ultralowly sensitive bioplatform of electrochemical aptasensor toward ampicillin, Biosens. Bioelectron., 2019, 123, 59-68.

168 W. Jin, J. Zou, S. Zeng, S. Inguva, G. Xu, X. Li, M. Peng and $\mathrm{X}$. Zeng, Tailoring the structure of clew-like carbon skeleton with 2D Co-MOF for advanced Li-S cells, Appl. Surf. Sci., 2019, 469, 404-413.

169 P. Sengodu, C. Bongu, M. Perumal and M. Paramasivam, Easy synthesis of microporous/mesoporous cobalt organic framework as binder less lithium-ion battery electrode, J. Alloys Compd., 2017, 714, 603-609.

170 T. W. Murinzi, E. Hosten and G. M. Watkins, Synthesis and characterization of a cobalt-2,6-pyridinedicarboxylate MOF 
with potential application in electrochemical sensing, Polyhedron, 2017, 137, 188-196.

171 R. Mehek, N. Iqbal, T. Noor, H. Nasir, Y. Mehmood and S. Ahmed, Novel Co-MOF/Graphene Oxide electrocatalyst for methanol oxidation, Electrochim. Acta, 2017, 255, 195-204.

172 H. Lu, H. Zhang, R. Liu, X. Zhang, H. Zhao and G. Wang, Macroscale cobalt-MOFs derived metallic Co nanoparticles embedded in N-doped porous carbon layers as efficient oxygen electrocatalysts, Appl. Surf. Sci., 2017, 392, 402-409.

173 H. Bigdeli, M. Moradi, S. Hajati, M. A. Kiani and J. Toth, Cobalt terephthalate MOF-templated synthesis of porous nano-crystalline $\mathrm{Co}_{3} \mathrm{O}_{4}$ by the new indirect solid state thermolysis as cathode material of asymmetric supercapacitor, Phys. E, 2017, 94, 158-166.

174 A. D. Oliveira, G. F. D. Lima and H. A. D. Abreu, Structural and electronic properties of M-MOF-74 $(\mathrm{M}=\mathrm{Mg}$, Co or Mn), Chem. Phys. Lett., 2018, 691, 283-290.

175 I. Choi, Y. Kim, D. N. Lee and S. Huh, Three-dimensional cobalt(II) and cadmium(II) MOFs containing 1,4-naphthalenedicarboxylate: catalytic activity of Cd-MOF, Polyhedron, 2016, 105, 96-103.

176 X. Liu, C. Shi, C. Zhai, M. Cheng, Q. Liu and G. Wang, Cobalt-based layered metal-organic framework as an ultrahigh capacity supercapacitor electrode material, ACS Appl. Mater. Interfaces, 2016, 8, 4585-4591.

177 M. Y. Masoomi, M. Bagheri and A. Morsali, Application of two cobalt-based metal-organic frameworks as oxidative desulfurization catalysts, Inorg. Chem., 2015, 54, 11269-11275.

178 M. Zeng, Z. Yin, Y. Tan, W. Zhang, Y. He and M. Kurmoo, Nanoporous cobalt(II) MOF exhibiting four magnetic ground states and changes in gas sorption upon post-synthetic modification, J. Am. Chem. Soc., 2014, 136, 4680-4688.

179 H. Jasuja, Y. Jiao, N. C. Burtch, Y. G. Huang and K. S. Walton, Synthesis of Cobalt-, Nickel-, Copper-, and Zincbased, Water-stable, Pillared Metal-Organic Frameworks, Langmuir, 2014, 30, 14300-14307.

180 D. O. Miles, D. Jiang, A. D. Burrows, J. E. Halls and F. Marken, Conformal transformation of [Co(bdc)(DMF)] (Co-MOF-71, bdc = 1,4-benzenedicarboxylate, DMF $=N, N$ dimethylformamide) into porous electrochemically active cobalt hydroxide, Electrochem. Commun., 2013, 27, 9-13.

181 S. S. Wang, L. Jiao, Y. Qian, W. C. Hu, G. Y. Xu, C. Wang and H. L. Jiang, Boosting Electrocatalytic Hydrogen Evolution over Metal-Organic Frameworks by Plasmon-Induced HotElectron Injection, Angew. Chem., Int. Ed., 2019, 58, 10713-10717.

182 P. Arul and S. A. John, Size controlled synthesis of Ni-MOF using polyvinylpyrrolidone: new electrode material for the trace level determination of nitrobenzene, J. Electroanal. Chem., 2018, 829, 168-176.

183 C. R. Rawool, S. P. Karna and A. K. Srivastava, Enhancing the supercapacitive performance of Nickel based metal organic framework-carbon nanofibers composite by changing the ligands, Electrochim. Acta, 2019, 294, 345-356.

184 H. Wu, M. Li, Z. Wang, H. Yu, J. Han, G. Xie and S. Chen, Highly stable Ni-MOF comprising triphenylamine moieties as a high-performance redox indicator for sensitive aptasensor construction, Anal. Chim. Acta, 2019, 1049, 74-81.

185 F. Wang, X. Chen, L. Chen, J. Yang and Q. Wang, Highperformance non-enzymatic glucose sensor by hierarchical flower-like nickel(II)-based MOF/carbon nanotubes composite, Mater. Sci. Eng., C, 2019, 96, 41-50.

186 A. Katoch, R. Bhardwaj, N. Goyal and S. Gautam, Synthesis, structural and optical study of Ni-doped Metal-organic framework for adsorption based chemical sensor application, Vacuum, 2018, 158, 249-256.

187 J. Chen, Y. Shu, H. Li, Q. Xu and X. Hu, Nickel metalorganic framework 2D nanosheets with enhanced peroxidase nanozyme activity for colorimetric detection of $\mathrm{H}_{2} \mathrm{O}_{2}$, Talanta, 2018, 189, 254-261.

188 P. Du, Y. Dong, C. Liu, W. Wei, D. Liu and P. Liu, Fabrication of hierarchical porous nickel based metal-organic framework (Ni-MOF) constructed with nanosheets as novel pseudocapacitive material for asymmetric supercapacitor, J. Colloid Interface Sci., 2018, 518, 57-68.

189 K. M. Elsabawy and A. M. Fallatah, Microwave assisted synthesis and molecular structure visualization of ultrahigh surface area Ni-6,6'-dibromo-indigo coordinated polymeric MOFs stabilized via hydrogen bonding, Inorg. Chem. Commun., 2018, 92, 78-83.

190 C. I. Ezugwu, M. A. Asraf, X. Li, S. Liu, C. Kao, S. Zhuiykov and F. Verpoort, Cationic Nickel Metal-organic frameworks for adsorption of negatively charged dye molecules, Data Brief, 2018, 18, 1952-1961.

191 S. He, S. He, X. Bo, Q. Wang, F. Zhan, Q. Wang and C. Zhao, Porous $\mathrm{Ni}_{2} \mathrm{P} / \mathrm{C}$ microrods derived from microwave-prepared MOF-74-Ni and its electrocatalysis for hydrogen evolution reaction, Mater. Lett., 2018, 231, 94-97.

192 X. Hou, X. Yan, X. Wang and Q. Zhai, Tuning the porosity of mesoporous NiO through calcining isostructural Ni-MOFs toward supercapacitor applications, J. Solid State Chem., 2018, 263, 72-78.

193 L. Ji, Y. Jin, K. Wu, C. Wan, N. Yang and Y. Tang, Morphology-dependent electrochemical sensing performance of metal (Ni, Co, Zn)-organic frameworks, Anal. Chim. Acta, 2018, 1031, 60-66.

194 Y. Lv, P. Xu, H. Yu, J. Xu and X. Li, Ni-MOF-74 as Sensing Material for Resonant-gravimetric Detection of ppb-level CO, Sens. Actuators, B, 2018, 262, 562-569.

195 X. Sun, Y. Shi, W. Zhang, C. Li, Q. Zhao, J. Gao and X. Li, A new type Ni-MOF catalyst with high stability for selective catalytic reduction of $\mathrm{NO}_{x}$ with $\mathrm{NH}_{3}$, Catal. Commun., 2018, 114, 104-108.

196 Q. Wang, Q. Wang, B. Xu, F. Gao, F. Gao and C. Zhao, Flower-shaped multiwalled carbon nanotubes@nickel-trimesic acid MOF composite as a high-performance cathode material for energy storage, Electrochim. Acta, 2018, 281, 69-77.

197 L. Zhang, Y. Zhang, S. Huang, Y. Yuan, H. Li, Z. Jin, W. Jiahao, Q. Liao, L. Hu, J. Lu, S. Ruan and Y. Zeng, $\mathrm{Co}_{3} \mathrm{O}_{4} / \mathrm{Ni}$-based MOFs on carbon cloth for flexible alkaline batterysupercapacitor hybrid devices and near-infrared photocatalytic hydrogen evolution, Electrochim. Acta, 2018, 281, 189-197. 
198 W. Zhu, C. Zhang, Q. Li, L. Xiong, R. Chen, X. Wan, Z. Wang, W. Chen, Z. Deng and Y. Peng, Selective reduction of $\mathrm{CO}_{2}$ by conductive MOF nanosheets as an efficient co-catalyst under visible light illumination, Appl. Catal., B, 2018, 238, 339-345.

199 H. T. T. Nguyen, D. N. A. Doan and T. Truong, Unprecedented salt-promoted direct arylation of acidic $\mathrm{sp}^{2} \mathrm{C}-\mathrm{H}$ bonds under heterogeneous Ni-MOF-74 catalysis: synthesis of bioactive azole derivatives, J. Mol. Catal. A: Chem., 2017, 426, 141-149.

200 T. Q. N. Tran, G. Das and H. H. Yoon, Nickel-metal organic framework/MWCNT composite electrode for non-enzymatic urea detection, Sens. Actuators, B, 2017, 243, 78-83.

201 C. Qu, Y. Jiao, B. Zhao, D. Chen, R. Zou, K. S. Walton and M. Liu, Nickel-based pillared MOFs for high-performance supercapacitors: design, synthesis and stability study, Nano Energy, 2016, 26, 66-73.

202 T. Xu, X. Hou, S. Liu and B. Liu, One-step synthesis of magnetic and porous Ni@MOF-74(Ni) composite, Microporous Mesoporous Mater., 2018, 259, 178-183.

203 Y. Xu, A. J. Howarth, T. Islamoglu, C. T. D. Silva, J. T. Hupp and O. K. Farha, Combining solvent-assisted linker exchange and transmetallation strategies to obtain a new non-catenated nickel(II) pillared-paddlewheel MOF, Inorg. Chem. Commun., 2016, 67, 60-63.

204 L. Jiao, W. Yang, G. Wan, R. Zhang, X. Zheng, H. Zhou, S. H. Yu and H. L. Jiang, Single-Atom Electrocatalysts from Multivariate Metal-Organic, Angew. Chem., Int. Ed., 2020, 59, 20589-20595.

205 A. H. Wibowo, Y. I. F. Hasanah, M. Firdaus, D. M. Widjonarko and J. Cepeda, Efficient $\mathrm{CO}_{2}$ adsorption by $\mathrm{Cu}(\mathrm{II})$ acetate and itaconate bioproduct based MOF, J. Environ. Chem. Eng., 2018, 6, 2910-2917.

206 Z. Wang, L. Ge, M. Li, R. Lin, H. Wang and Z. Zhu, Orientated growth of Copper-based MOF for acetylene storage, Chem. Eng. J., 2019, 357, 320-327.

207 J. Lincke, D. Lassig, J. Moellmer, C. Reichenbach, A. Puls, A. Moeller, R. Glaser, G. Kalies, R. Staudt and H. Krautscheid, A novel copper-based MOF material: Synthesis, characterization and adsorption studies, Microporous Mesoporous Mater., 2011, 142, 62-69.

208 G. Calleja, R. Sanz, G. Orcajo, D. Briones, P. Leo and F. Martinez, Copper-based MOF-74 material as effective acid catalyst in Friedel-Crafts acylation of anisole, Catal. Today, 2014, 227, 130-137.

209 S. Bashkova and T. J. Bandosz, Effect of surface chemical and structural heterogeneity of copper-based MOF/graphite oxide composites on the adsorption of ammonia, J. Colloid Interface Sci., 2014, 417, 109-114.

210 F. Abbasloo, S. A. Khosravani, M. Ghaedi, K. Dashtian, E. Hosseini, L. Manzouri, S. S. Khorramrooz, A. Sharifi, R. Jannesar and F. Sadri, Sonochemical-solvothermal synthesis of guanine embedded copper based metalorganic framework (MOF) and its effect on oprD gene expression in clinical and standard strains of pseudomonas aeruginosa, Ultrason. Sonochem., 2018, 42, 237-243.
211 H. Mollabagher, S. Taheri, M. Mojtahedi and S. A. Seyedmousavi, Cu-metal organic frameworks (Cu-MOF) as an environment-friendly and economical catalyst for one pot synthesis of tacrine derivatives, $R S C A d v$., 2020, 10, 1995-2003.

212 J. Wang, A. S. Cherevan, C. Hannecart, S. Naghdi, S. P. Nandan, T. Gupta and D. Eder, Ti-based MOFs: new insights on the impact of ligand composition and hole scavengers on stability, charge separation and photocatalytic hydrogen evolution, Appl. Catal., B, 2021, 283, 119626.

213 F. Cheng, Z. Li, L. Wang, B. Yang, J. Lu, L. Lei, T. Ma and Y. Hou, In situ Identification of Electrocatalytic Water Oxidation Behavior of Nickel-Based Metal-Organic Framework Nanoarray, Mater. Horiz., 2021, 8, 556-564.

214 X. Xuana, M. Qiana, L. Pan, T. Lu, L. Hanb, H. Yu, L. Wan, Y. Niua and S. Gong, Longitudinally Expanded Ni-Based Metal-Organic Framework with Enhanced Double Nickel Cation Catalysis Reaction Channels for Non-Enzymatic Sweat Glucose Biosensor, J. Mater. Chem. B, 2020, 8, 9094-9109.

215 K. Wang, B. Lv, Z. Wang, H. Wu, J. Xua and Q. Zhang, Twofold interpenetrated Mn-based metal-organic frameworks (MOFs) as battery-type electrode materials for charge storage, Dalton Trans., 2020, 49, 411-417.

216 M. Ganesh, P. Hemalatha, M. M. Peng, W. S. Cha and H. T. Jang, Zr-Fumarate MOF a Novel $\mathrm{CO}_{2}$-Adsorbing Material: Synthesis and Characterization, Aerosol. Air Qual. Res., 2014, 14, 1605-1612.

217 A. Kumar, M. Naushad, T. Ahamad and N. Viswanathan, Facile fabrication of tunable porous zirconium fumaratebased metal organic frameworks in the retention of nutrients from water, Environ. Sci.: Water Res. Technol., 2020, 6, 2856-2870.

218 A. Asghar, N. Iqbal, T. Noor, B. M. Kariuki, L. Kidwell and T. L. Easun, Efficient electrochemical synthesis of a manganese-based metal-organic framework for $\mathrm{H}_{2}$ and $\mathrm{CO}_{2}$ uptake, Green Chem., 2021, 23, 1220-1227.

219 H. Kaur, S. Sinha, V. Krishnan and R. R. Koner, Photocatalytic Reduction and Recognition of Cr(vI): New Zn(II)Based Metal-Organic Framework as Catalytic Surface, Ind. Eng. Chem. Res., 2020, 59, 8538-8550.

220 G. Li, F. Li and J. Liu, Caimei Fan, Fe-based MOFs for photocatalytic $\mathrm{N}_{2}$ reduction: key role of transition metal iron in nitrogen activation, J. Solid State Chem., 2020, 285, 121245.

221 F. Li, J. Li, L. Zhou and S. Dai, Enhanced OER performance of composite Co-Fe based MOF catalysts via a one-pot ultrasonic assisted synthetic approach, Sustainable Energy Fuels, 2021, 5, 1095-1102.

222 N. Liu, Q. Q. Zhang and J. Guan, A binuclear Co-based metal-organic framework towards efficient oxygen evolution reaction, Chem. Commun., 2021, 57, 5016-5019.

223 Y. Li, X. Hu, X. Zhang, H. Cao and Y. Huang, Unconventional application of gold nanoclusters/Zn-MOF composite for fluorescence turn-on sensitive detection of zinc ion, Anal. Chim. Acta, 2018, 1024, 145-152.

224 R. Pena-Rodriguez, J. A. Molina-gonzález, H. DesirenaEnrriquez, J. M. Rivera-Villanueva and S. E. Castillo-Blum, 
Tunable luminescence modulation and warm light emission of Zn-MOF (4,4'-bipyridyl and zinc acetate) doped with $\mathrm{Eu}^{3+}$ and $\mathrm{Tb}^{3}$, Mater. Chem. Phys., 2019, 223, 494-502.

225 H. Duan, W. Dan and X. Fang, Zinc-coordinated MOFs complexes regulated by hydrogen bonds: synthesis, structure and luminescence study toward broadband white-light emission, J. Solid State Chem., 2018, 260, 159-164.

226 J. Zou, L. Li, S. You, H. Cui, Y. Liu, K. Chen, Y. Chen, J. Cui and S. Zhang, Sensitive luminescent probes of aniline, benzaldehyde and $\mathrm{Cr}(\mathrm{vI})$ based on a zinc(II) metal-organic framework and its lanthanide(III) post-functionalizations, Dyes Pigm., 2018, 159, 429-438.

227 K. Li, K. He, Q. Li, B. Xia, Q. Wang and Y. Zhang, A zinc(II) MOF based on secondary building units of infinite wavyshaped chain exhibiting obvious luminescent sense effects, Chin. Chem. Lett., 2019, 30, 499-501.

228 I. T. Kim, S. Shin and M. W. Shin, Development of 3D interconnected carbon materials derived from Zn-MOF-74@carbon nanofiber web as an efficient metal-free electrocatalyst for oxygen reduction, Carbon, 2018, 135, 35-43.

229 W. W. Lestari, M. Arvinawati, R. Martien and T. Kusumaningsih, Green and facile synthesis of MOF and nano MOF containing zinc(II) and benzen 1,3,5-tri carboxylate and its study in ibuprofen slow-release, Mater. Chem. Phys., 2018, 204, 141-146.

230 D. K. Yadav, V. Ganesan, F. Marken, R. Gupta and P. K. Sonkar, Metal@MOF Materials in Electroanalysis: SilverEnhanced Oxidation Reactivity Towards Nitrophenols Adsorbed into a Zinc Metal organic Framework-Ag@MOF-5(Zn), Electrochim. Acta, 2016, 219, 482-491.

231 S. Wang, Y. Lv, Y. Yao, H. Yu and G. Lu, Modulated synthesis of monodisperse MOF-5 crystals with tunable sizes and shapes, Inorg. Chem. Commun., 2018, 93, 56-60.

232 S. M. Mirsoleimani-azizi, P. Setoodeh, S. Zeinali and M. R. Rahimpour, Tetracycline antibiotic removal from aqueous solutions by MOF-5: adsorption isotherm, kinetic and thermodynamic studies, J. Environ. Chem. Eng., 2018, 6, 6118-6130.

233 H. A. Ozen and B. Ozturk, Gas separation characteristic of mixed matrix membrane prepared by MOF- 5 including different metals, Sep. Purif. Technol., 2019, 211, 514-521.

234 K. G. Liu, Z. Sharifzadeh, F. Rouhani, M. Ghorbalnoo and A. Morsali, Metal-organic framework composites as green/ sustainable catalysts, Coord. Chem. Rev., 2021, 436, 213827.

235 Y. Y. Kannangara, U. A. Rathnayake and J. Song, Redox active multi-layered Zn-pPDA MOFs as high-performance supercapacitor electrode material, Electrochim. Acta, 2019, 297, 145-154.

236 Y. Wu, H. Pang, W. Yao, X. Wang, S. Yu, Z. Yu and X. Wang, Synthesis of rod-like metal-organic framework (MOF-5) nanomaterial for efficient removal of $\mathrm{U}(\mathrm{v})$ : batch experiments and spectroscopy study, Sci. Bull., 2018, 63, 831-839.

237 Y. Z. Chen, Z. U. Wang, H. Wang, J. Lu, S. H. Yu and H. L. Jiang, Singlet Oxygen-Engaged Selective Photo-oxidation over Pt Nanocrystals/Porphyrinic MOF: The Roles of Photothermal Effect and Pt Electronic State, J. Am. Chem. Soc., 2017, 139, 2035-2044. 